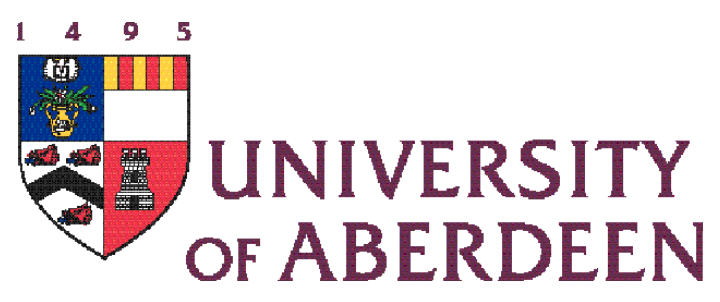

\author{
NORTH SEA STUDY OCCASIONAL PAPER \\ No. 138
}

\title{
The Prospects for Activity in the UKCS to 2050 under "Lower for Longer" Oil and Gas Price Scenarios, and the Unexploited Potential
}

\author{
Professor Alexander G. Kemp \\ and \\ Linda Stephen
}

February, 2017

Aberdeen Centre for Research in Energy Economics and Finance (ACREEF)

(C) A.G. Kemp and Linda Stephen 
ISSN 0143-022X

\section{NORTH SEA ECONOMICS}

Research in North Sea Economics has been conducted in the Economics Department since 1973. The present and likely future effects of oil and gas developments on the Scottish economy formed the subject of a long term study undertaken for the Scottish Office. The final report of this study, The Economic Impact of North Sea Oil on

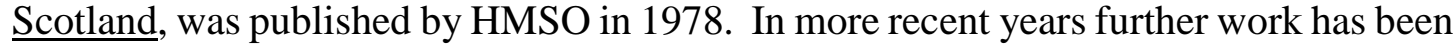
done on the impact of oil on local economies and on the barriers to entry and characteristics of the supply companies in the offshore oil industry.

The second and longer lasting theme of research has been an analysis of licensing and fiscal regimes applied to petroleum exploitation. Work in this field was initially financed by a major firm of accountants, by British Petroleum, and subsequently by the Shell Grants Committee. Much of this work has involved analysis of fiscal systems in other oil producing countries including Australia, Canada, the United States, Indonesia, Egypt, Nigeria and Malaysia. Because of the continuing interest in the UK fiscal system many papers have been produced on the effects of this regime.

From 1985 to 1987 the Economic and Social Science Research Council financed research on the relationship between oil companies and Governments in the UK, Norway, Denmark and The Netherlands. A main part of this work involved the construction of Monte Carlo simulation models which have been employed to measure the extents to which fiscal systems share in exploration and development risks.

Over the last few years the research has examined the many evolving economic issues generally relating to petroleum investment and related fiscal and regulatory matters. Subjects researched include the economics of incremental investments in mature oil fields, economic aspects of the CRINE initiative, economics of gas developments and contracts in the new market situation, economic and tax aspects of tariffing, economics of infrastructure cost sharing, the effects of comparative petroleum fiscal systems on incentives to develop fields and undertake new exploration, the oil price responsiveness of the UK petroleum tax system, and the economics of decommissioning, mothballing and re-use of facilities. This work has been financed by a group of oil companies and Scottish Enterprise, Energy. The work on CO2 Capture, EOR and storage was financed by a grant from the Natural Environmental Research Council (NERC) in the period $2005-2008$.

For 2016 the programme examines the following subjects:
a. Decommissioning Tax Relief
b. Further Research on Economics of EOR with Emphasis on Tax
c. Collaborative Agreements among Licensees: Cluster Developments
d. Collaborative Agreements among Licensees and Contractors
e. Facilitation of Decommissioning Cost Reductions including by Collaboration
f. Prospects for Activity in the UKCS to 2050 
The authors are solely responsible for the work undertaken and views expressed. The sponsors are not committed to any of the opinions emanating from the studies.

Papers are available from:

The Secretary (NSO Papers)

University of Aberdeen Business School

Edward Wright Building

Dunbar Street

Aberdeen A24 3QY

Tel No: $\quad$ (01224) 273427

Fax No: $\quad$ (01224) 272181

Email: $\quad$ a.g.kemp@abdn.ac.uk

Recent papers published are:

OP 98 Prospects for Activity Levels in the UKCS to 2030: the 2005 Perspective

By A G Kemp and Linda Stephen (May 2005), pp. 52

$£ 20.00$

OP 99 A Longitudinal Study of Fallow Dynamics in the UKCS

By A G Kemp and Sola Kasim, (September 2005), pp. 42

$£ 20.00$

OP 100 Options for Exploiting Gas from West of Scotland

By A G Kemp and Linda Stephen, (December 2005), pp. 70

OP 101 Prospects for Activity Levels in the UKCS to 2035 after the 2006 Budget

By A G Kemp and Linda Stephen, (April 2006) pp. 61

$£ 30.00$

OP 102 Developing a Supply Curve for $\mathrm{CO}_{2}$ Capture, Sequestration and EOR in the UKCS: an Optimised Least-Cost Analytical

Framework

By A G Kemp and Sola Kasim, (May 2006) pp. 39

OP 103 Financial Liability for Decommissioning in the UKCS: the Comparative Effects of LOCs, Surety Bonds and Trust Funds

By A G Kemp and Linda Stephen, (October 2006) pp. 150

OP 104 Prospects for UK Oil and Gas Import Dependence

By A G Kemp and Linda Stephen, (November 2006) pp. 38

OP 105 Long-term Option Contracts for CO2 Emissions

By A G Kemp and J Swierzbinski, (April 2007) pp. 24

OP 106 The Prospects for Activity in the UKCS to 2035: the 2007

Perspective

By A G Kemp and Linda Stephen (July 2007) pp.56 
OP 107 A Least-cost Optimisation Model for $\mathrm{CO}_{2}$ capture

By A G Kemp and Sola Kasim (August 2007) pp.65

OP 108 The Long Term Structure of the Taxation System for the UK

Continental Shelf

By A G Kemp and Linda Stephen (October 2007) pp.116

OP 109 The Prospects for Activity in the UKCS to 2035: the 2008

Perspective

By A G Kemp and Linda Stephen (October 2008) pp.67

OP 110 The Economics of PRT Redetermination for Incremental Projects in the UKCS

By A G Kemp and Linda Stephen (November 2008) pp. 56

OP 111 Incentivising Investment in the UKCS: a Response to Supporting Investment: a Consultation on the North Sea Fiscal Regime By A G Kemp and Linda Stephen (February 2009) pp.93

OP 112 A Futuristic Least-cost Optimisation Model of $\mathrm{CO}_{2} £ 25.00$ Transportation and Storage in the UK/ UK Continental Shelf By A G Kemp and Sola Kasim (March 2009) pp.53

OP 113 The Budget 2009 Tax Proposals and Activity in the UK $£ 25.00$ Continental Shelf (UKCS)

By A G Kemp and Linda Stephen (June 2009) pp. 48

OP $\quad 114$ The Prospects for Activity in the UK Continental Shelf to 2040: the 2009 Perspective By A G Kemp and Linda Stephen (October 2009) pp. 48

OP 115 The Effects of the European Emissions Trading Scheme (EU ETS) on Activity in the UK Continental Shelf (UKCS) and $\mathrm{CO}_{2}$ Leakage By A G Kemp and Linda Stephen (April 2010) pp. 117

OP 116 Economic Principles and Determination of Infrastructure Third Party Tariffs in the UK Continental Shelf (UKCS)

By A G Kemp and Euan Phimister (July 2010) pp. 26

OP 117 Taxation and Total Government Take from the UK Continental Shelf (UKCS) Following Phase 3 of the European Emissions Trading Scheme (EU ETS)

By A G Kemp and Linda Stephen (August 2010) pp. 168

OP 118 An Optimised Illustrative Investment Model of the Economics of Integrated Returns from CCS Deployment in the UK/UKCS BY A G Kemp and Sola Kasim (December 2010) pp. 67 
OP 119 The Long Term Prospects for Activity in the UK Continental Shelf

BY A G Kemp and Linda Stephen (December 2010) pp. 48

OP 120 The Effects of Budget 2011 on Activity in the UK Continental Shelf

BY A G Kemp and Linda Stephen (April 2011) pp. 50

OP 121 The Short and Long Term Prospects for Activity in the UK Continental Shelf: the 2011 Perspective BY A G Kemp and Linda Stephen (August 2011) pp. 61

OP 122 Prospective Decommissioning Activity and Infrastructure Availability in the UKCS

BY A G Kemp and Linda Stephen (October 2011) pp. 80

OP 123 The Economics of $\mathrm{CO}_{2}$-EOR Cluster Developments in the UK Central North Sea/ Outer Moray Firth BY A G Kemp and Sola Kasim (January 2012) pp. 64

OP 124 A Comparative Study of Tax Reliefs for New Developments in the UK Continental Shelf after Budget 2012 BY A G Kemp and Linda Stephen (July 2012) pp.108

OP 125 Prospects for Activity in the UK Continental Shelf after Recent Tax Changes: the 2012 Perspective BY A G Kemp and Linda Stephen (October 2012) pp.82

OP 126 An Optimised Investment Model of the Economics of Integrated Returns from CCS Deployment in the UK/UKCS

BY A G Kemp and Sola Kasim (May 2013) pp.33

OP 127 The Full Cycle Returns to Exploration in the UK Continental Shelf

BY A G Kemp and Linda Stephen (July 2013) pp.86

OP 128 Petroleum Taxation for the Maturing UK Continental Shelf (UKCS)

BY A G Kemp, Linda Stephen and Sola Kasim (October 2014) pp.94

OP 129 The Economics of Enhanced Oil Recovery (EOR) in the UKCS and the Tax Review BY A G Kemp and Linda Stephen (November 2014) pp.47

OP 130 Price Sensitivity, Capital Rationing and Future Activity in the UK Continental Shelf after the Wood Review

BY A G Kemp and Linda Stephen (November 2014) pp.41 
OP 131 Tax Incentives for $\mathrm{CO}_{2}$-EOR in the UK Continental Shelf BY A G Kemp and Sola Kasim (December 2014) pp. 49

OP 132 The Investment Allowance in the Wider Context of the UK

Continental Shelf in 2015: A Response to the Treasury

Consultation

BY A G Kemp and Linda Stephen (February 2015) pp. 27

OP 133 The Economics of Exploration in the UK Continental Shelf: the 2015 Perspective

BY A G Kemp and Linda Stephen (August 2015) pp. 71

OP 134 Prospective Returns to Exploration in the UKCS with Cost Reductions and Tax Incentives

BY A G Kemp and Linda Stephen (December 2015) pp.81

OP 135 Maximising Economic Recovery from the UK Continental Shelf: A Response to the Draft DECC Consultation Strategy BY A G Kemp (January 2016) pp. 16

OP 136 Field Development Tax Incentives for the UK Continental Shelf (UKCS)

BY A G Kemp and Linda Stephen (March 2016) pp.66

OP 137 Economic and Tax Issues relating to Decommissioning in the UKCS: the 2016 Perspective

BY A G Kemp and Linda Stephen (July 2016) pp.63

OP 138 The Prospects for Activity in the UKCS to 2050 under "Lower for Longer" Oil and Gas Price Scenarios, and the Unexploited Potential

BY A G Kemp and Linda Stephen (February 2017) pp.86 


\section{The Prospects for Activity in the UKCS to 2050 under \\ "Lower for Longer" Oil and Gas Price Scenarios, and the Unexploited Potential}

Professor Alexander G. Kemp and Linda Stephen

$\underline{\text { Contents }}$

Page

1. Introduction ............................................ 1

2. Methodology and Data..................................... 2

3. Results................................................ 10

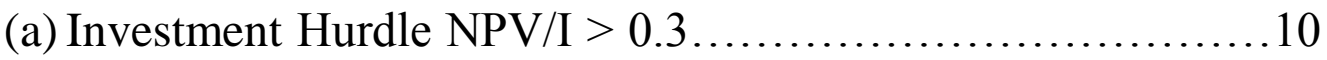

(i) Numbers of Producing Fields........................10

(ii) Potential Production...............................13

(iii) Field Expenditures by Category and Decommissioning Activity..........................................24

(b) Investment Hurdle NPV/I $>0.5 \ldots \ldots \ldots \ldots \ldots \ldots \ldots \ldots \ldots . \ldots 43$

(i) Numbers of Producing Fields.........................43

(ii) Potential Production................................46

(iii) Field Expenditures by Category and Related Decommissioning Activity............................58

4. Summary and Conclusions....................................79

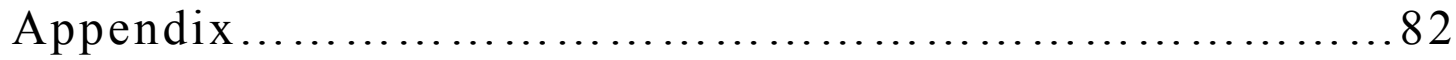




\title{
The Prospects for Activity in the UKCS to 2050 under "Lower for \\ Longer" Oil and Gas Price Scenarios, and the Unexploited Potential
}

\author{
Professor Alex Kemp and Linda Stephen
}

Aberdeen Centre for Research in Energy Economics and Finance (ACREEF)

\section{Introduction}

Over the past few years activity in the UK Continental Shelf (UKCS) has exhibited dramatic changes. In the period 2009-2014 there was a major investment boom which at its peak exceeded in real terms the levels experienced in the earlier boom years of the 1970's. The very high field investment activity in 2009-2014 conceded underlying problems such as the dramatic cost inflation and the relentless decrease in production and the exploration effort. The dramatic fall in the oil price in the later months of 2014 thus came on top of the emerging problems of the maturity of the province.

Since then the industry has been painfully adjusting to the changed environment where net cash flows have dramatically fallen to negative levels and prospective returns on new investments projects have similarly been substantially reduced. Major tax concessions introduced in 2015 and 2016 along with the major reductions realised across all categories of costs by the industry have transformed the situation. But it remains challenging.

The Purpose of this study is to examine prospective long term activity levels within an environment of "lower for longer" oil prices, given the cost and tax reductions which have been achieved to date. The study also 
highlights the size of the unexploited potential within this "lower for longer" context. This highlights the challenge facing the OGTC, the OGA and the whole industry, given the commitment to maximise economic recovery from the substantial remaining reserves.

\section{Methodology and Data}

The projections of production and expenditures have been made through the use of financial simulation modelling, including the use of the Monte Carlo technique, informed by a large field database validated by the relevant operators and other sources. The overall field database incorporates key, best estimate information on production, and investment, operating and decommissioning expenditures. These refer to 404 sanctioned fields, 51 incremental projects relating to these fields, 14 probable fields, and 14 possible fields. The unsanctioned fields are currently being examined for development. An additional database contains 249 fields defined as being in the category of technical reserves. Only summary data on reserves (oil/gas/condensate) and block locations are available for these. They are not currently being examined for development by licensees.

Monte Carlo modelling was employed to estimate the possible numbers of new discoveries in the period to 2047. The modelling incorporated assumptions based on recent trends relating to exploration effort, success rates, sizes, and types of discovery (oil, gas, condensate). A moving average of the behaviour of these variables over the past 5 years was calculated separately for 5 areas of the UKCS (southern North Sea (SNS), Central North Sea/Moray Firth (CNS/MF), Northern North Sea (NNS), West of Shetlands (WoS), and Irish Sea (IS)). The results were employed for use by the Monte Carlo Analysis. Because of the very limited data for 
WoS and IS over the period judgemental assumptions on success rate and average sizes of discoveries were made for the modelling.

It is postulated that the exploration effort depends substantially on a combination of (a) the expected success rates, (b) the likely size of discovery, and (c) oil/gas prices. In the present study 2 future oil/gas price scenarios were employed as follows:

\begin{tabular}{|l|l|l|}
\hline \multicolumn{3}{|c|}{ Table 1 } \\
Future Oil and Gas Price Scenarios \\
\hline \multirow{2}{*}{$\begin{array}{l}\text { Oil Price (real) } \\
\$ / \mathrm{bbl}\end{array}$} & $\begin{array}{l}\text { Gas Price (real) } \\
\text { pence/therm }\end{array}$ \\
\hline Medium & 60 & 50 \\
\hline Low & 50 & 40 \\
\hline
\end{tabular}

These price scenarios are designed to reflect investment screening prices, not market values. In this context it should be noted that, when oil prices were $\$ 100$ or more banks typically employed oil prices in the $\$ 65-\$ 75$ range to assess loan applications. In MOD terms the price scenario starting with $\$ 60$ in 2017 becomes $\$ 115$ in 2050, and the scenario starting with $\$ 50$ in 2017 becomes over $\$ 96$ in 2050 . The exchange rate employed was $£ 1$ $=\$ 1.267$ which was the rate when the modelling commenced. The structure of costs between dollars and sterling in the modelling reflects the up-to-date position.

The postulated numbers of annual exploration wells drilled for the whole of the UKCS are as follows for 2017, 2030, 2040, and 2045: 


\begin{tabular}{|l|c|c|c|c|}
\hline \multicolumn{5}{|c|}{ Table 2 } \\
\multicolumn{5}{|c|}{ Exploration Wells Drilled } \\
\hline & 2017 & 2030 & 2040 & 2045 \\
\hline Medium & 15 & 12 & 10 & 9 \\
\hline Low & 12 & 9 & 7 & 6 \\
\hline
\end{tabular}

It is postulated that success rates depend substantially on a combination of (a) recent experience, and (b) size of the effort. It is further suggested that higher effort is associated with more discoveries, but with lower success rate compared to reduced levels of effort. This reflects the view that low levels of effort will be concentrated on the lowest risk prospects, and thus higher effort involves the acceptance of higher risk. For the UKCS as a whole 2 success rates were postulated as follows with the medium one reflecting the average over the past 5 years.

\begin{tabular}{|lc|}
\hline \multicolumn{2}{|c|}{ Table 3 } \\
Success Rates for UKCS \\
\hline Low effort/Medium success rate & $33 \%$ \\
\hline Medium effort/Lower success rate & $30 \%$ \\
\hline
\end{tabular}

It should be noted that success rates have varied considerably across the 5 sectors of the UKCS. The annual number of discoveries has been low since 2010 which is not surprising, given the large decline in the number of exploration wells since 2008. It is assumed that technological progress will maintain historic success rates over the time period.

The mean sizes of discoveries made in the historic periods for each of the 5 regions were calculated. It was then assumed that the mean size of 
discovery would decrease in line with recent historic experience. They are shown in Table 4.

\begin{tabular}{|l|c|c|}
\hline \multicolumn{3}{|c|}{ Table 4 } \\
\multicolumn{3}{|c|}{ Mean Discovery Size MMboe } \\
\hline Year & $\mathbf{2 0 1 7}$ & $\mathbf{2 0 4 5}$ \\
\hline SNS & $\mathbf{2 0}$ & $\mathbf{1 5}$ \\
\hline CNS/MF & $\mathbf{1 7}$ & $\mathbf{1 2}$ \\
\hline NNS & $\mathbf{3 8}$ & $\mathbf{6}$ \\
\hline WoS & $\mathbf{5 9}$ & $\mathbf{2 8}$ \\
\hline IS & $\mathbf{9}$ & $\mathbf{4}$ \\
\hline
\end{tabular}

For purposes of the Monte Carlo modelling of the size of new discoveries the standard deviation (SD) was set at $50 \%$ of the mean value. In line with historic experience the size distribution of discoveries was taken to be lognormal. The most likely size is thus less than the average.

Using the above information the Monte Carlo technique was employed to project discoveries in the 5 regions to 2047. For the whole period the total numbers of discoveries for the whole of the UKCS were as follows:

\section{Table 5}

Total Number of Discoveries to 2050

\begin{tabular}{ll}
\hline High effort/Lower success rate & 117
\end{tabular}

Medium Effort/Medium Success Rate 97 
For each region the average development costs (per boe) of fields in the probable and possible categories were calculated. These reflect the cost reductions over the last two years. Investment costs per boe depend on several factors including not only the absolute costs in different operating conditions (such as water depth) but on the size of the fields. For all of the UKCS the average development cost was $\$ 16.66$ per boe with the highest being \$21.72. In the SNS development costs were found to average \$11.44 per boe. In the CNS/MF, they averaged $\$ 18.5$ per boe, in the WoS average development costs were $\$ 15.78$ per boe (reflecting the relative large size of fields), and in the NNS they averaged $\$ 21.6$ per boe. Operating costs over the lifetime of the fields were also calculated. The average has fallen from $\$ 19$ per boe to $\$ 11.5$ for all of the UKCS. They are now at $\$ 6$ per boe in the SNS, $\$ 13$ per boe in the CNS/MF, $\$ 12.5$ per boe in the WoS, and $\$ 14.6$ per boe in the NNS. Total lifetime field costs (including decommissioning but excluding $\mathrm{E}$ and $\mathrm{A}$ costs) were found to have fallen from an average of $\$ 38.9$ per boe all of the UKCS to $\$ 34.8$ per boe, with $\$ 23$ per boe in the SNS, \$38 per boe in the CNS/MF, $\$ 30$ per boe in the WoS (reflecting the relatively large size of fields), and $\$ 41$ per boe in the NNS.

Using these as the mean values the Monte Carlo technique was employed to calculate the development costs of new discoveries. A normal distribution with a $\mathrm{SD}=20 \%$ of the mean value was employed. For new discoveries annual operating costs were modelled as a percentage of accumulated development costs. This percentage varied according to field size. It was taken to increase as the size of the field was reduced reflecting the presence of economic scale. Thus the field lifetime costs in very small fields could become very high on a boe basis. 
With respect to fields in the category of technical reserves it was recognised that many face major challenges, and so the mean development costs in each of the basins was set at $\$ 5 /$ boe higher than the mean for the new discoveries in that basin. Thus for the CNS/MF the mean development costs are \$23.5 per boe, and in NNS over \$26 per boe. The distribution of these costs was assumed to be normal with a $\mathrm{SD}=20 \%$ of the mean value. A binomial distribution was employed to find the order of new developments of fields in this category.

The annual numbers of new field developments were assumed to be constrained by the physical and financial capacity of the industry. The ceilings were assumed to be linked to the oil/gas price scenarios with maxima of 18 and 15 respectively for the Medium and Low price cases. These constrains do not apply to incremental projects which are additional to new field developments.

There is a wide range in the development and operating costs of the set of incremental projects currently being examined for development. For all of the UKCS the mean development costs are $\$ 25.58$ per boe, but the highest is over $\$ 87$ per boe. In the SNS the average development costs are $\$ 25.32$ per boe, but in the NNS it is $\$ 21.85$ per boe. While operating costs average $\$ 11.9$ per boe across all of the UKCS, they are very high in a number of cases, with examples in the $\$ 20$ to $\$ 45$ per boe range over their lifetime.

A noteworthy feature of the 51 incremental projects in the database is the expectation that the great majority will be executed over the next 3 or 4 years. It is virtually certain that in the medium and longer-term many further incremental projects will be designed and executed. They are just not yet at the serious planning stage. Such projects can be expected to be 
linked not only to currently sanctioned fields, but also to those presently classified as in the categories of probable, possible, technical reserves, and future discoveries.

Accordingly, estimates were made of the potential extra incremental projects from all these sources. Examination of the numbers of such projects and their key characteristics (reserves and costs) being examined by operators over the past 6 years indicated a decline rate in the volumes. On the basis of this, and utilising the information of the key characteristics of the projects in the database, it was felt that, with a decline rate reflecting historic experience, further portfolios of incremental projects could reasonably be expected. As noted above such future projects would be spread over all categories of host fields. Their sizes and costs reflect recent trends.

With respect to investment decision making and project screening criterial oil companies (even medium-sized and smaller ones) currently assess their opportunities in the UKCS in comparison to those available in other parts of the world. Capital is allocated on this basis with the UKCS having to compete for funds against the opportunities in other provinces. A problem with the growing maturity of the UKCS is the relatively small average field size and the high unit costs. Mean discovery sizes are shown in Table 4, but, given the lognormal distributions, the most likely sizes are below these averages. It follows that the materiality of returns, expressed in terms of net present values (NPVs), is quite low in relation to those in prospect in other provinces (such as offshore Angola, or Brazil, for example). Oil companies frequently rank investment projects according to the NPV/I ratio. Accordingly, this screening method has been adopted in the present study. Specifically, the numerator is the post-tax NPV at $10 \%$ discount 
rate in real terms and the denominator is the pre-tax field investment at $10 \%$ discount rate in real terms. This differs from the textbook version which states that I should be in post-tax terms because the expenditures are tax deductible. Oil companies maintain that they allocate capital funds on a pre-tax basis, and this is employed here as the purpose is to reflect realistically the decision-making process. In one scenario the development project goes ahead when the NPV/I ratio as defined above in real terms $\geq$ 0.3. To reflect the effects of severe capital rationing another scenario when the hurdle is NPV/I $\geq 0.5$ is also shown. The $10 \%$ real discount rate reflects the weighted average cost of capital to the investor. The modelling has been undertaken under the current tax system and it is assumed that already sanctioned fields and incremental projects can use tax allowances immediately but probable and possible fields, technical reserves and new discoveries must generate taxable income from the new projects before they can use tax allowances. Thus the Ring Fence Expenditure Supplement (RFES) is employed. The modelling is initially undertaken in MOD terms with an inflation rate of $2 \%$. This incorporates the effects of any fiscal drag. The results are then converted to real terms.

In the light of experience over the past few years some rephasing of the timing of the commencement dates of new field developments and incremental projects from those projected by operators was undertaken relating to the probability that the project would go ahead. Where the operator indicated that a new field development had a probability $\geq 80 \%$ of going ahead the date was left unchanged. Where the probability $\geq 70 \%$ $<80 \%$ the commencement date was slipped by 1 year and where the probability $\geq 50 \%<70 \%$ the commencement date was slipped by 2 years. Where the probability $\geq 40 \%<50 \%$ the date was slipped by 3 years. Where the probability was $\geq 30 \%<40 \%$ the date was slipped by 4 years, 
and where the probability was $\geq 20 \%<30 \%$ it was slipped by 5 years. Where the probability was $<20 \%$ it was slipped by 6 years. If an incremental project had a probability of proceeding $\geq 70 \%$ the date was retained but where it was $\geq 30 \%<70 \%$ it was slipped by 1 year and where it was $<30 \%$ it was slipped by 2 years.

\section{Results}

(a) Investment Hurdle NPV/I > 0.3

(i) Numbers of Producing Fields

In Chart 1 the numbers of new field developments and COP dates are shown at the $\$ 60,50$ pence price scenario. It is seen that the numbers of fields in production fall steadily over the period falling to less than 50 after 2040. Over the period there are 213 new field developments triggered, of which 2 are in the sanctioned category, 7 are in the probable category, 7 in the possible category, 104 in the category of technical reserves, and 93 are future new discoveries. With the $\$ 60$ case and a 0.3 hurdle there are 183 fields which fail the hurdle rate, 14 of which are probable or possible fields, 145 are technical reserves, and 24 are new discoveries. There are also 21 incremental projects which fail the hurdle.

In Chart 2 the corresponding results are shown for the $\$ 50,40$ pence price case. In this scenario the numbers of fields in production are considerably less falling to less than 50 by 2035 . There are 105 new field developments over the period to 2050, of which 2 are sanctioned, 4 are in the probable category, 3 in the possible category, 51 in technical reserves, and 45 from new discoveries in the period. With the $\$ 50$ price and a 0.3 hurdle there are 271 fields which fail the test, 21 of which are probable or possible 
fields, 198 are technical reserves and 52 are new discoveries. There are also 28 incremental projects which fail the hurdle.

\section{Chart 1}

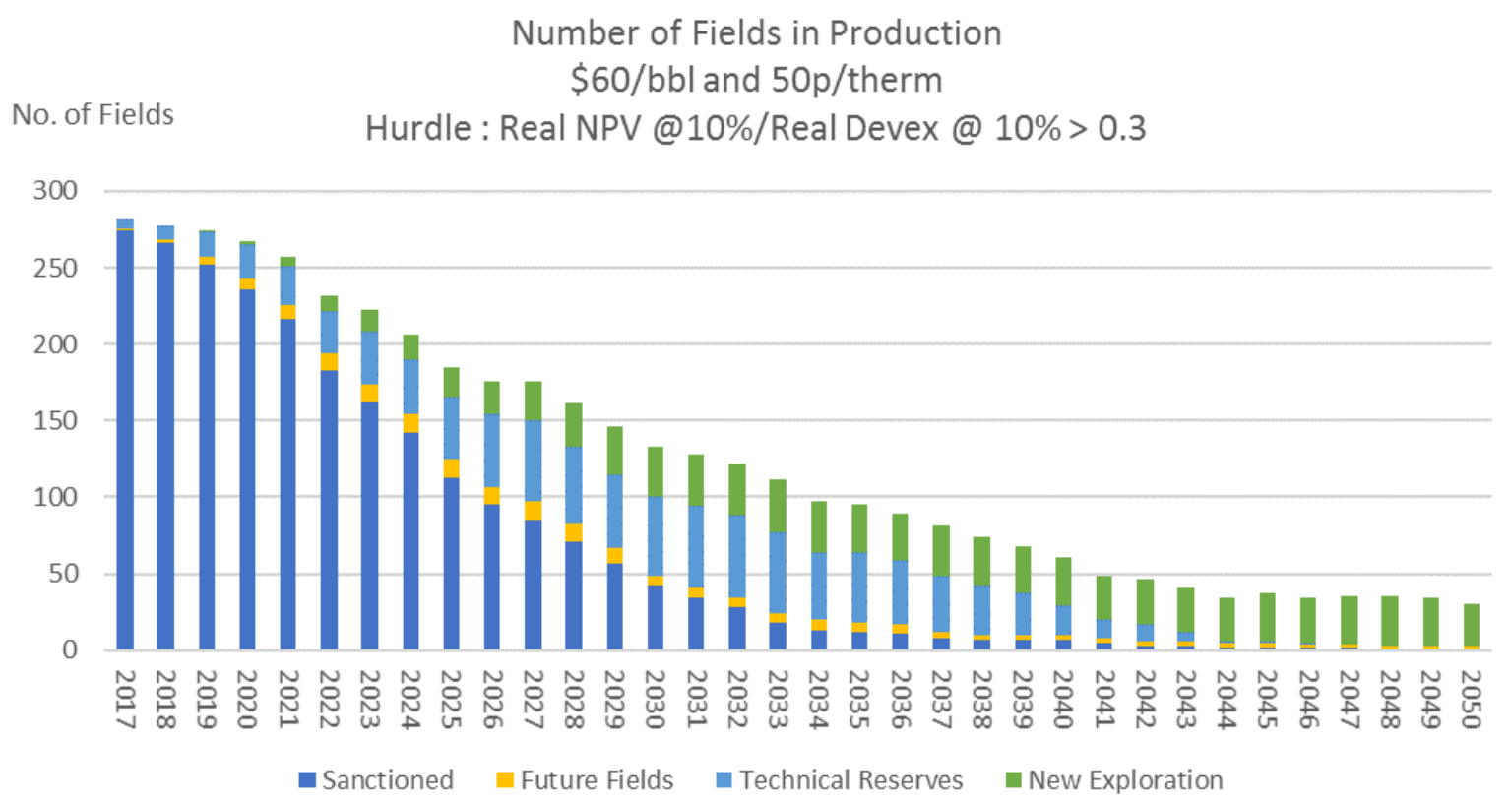

\section{Chart 2}

Number of Fields in Production $\$ 50 / \mathrm{bbl}$ and $40 \mathrm{p} /$ therm

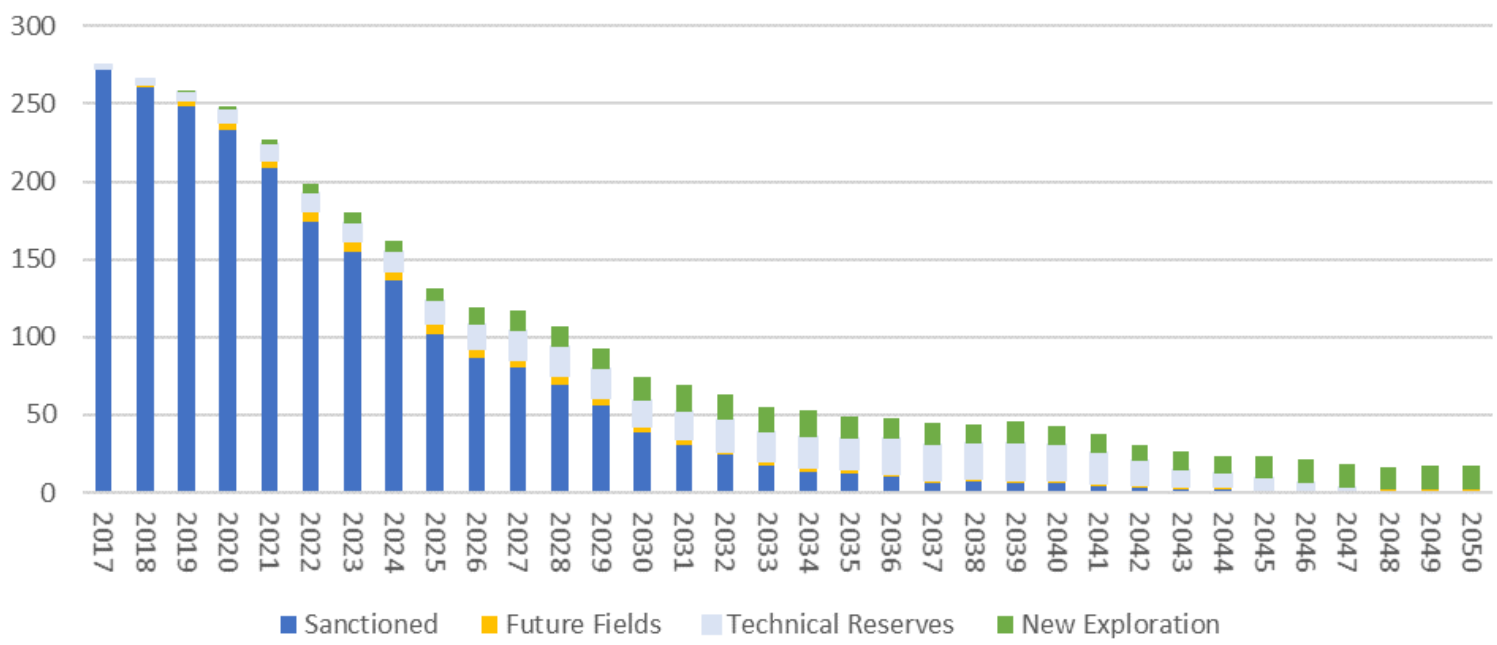


The same results are shown by area in Charts 3 and 4 .

\section{Chart 3}

Number of Fields in Production $\$ 60 / \mathrm{bbl}$ and $50 \mathrm{p} /$ therm

No. of Fields Hurdle : Real NPV @10\%/Real Devex @ 10\%>0.3

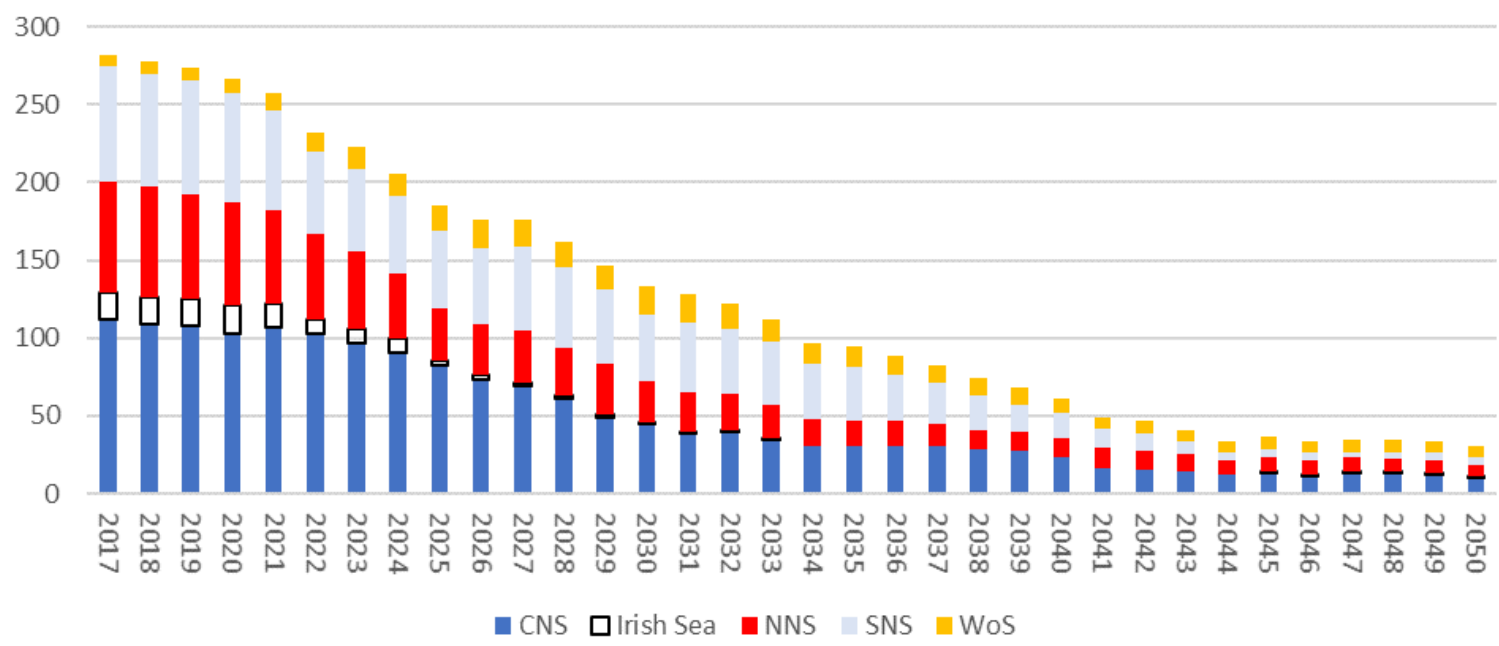

Chart 4

Number of Fields in Production $\$ 50 / \mathrm{bbl}$ and $40 \mathrm{p} /$ therm

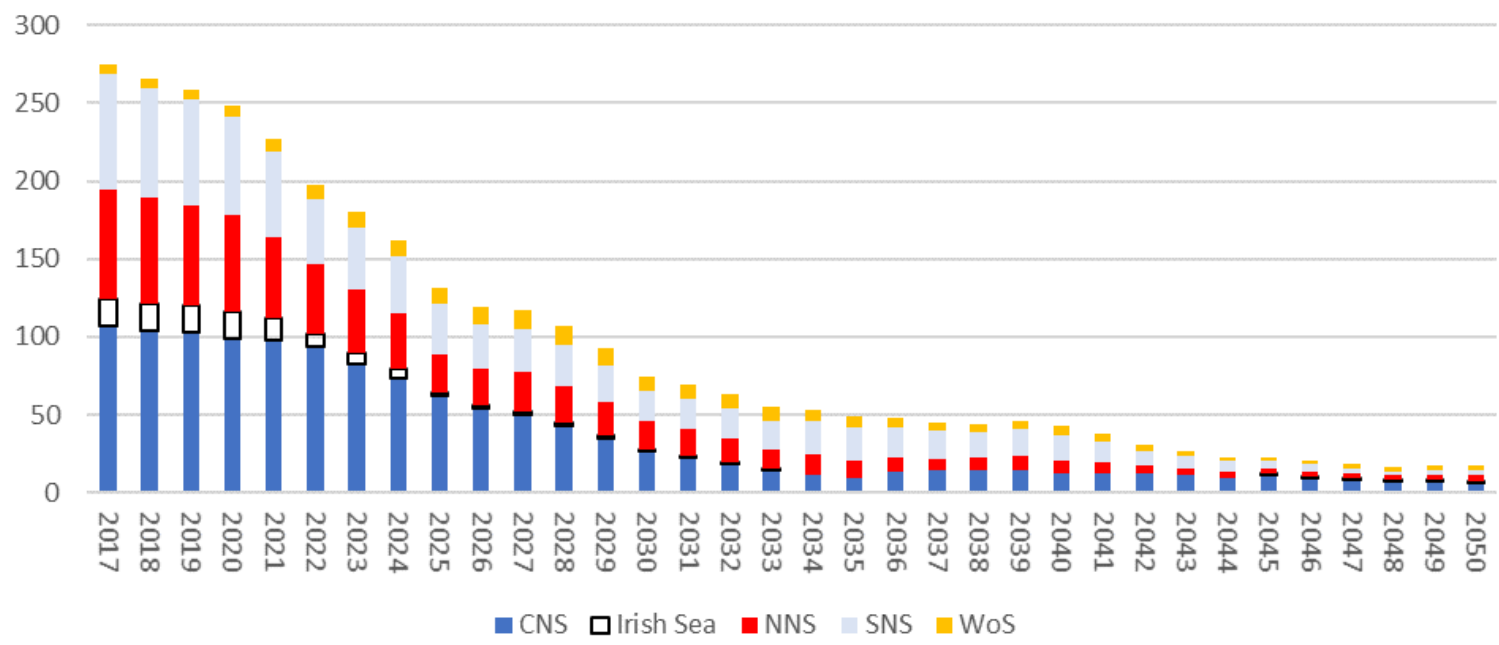


From Chart 3 it is seen that the CNS has the largest number of fields in production followed by the SNS. Of the 183 fields which fail the hurdle rate at $\$ 60,59$ are in the CNS/MF area, 39 are in the SNS, 55 in the NNS, 16 are in the WoS and 14 are in the Irish Sea. Of the 21 incremental projects which fail the hurdle rate 12 are in the CNS/MF area, 3 are in the SNS, 5 are in the NNS and 1 is in the Irish Sea. Of the total of 271 fields which fail the hurdle rate at $\$ 50,88$ are in the CNS/MF area, 70 are in the SNS, 69 in the NNS, 29 are in the WoS and 15 are in the Irish Sea. Of the total 28 incremental projects which fail the hurdle rate 15 are in the CNS/MF area, 3 are in the SNS, 9 in the NNS and 1 is in the Irish Sea. Further details of the unexploited potential are shown in the Appendix.

\section{(ii) Potential Production}

In Chart 5 potential oil production over the period to 2050 is shown for the $\$ 60,50$ pence case. Over the period cumulative oil production is just over 6,978 million barrels of which 3,786 million comes from sanctioned fields, 164 million from current incremental projects, 369 million from future incremental projects, 460 million from probable and possible fields, 811 million from technical reserves, and 1,388 million from future discoveries.

Chart 6 gives the same information on geographic area basis. It is seen that 2,591 million barrels comes from the CNS/MF area closely followed by 2,370 million barrels from the WoS area, and 1,983 million barrels from the NNS. 


\section{Chart 5}

Potential Oil Production

$\$ 60 / \mathrm{bbl}$ and $50 \mathrm{p} /$ therm

$\mathrm{tb} / \mathrm{d}$

Hurdle : Real NPV @ 10\%/Real Devex @ 10\% > 0.3

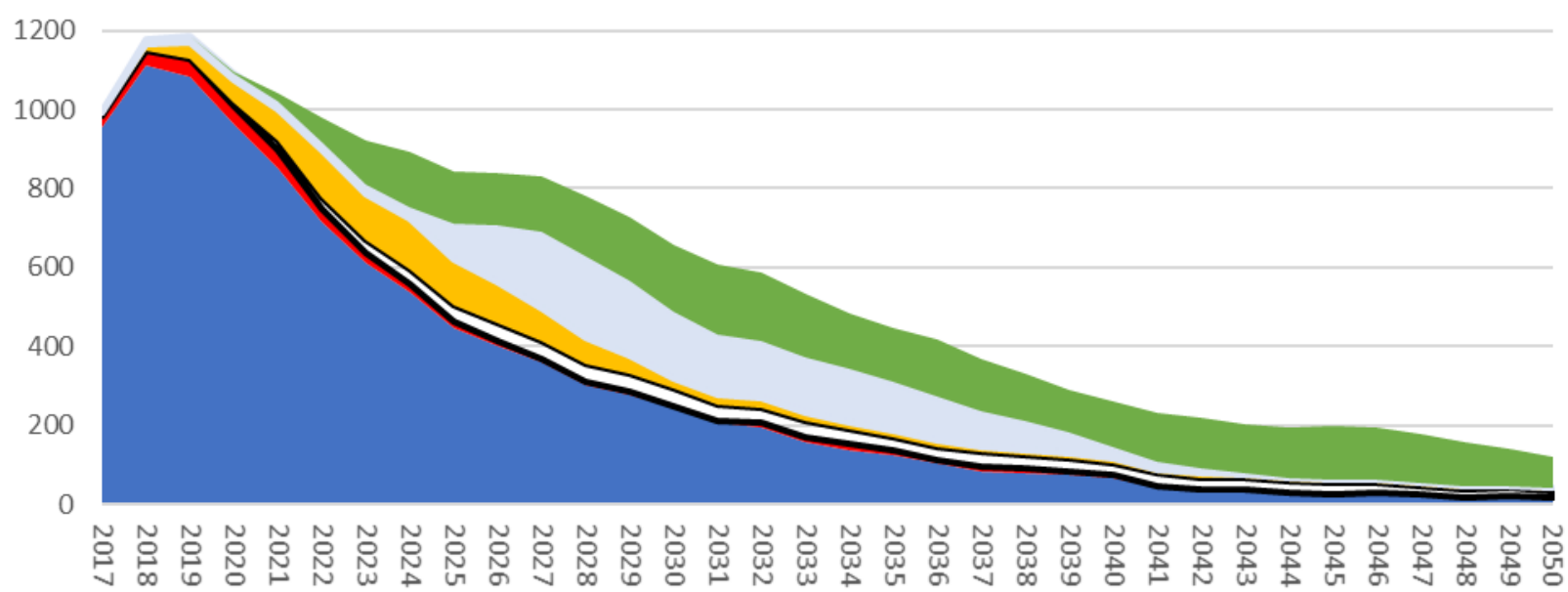

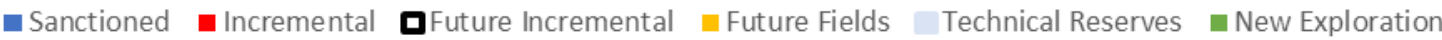

\section{Chart 6}

Potential Oil Production

$\$ 60 /$ bbl and 50p/therm

$\mathrm{tb} / \mathrm{d}$

Hurdle : Real NPV @ 10\%/Real Devex @ 10\% > 0.3

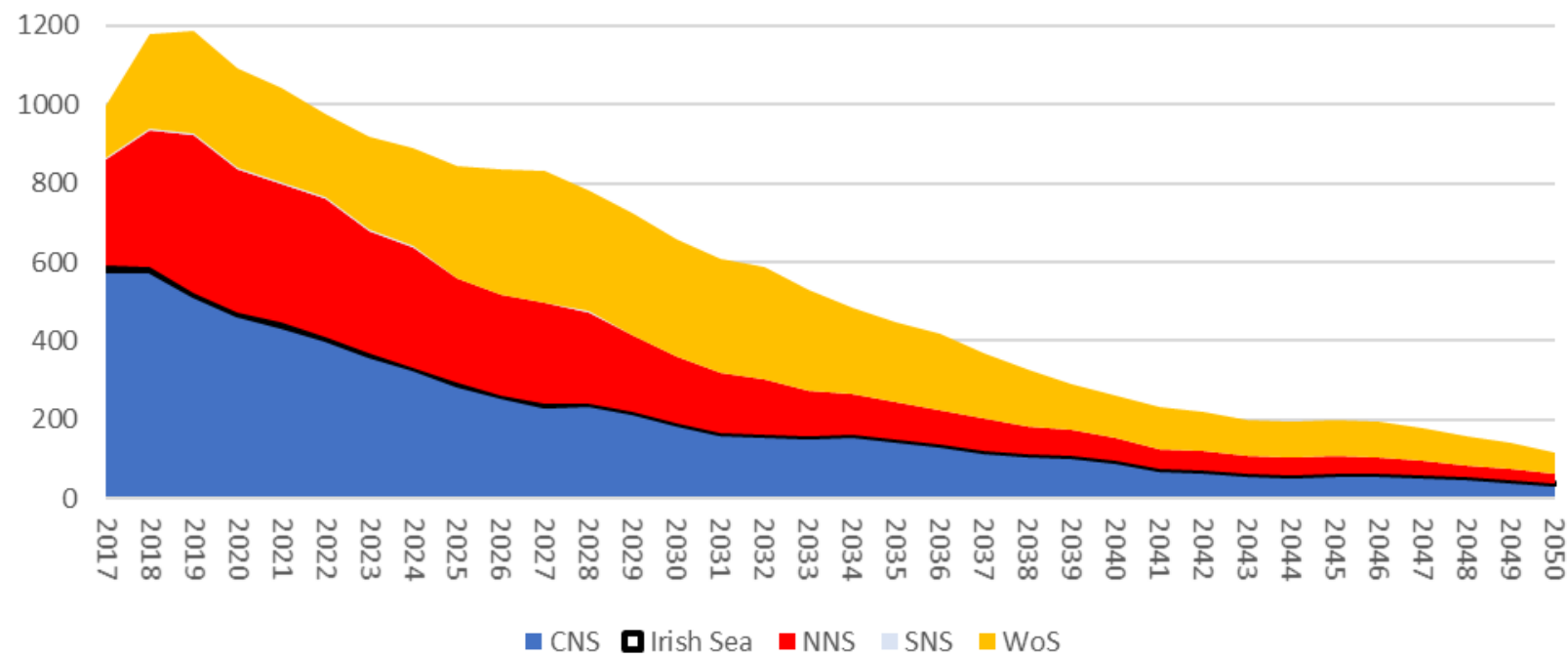

In Chart 7 potential gas production over the period to 2050 is shown for the $\$ 60,50$ pence case. Cumulative gas production is just over 3,547 
million barrels of oil equivalent of which 1,844 mmboe comes from sanctioned fields, 173 mmboe from current incremental projects, 377 mmboe from future incremental projects, 194 mmboe from probable and possible fields, $597 \mathrm{mmboe}$ from technical reserves, and $362 \mathrm{mmboe}$ from new discoveries.

Chart 8 gives the same information on geographic area basis. It is seen that 1,062 mmboe comes from the CNS/MF area, 1,331 mmboe comes from the SNS, 628 mmboe comes from the NNS, 430 mmboe from the WoS area and 97 mmboe from the Irish Sea.

\section{Chart 7}

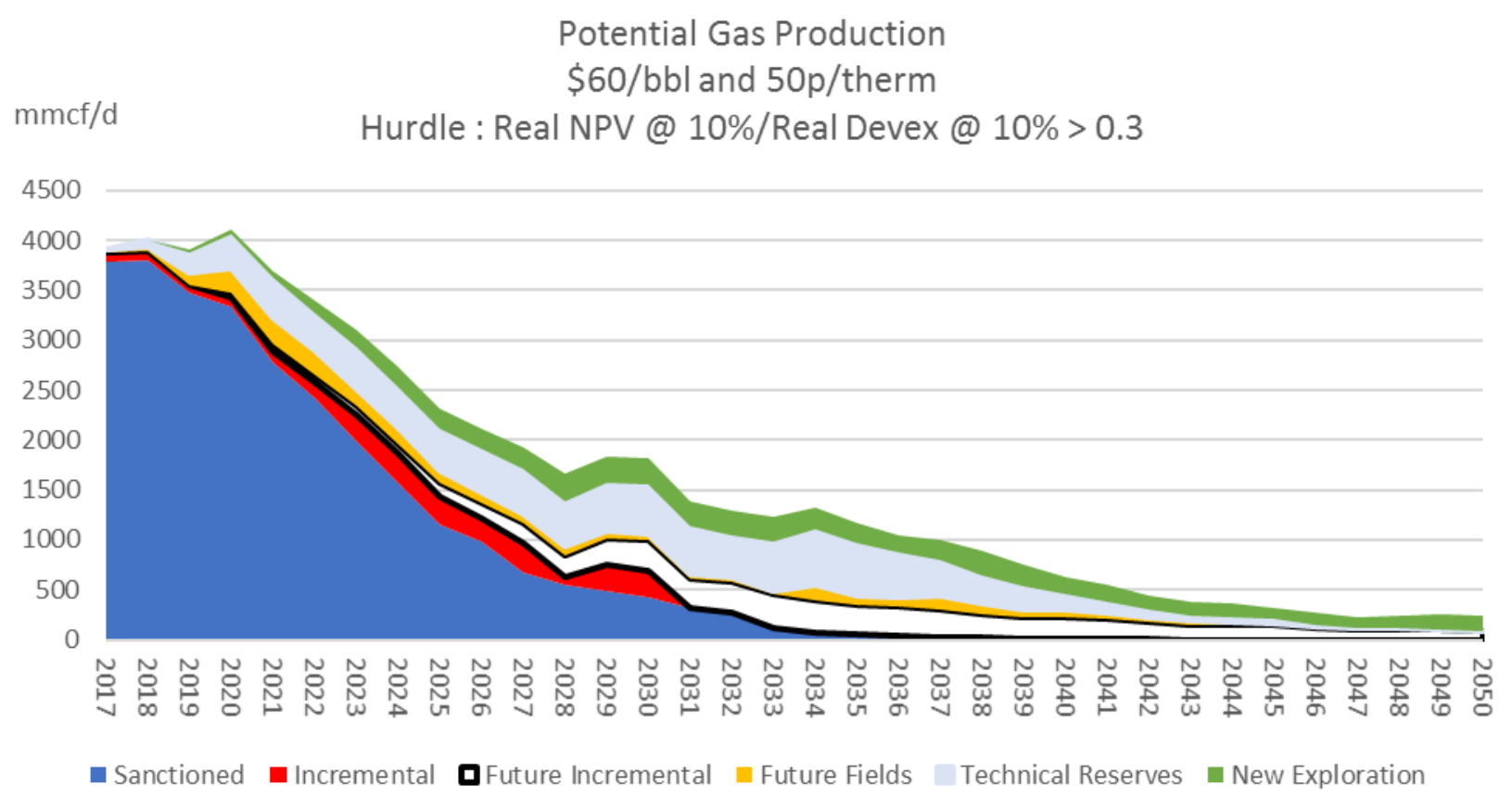


Chart 8

Potential Gas Production

$\$ 60 / \mathrm{bbl}$ and $50 \mathrm{p} /$ therm

$\mathrm{mmcf} / \mathrm{d}$

Hurdle : Real NPV @ 10\%/Real Devex @ 10\% > 0.3

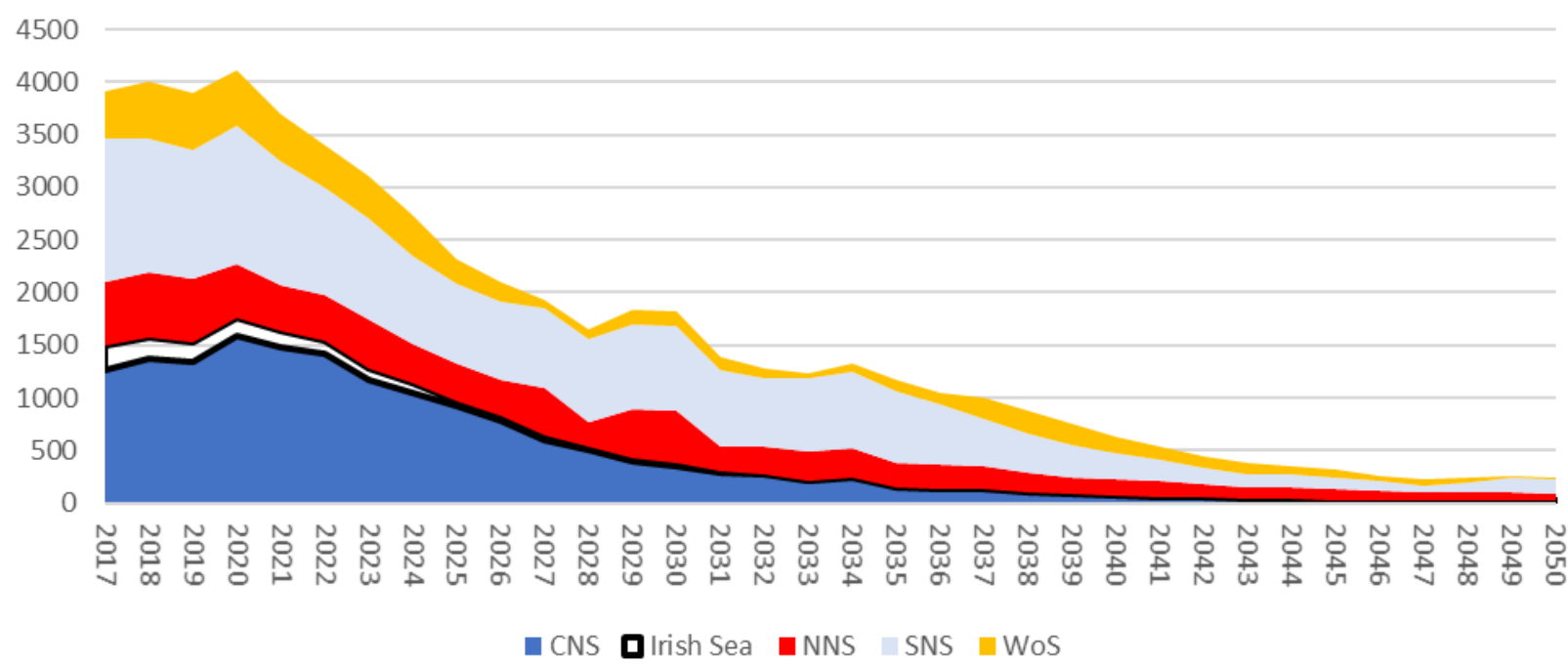

In Chart 9 potential total hydrocarbon production over the period to 2050 is shown for the $\$ 60,50$ pence case. Over the period cumulative total hydrocarbon production is just over 10,746 million barrels of oil equivalent of which 5,792 mmboe comes from sanctioned fields, 349 mmboe from current incremental projects, $782 \mathrm{mmboe}$ from future incremental projects, 661 mmboe from probable and possible fields, 1,409 mmboe from technical reserves, and 1,753 mmboe from new discoveries.

However, had the fields which failed the hurdle rate come into production the total hydrocarbon production could have increased by 5,595 mmboe with 179 mmboe coming from incremental projects, 1,208 mmboe from the probable and possible fields, $3,713 \mathrm{mmboe}$ from the technical reserve fields and 495 mmboe from new exploration finds. Further details of the unexploited potential are shown in the Appendix. 
Chart 10 gives the same information on geographic area basis. It is seen that 3,822 mmboe comes from the CNS/MF area, 1,345 mmboe comes from the SNS, 2,661 mmboe comes from the NNS, 2,805 mmboe from the WoS area and 113 mmboe from the Irish Sea.

If the fields which failed had come into production there would have been 1,653 mmboe more production from the CNS/MF area, 820 mmboe more from the SNS, 930 mmboe more from the NNS, 1,885 mmboe more from the WoS and 307 mmboe more from the Irish Sea.

\section{Chart 9}

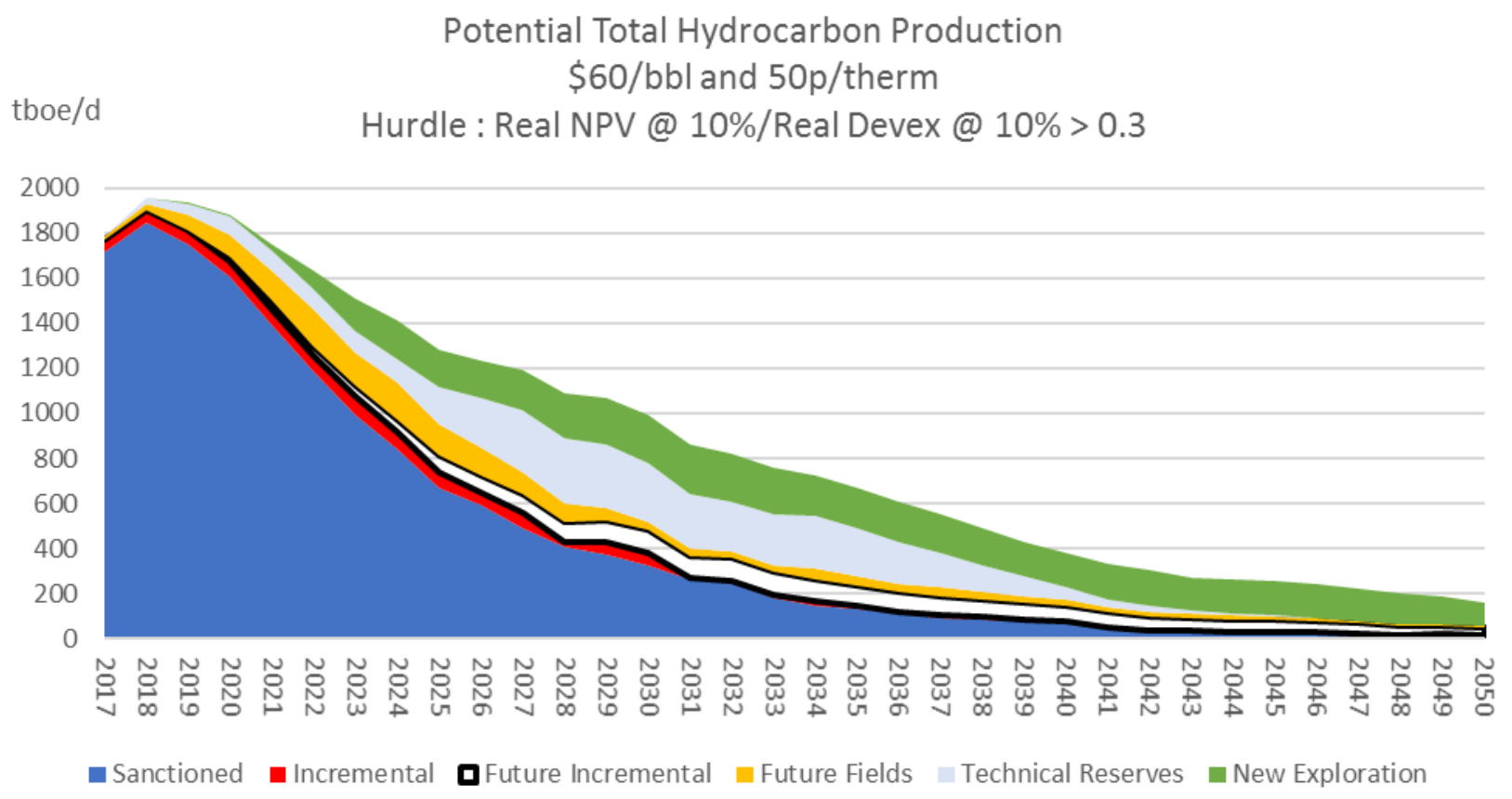




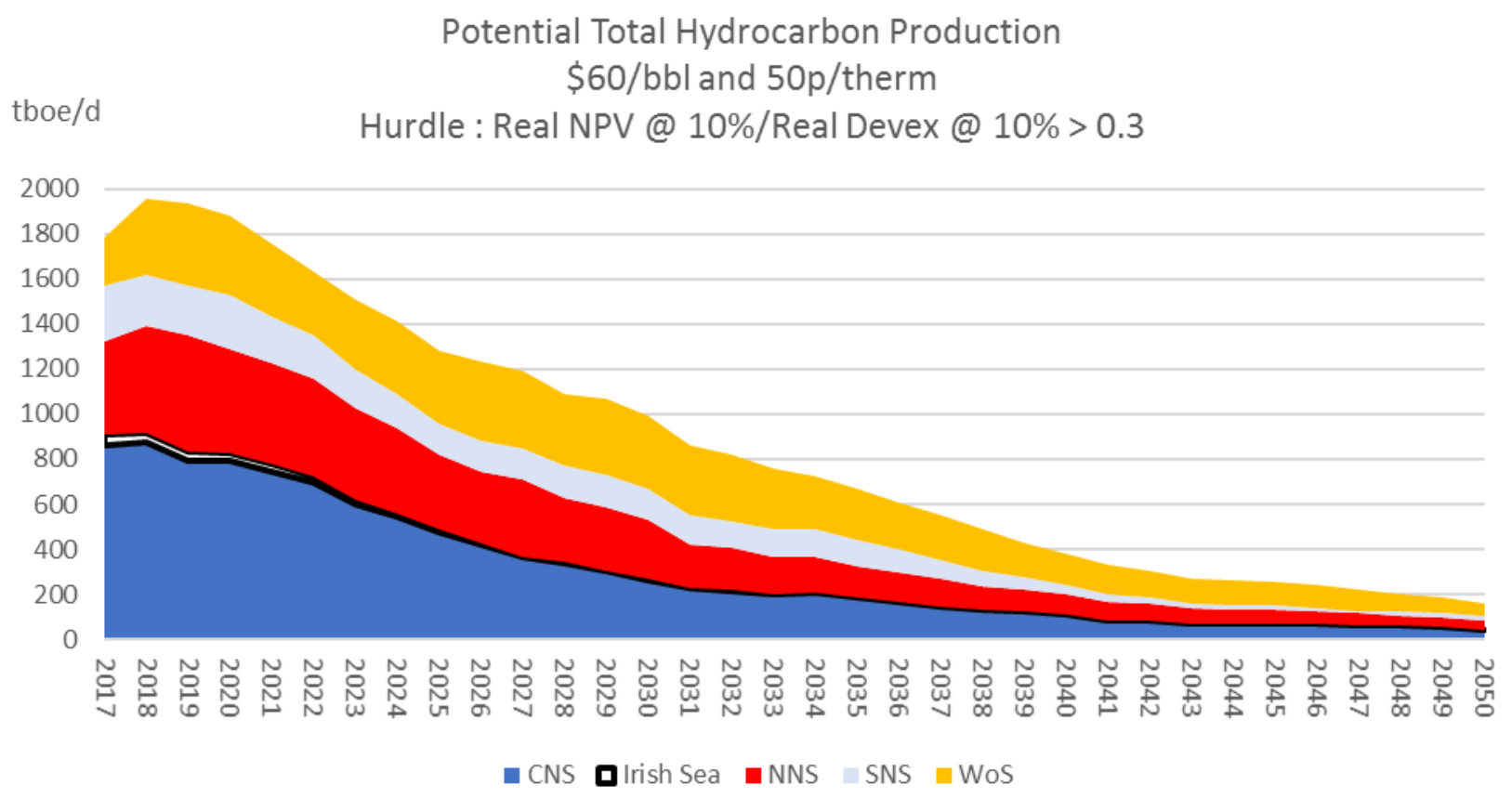

In Chart 11 potential oil production under the $\$ 50,40$ pence scenario is shown. Over the period cumulative oil production is 5,769 million barrels of which 3,733 million comes from sanctioned fields, 146 million from current incremental projects, 326 million from future incremental projects, 391 million from probable and possible fields, 595 million from technical reserves, and 577 million from new discoveries.

The reduction in prices from $\$ 60$ to $\$ 50$ results in a potential loss of 1,209 million barrels, 69 million of which is from the probable and possible fields, 216 million is from the technical reserve fields and 810 million from new discoveries (although there are 20 fewer new exploration finds at the $\$ 50$ price).

Chart 12 gives the same information on geographic area basis. It is seen that 2,125 million barrels comes from the CNS/MF area, closely followed 
by 1,997 million barrels from the WoS area, and 1,620 million barrels from the NNS area.

\section{Chart 11}

Potential Oil Production

$\$ 50 /$ bbl and 40p/therm

$\mathrm{tb} / \mathrm{d}$

Hurdle : Real NPV @ 10\%/Real Devex @ 10\% > 0.3

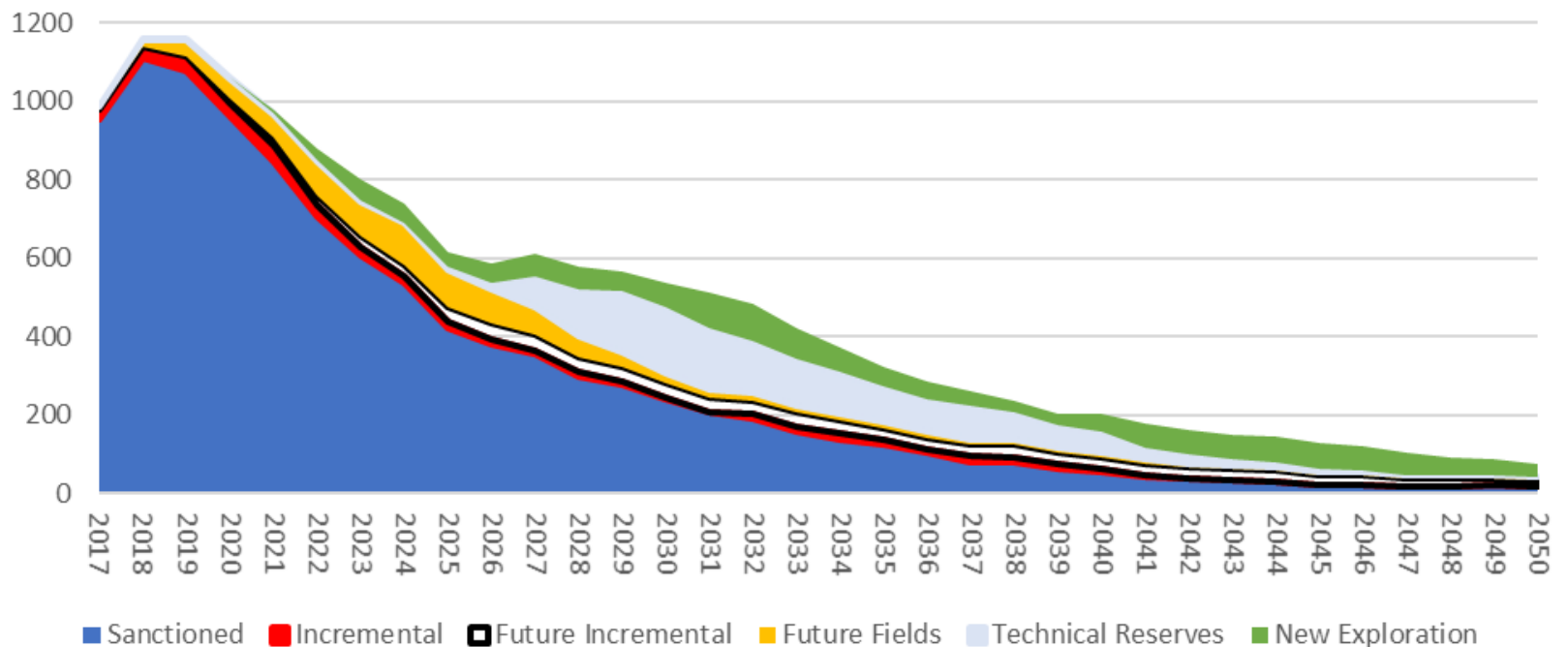

\section{Chart 12}

Potential Oil Production

$\$ 50 / \mathrm{bbl}$ and $40 \mathrm{p} /$ therm

$\mathrm{tb} / \mathrm{d}$

Hurdle : Real NPV @ 10\%/Real Devex @ 10\% > 0.3

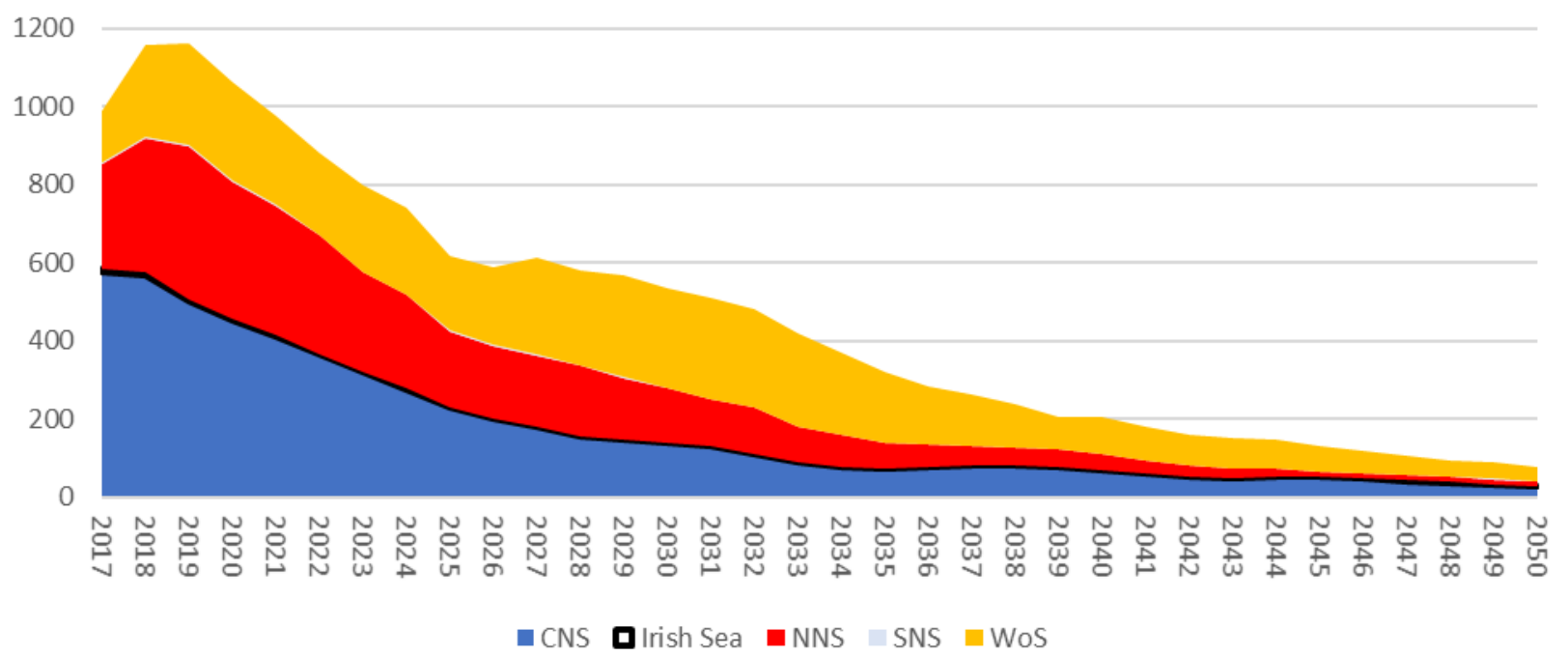


In Chart 13 potential gas production over the period to 2050 is shown for the $\$ 50,40$ pence case. Over the period cumulative gas production is just over 2,806 million barrels of oil equivalent of which 1,817 mmboe comes from sanctioned fields, 163 mmboe from current incremental projects, 354 mmboe from future incremental projects, 104 mmboe from probable and possible fields, 204 mmboe from technical reserves, and 166 mmboe from new discoveries.

The reduction in price from $\$ 60$ to $\$ 50$ results in a potential loss of 741 mmboe, 91 mmboe of which is from the probable and possible fields, 393 mmboe is from the technical reserve fields, and 196 mmboe from new discoveries (although there are 20 fewer new exploration finds at the lower price).

Chart 14 gives the same information on geographical area basis. It is seen that 959 mmboe comes from the CNS/MF area, 878 mmboe comes from the SNS, 598 mmboe comes from the NNS, 278 mmboe from the WoS area, and 94 mmboe from the Irish Sea.

The reduction in price results in a potential loss of 103 mmboe from the CNS/MF area, 453 mmboe from the SNS area, 30 mmboe from the NNS area, 152 mmboe from the WoS area, and 3 mmboe from the Irish Sea. 


\section{Chart 13}

Potential Gas Production

$\$ 50 /$ bbl and 40p/therm

$\mathrm{mmcf} / \mathrm{d}$

Hurdle : Real NPV @ 10\%/Real Devex @ 10\% > 0.3

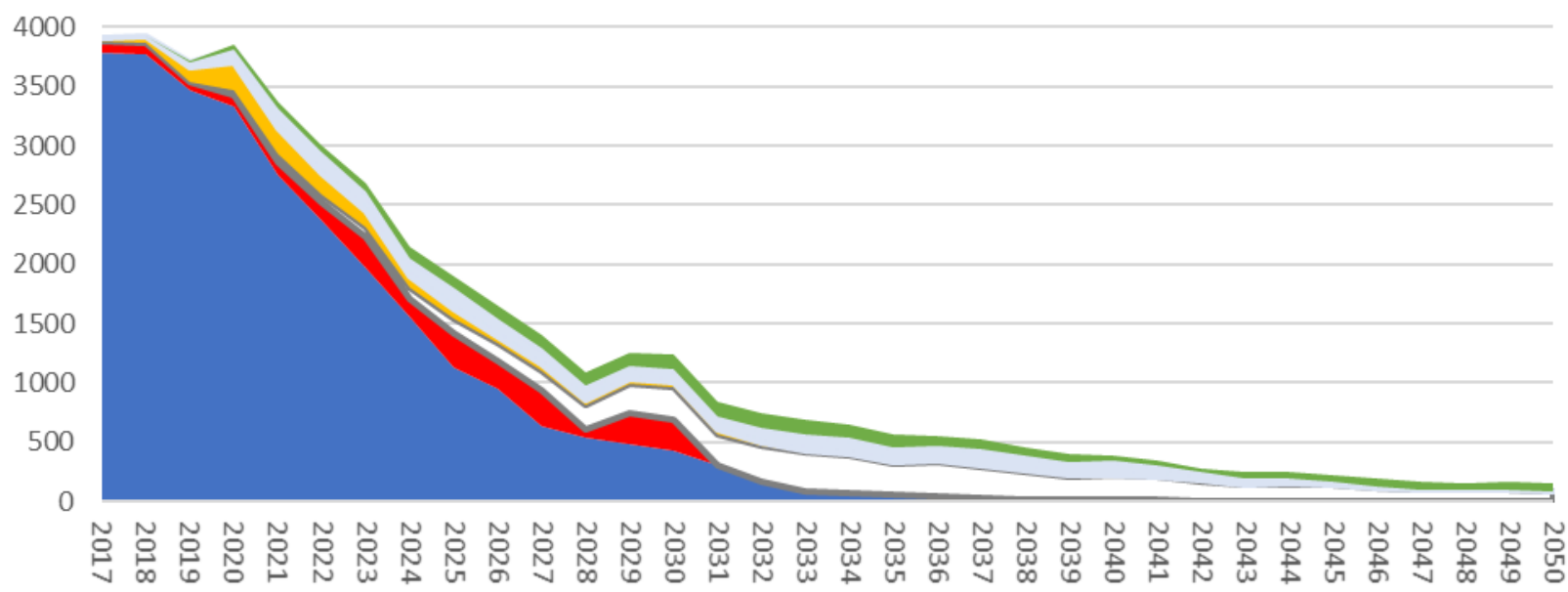

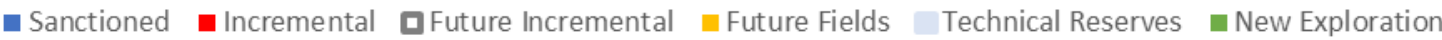

\section{Chart 14}

Potential Gas Production

$\$ 50 / \mathrm{bbl}$ and $40 \mathrm{p} /$ therm

mmcf/d Hurdle : Real NPV @ 10\%/Real Devex @ $10 \%>0.3$

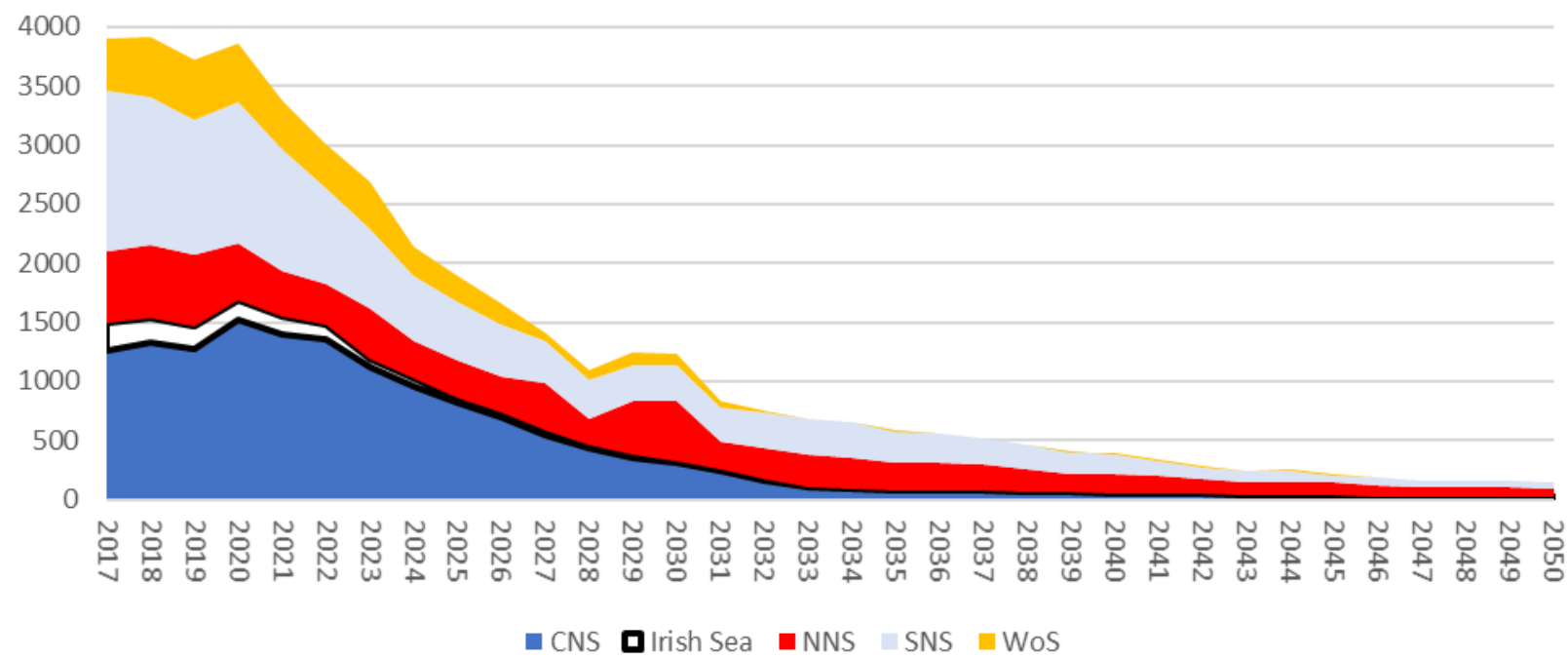

In Chart 15 potential total hydrocarbon production over the period to 2050 is shown for the $\$ 50,40$ pence case. Over the period cumulative total hydrocarbon production is just under 8,785 million barrels of oil equivalent 
of which 5,710 mmboe comes from sanctioned fields, $320 \mathrm{mmboe}$ from current incremental projects, $713 \mathrm{mmboe}$ from future incremental projects, $497 \mathrm{mmboe}$ from probable and possible fields, $800 \mathrm{mmboe}$ from technical reserves, and 745 mmboe from future discoveries.

The reduction in prices results in a potential loss of $1,961 \mathrm{mboe}, 164$ mmboe of which from the probable and possible fields, $610 \mathrm{mmboe}$ is lost from the technical reserve fields and 1,009 mmboe from new discoveries (although there are 20 fewer new exploration finds).

However, had the fields which failed the hurdle rate come into production the total hydrocarbon production could have increased by $6,910 \mathrm{mmboe}$ with 192 mmboe coming from the incremental projects, 1,340 mmboe from the probable and possible fields, 4,213 mmboe from the technical reserve fields and 1,165 mmboe from new exploration finds.

Chart 16 gives the same information on geographic area basis. It is seen that 3,245 mmboe comes from the CNS/MF area, 890 mmboe comes from the SNS, 2,267 mmboe comes from the NNS, 2,279 mmboe from the WoS area and 105 mmboe from the Irish Sea.

The largest reductions in potential production with the lower prices are from the CNS/MF and the WoS areas.

If the fields which failed had come into production there could have been 2,040 mmboe more production from the CNS/MF area, 1,192 mmboe more from the SNS, 1,184 mmboe more from the NNS, 2,211 mmboe more from the WoS and 283 mmboe more from the Irish Sea. Further details of the unexploited potential are shown in the Appendix. 


\section{Chart 15}

Potential Total Hydrocarbon Production

$\$ 50 /$ bbl and 40p/therm

tboe/d

Hurdle : Real NPV @ 10\%/Real Devex @ 10\% > 0.3

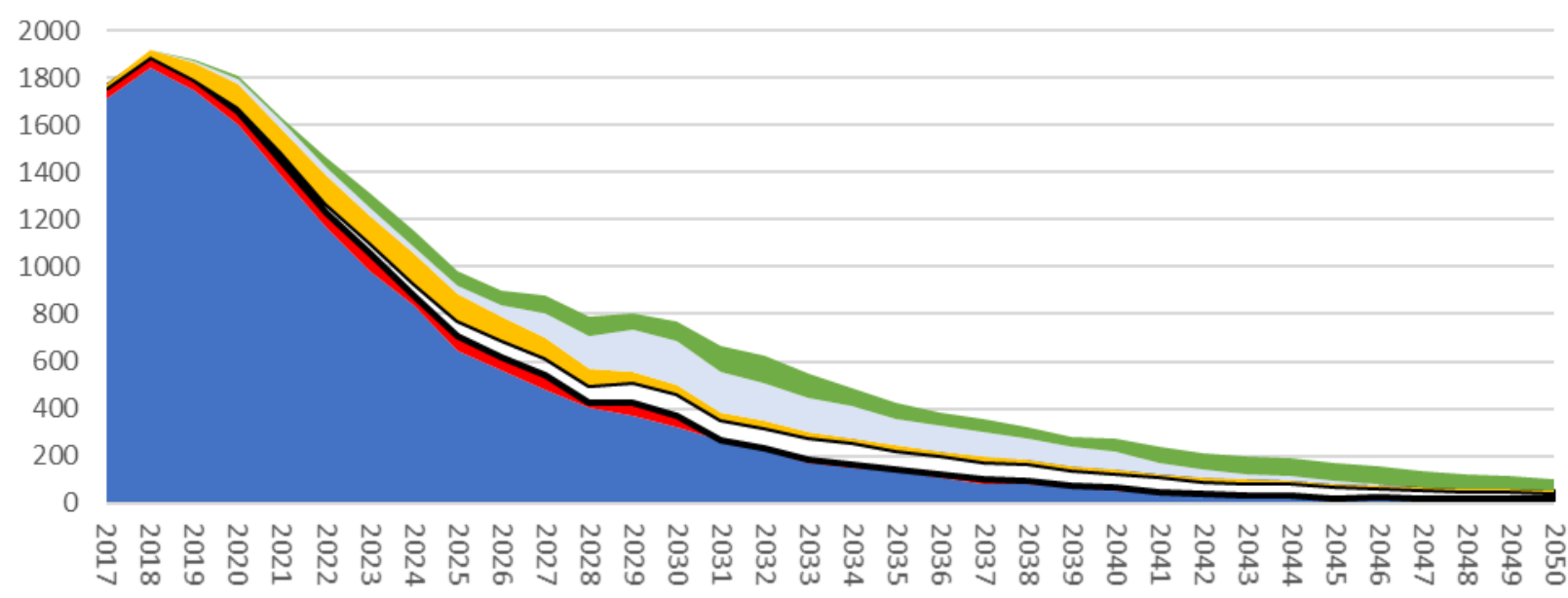

- Sanctioned Incremental

口Future Incremental $\square$ Future Fields 1 Technical Reserves

New Exploration

\section{Chart 16}

Potential Total Hydrocarbon Production $\$ 50 / \mathrm{bbl}$ and $40 \mathrm{p} /$ therm

tboe/d Hurdle : Real NPV @ 10\%/Real Devex @ 10\% > 0.3

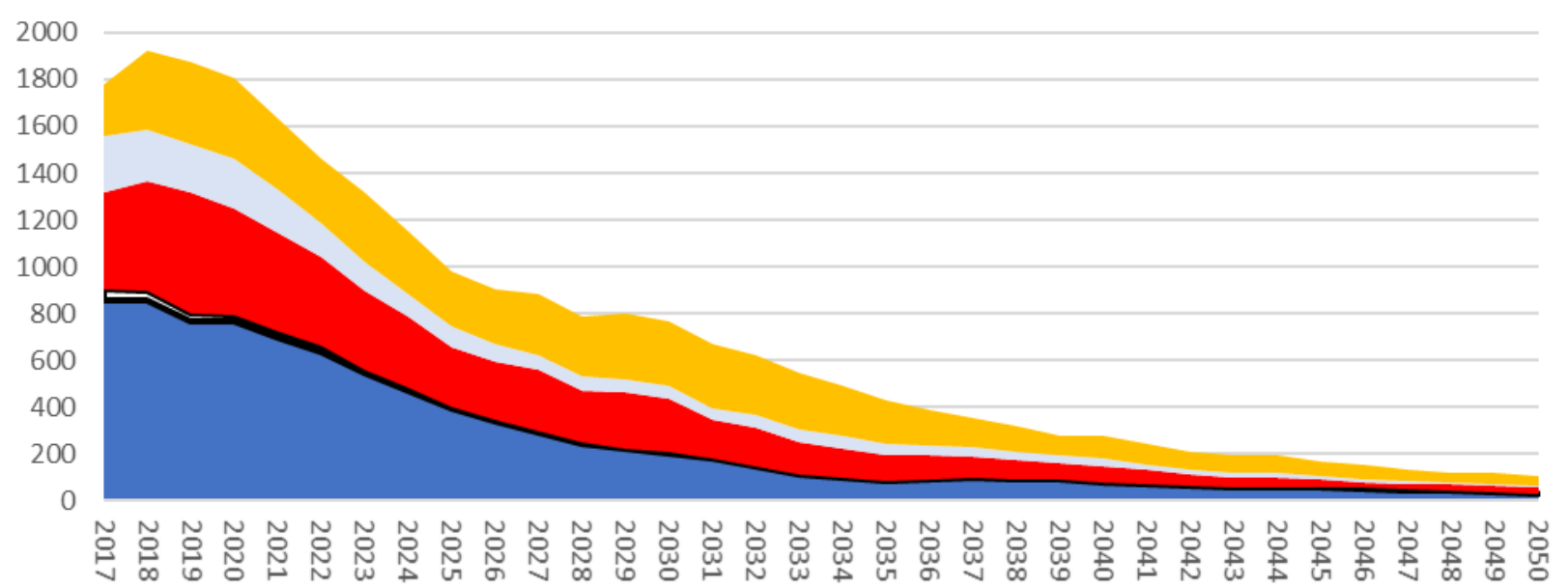

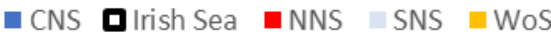




\section{(iii) Field Expenditures by Category and Related Decommissioning Activity}

In Chart 17 potential development expenditure is shown under the $\$ 60,50$ pence price case. The decrease from current levels over the next few years is notable. Over the period to 2050 cumulative development expenditures amount to $£ 89,257$ million at 2017 prices. The sanctioned fields contribute to the total until 2043 and account for $£ 28,049$ million. Current incremental projects account for $£ 3,425$ million, future incremental projects $£ 10,012$ million, probable and possible fields $£ 6,573$ million, technical reserve fields $£ 17,461$ million, and new exploration finds $£ 23,738$ million.

Chart 18 gives the same information on geographic area basis. The CNS/MF area accounts for $£ 30,315$ million, the SNS $£ 8,773$ million, the NNS $£ 27,394$ million, the WoS $£ 22,422$ million and the Irish Sea $£ 353$ million.

Chart 17

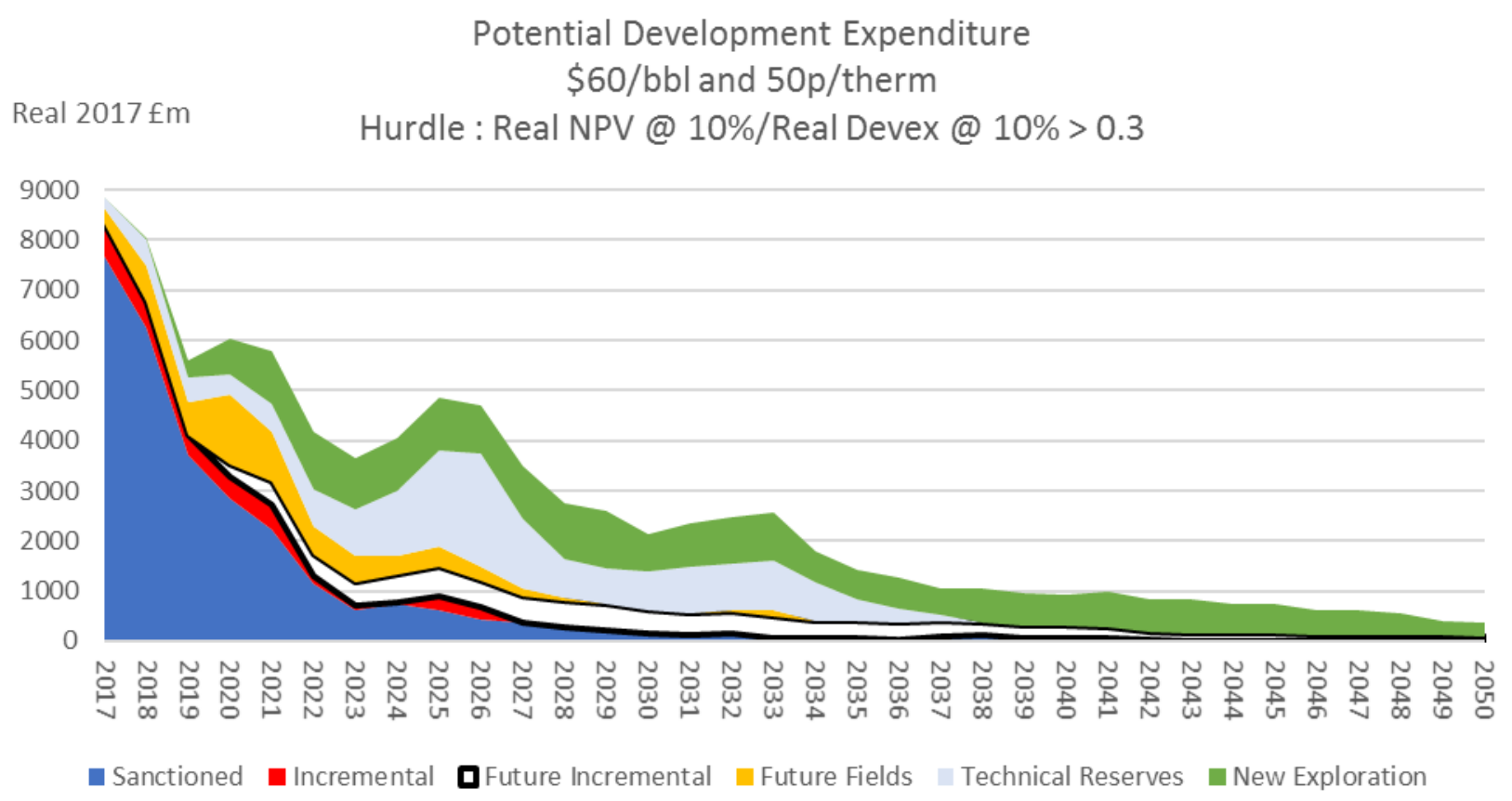




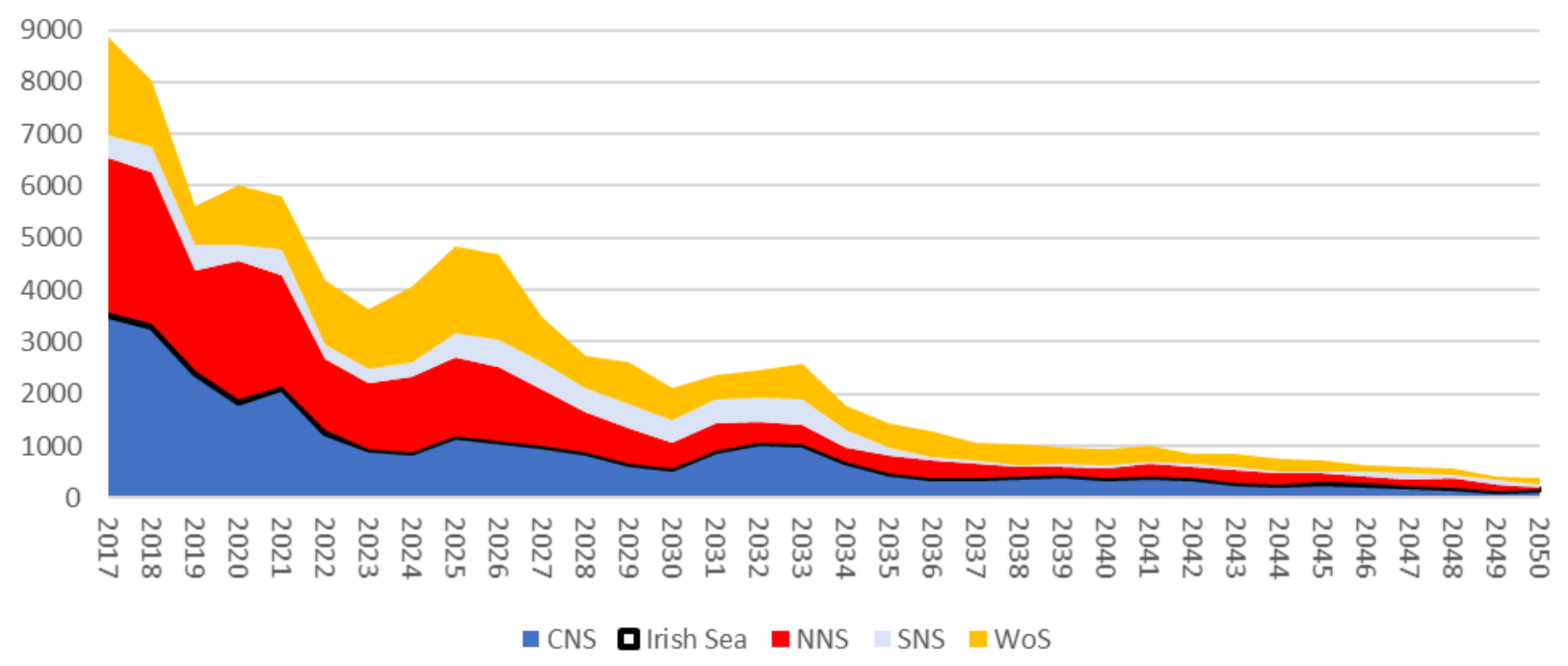

In Chart 19 potential operating expenditure is shown under the $\$ 60,50$ pence price case. Over the period to 2050 cumulative expenditures amount to $£ 123,700$ million at 2017 prices. The sanctioned fields account for $£ 82,079$ million, current incremental projects $£ 2,126$ million, future incremental projects $£ 4,802$ million, probable and possible fields $£ 6,108$ million, technical reserve fields $£ 11,416$ million, and new exploration finds $£ 17,168$ million.

Chart 20 gives the same information on geographic area basis. The CNS/MF area accounts for $£ 51,027$ million, the SNS $£ 9,454$ million, the NNS $£ 36,086$ million, the WoS $£ 25,341$ million, and the Irish Sea $£ 1,792$ million. 


\section{Chart 19}

Potential Operating Expenditure

$\$ 60 / \mathrm{bbl}$ and $50 \mathrm{p} /$ therm

Real $2017 \mathrm{fm}$

Hurdle : Real NPV @ 10\%/Real Devex @ 10\% > 0.3

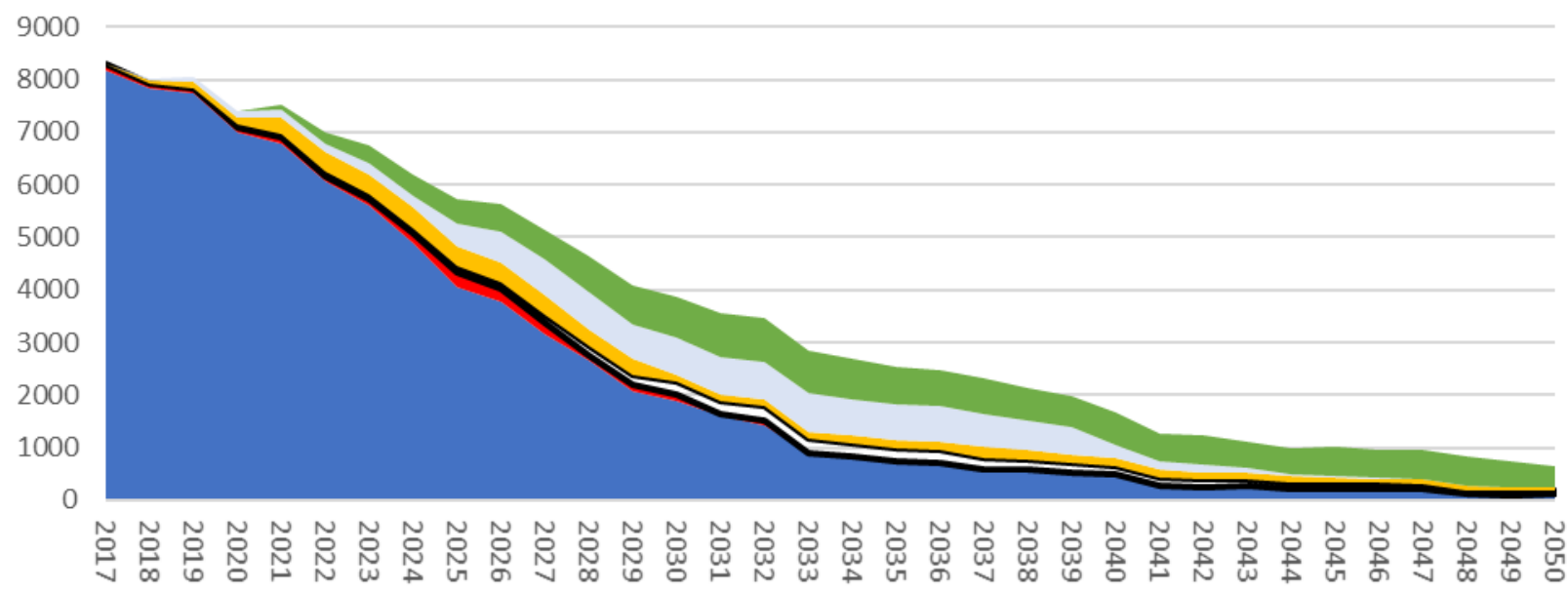

\section{Chart 20}

Potential Operating Expenditure

$\$ 60 / \mathrm{bbl}$ and $50 \mathrm{p} /$ therm

Real $2017 \mathrm{fm}$

Hurdle : Real NPV @ 10\%/Real Devex @ 10\% > 0.3

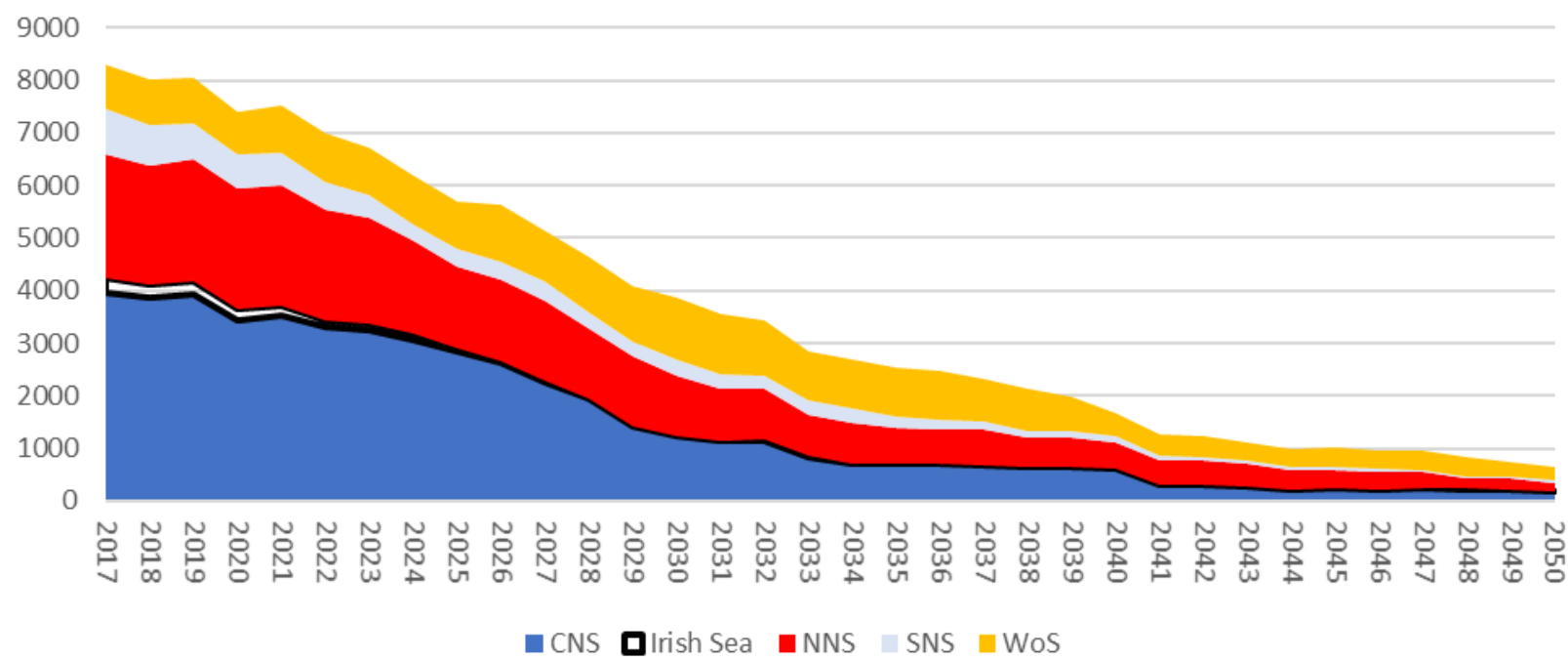

In Chart 21 cumulative potential decommissioning costs are shown under the $\$ 60,50$ pence price case. Over the period to 2050 cumulative 
decommissioning costs amount to $£ 54,246$ million at 2017 prices. The sanctioned fields account for $£ 49,599$ million, current incremental projects $£ 259$ million, future incremental projects $£ 464$ million, probable and possible fields $£ 356$ million, technical reserve fields $£ 1,746$ million, and new exploration finds $£ 1,823$ million. By 2025 the cumulative decommissioning spend could be $£ 22,999$ million. The bulk of the expenditure occurs before 2035 .

Chart 22 gives the same information on geographic area basis. The CNS/MF area accounts for $£ 22,907$ million, the SNS $£ 7,277$ million, the NNS $£ 18,214$ million, the WoS $£ 4,516$ million, and the Irish Sea $£ 1,334$ million.

Chart 21

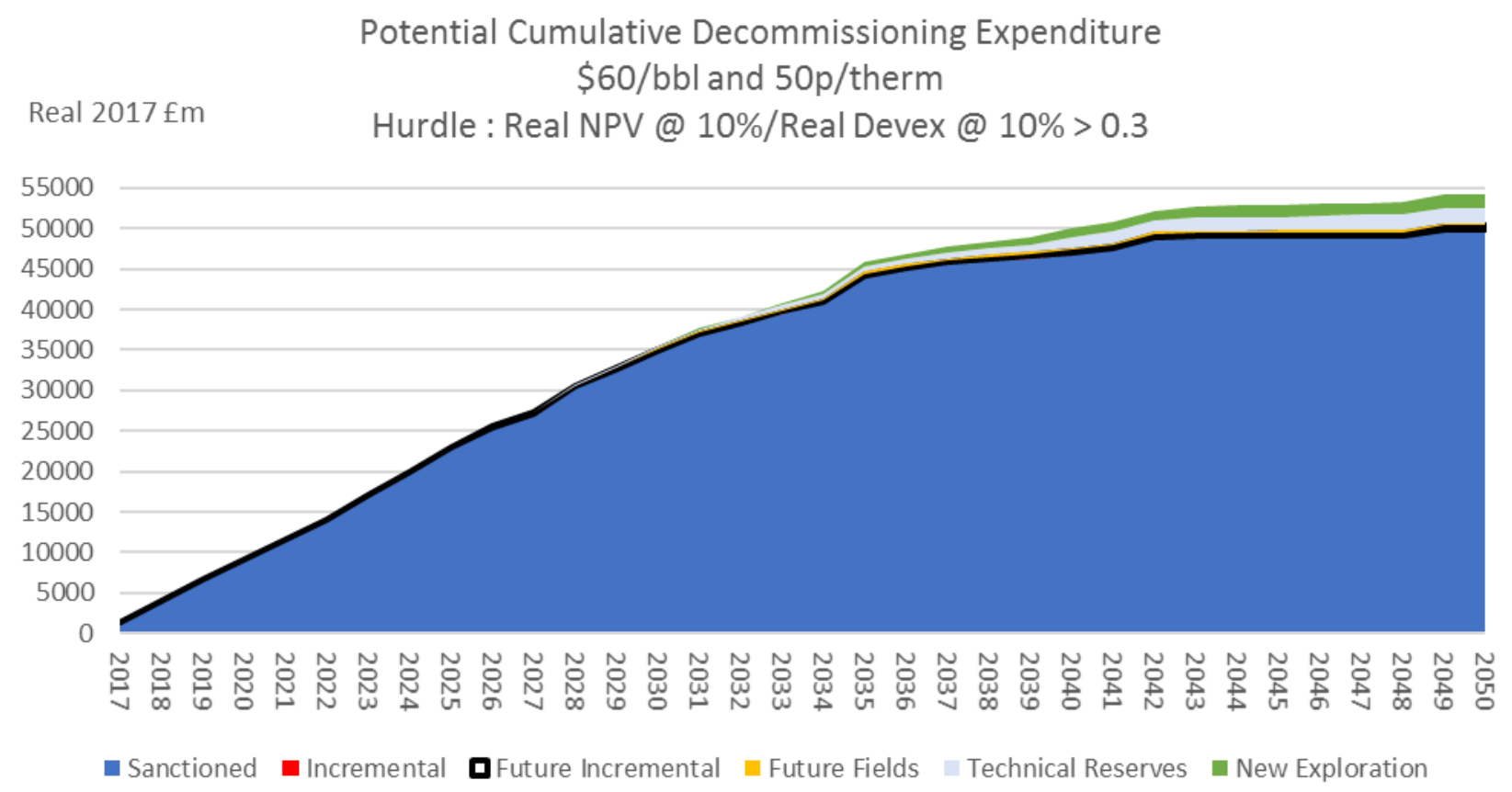


Potential Cumulative Decommissioning Expenditure $\$ 60 /$ bbl and 50p/therm

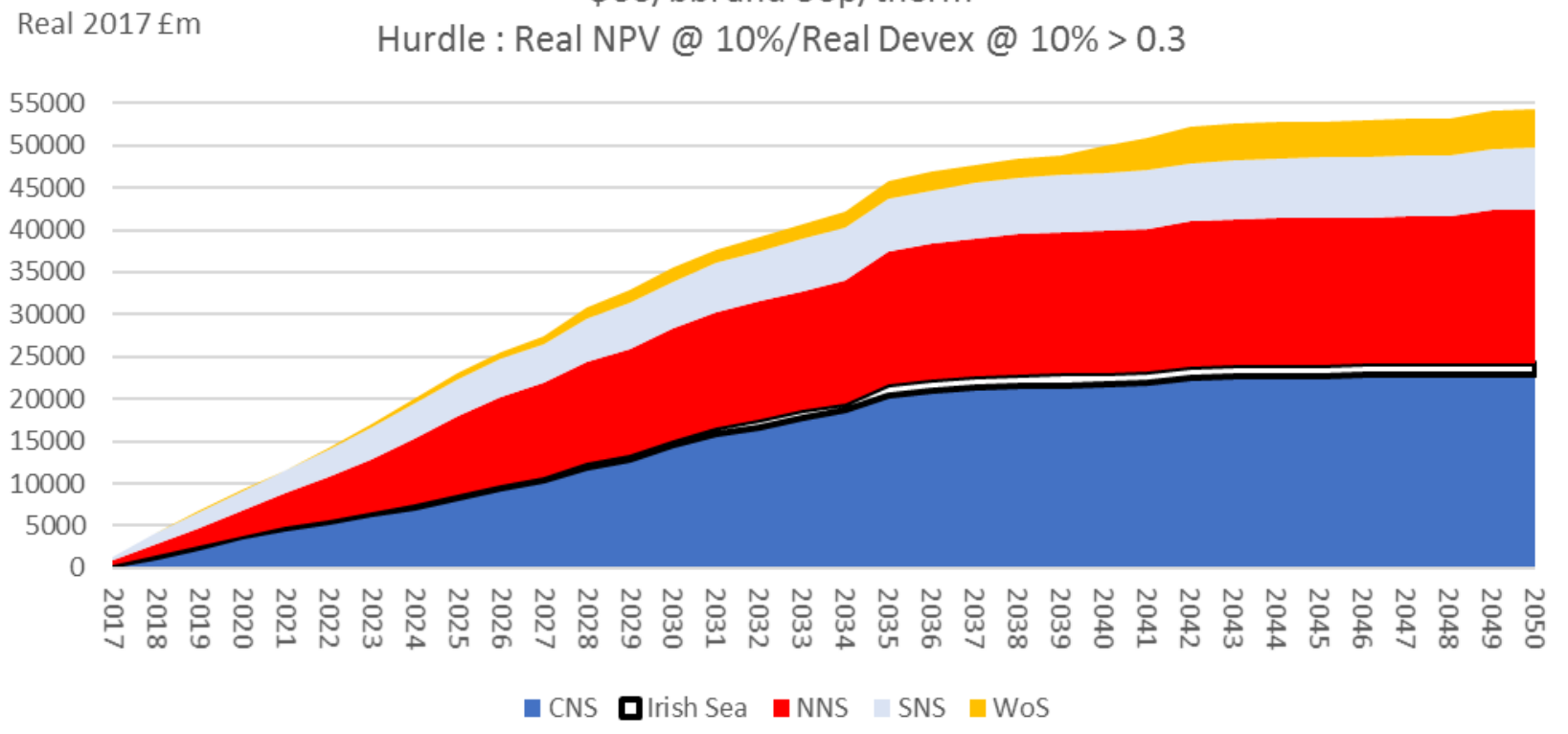

Chart 23 shows the number of fields decommissioning over time under the $\$ 60,50$ pence price case. Decommissioning expenditure can be spread over many years. By 2025 there could be as many as 200 fields either undergoing or having completed decommissioning, and by 2050 there could be 487 fields in this position. By 2025 there are 194 sanctioned fields and 6 technical reserve fields. By 2050 there are 307 sanctioned fields, 12 probable and possible fields, 104 technical reserve fields, and 64 new discoveries.

Chart 24 gives the same information on geographic area basis. By 2025 there could be 65 fields in the CNS/MF area undergoing or having completed decommissioning, and there could be 64 fields in the SNS, 53 fields in the NNS, 3 fields in the WoS, and 15 fields in the Irish Sea in the same position. By 2050 there could be 187 fields in the CNS/MF area undergoing or having completed decommissioning, and there could be 150 
fields in the SNS, 104 fields in the NNS, 28 fields in the WoS and 18 fields in the Irish Sea in the same position.

\section{Chart 23}

Potential Number of Fields Decommissioning $\$ 60 / \mathrm{bbl}$ and $50 \mathrm{p} /$ therm

No. of Fields Hurdle : Real NPV @ 10\%/Real Devex @ 10\%>0.3

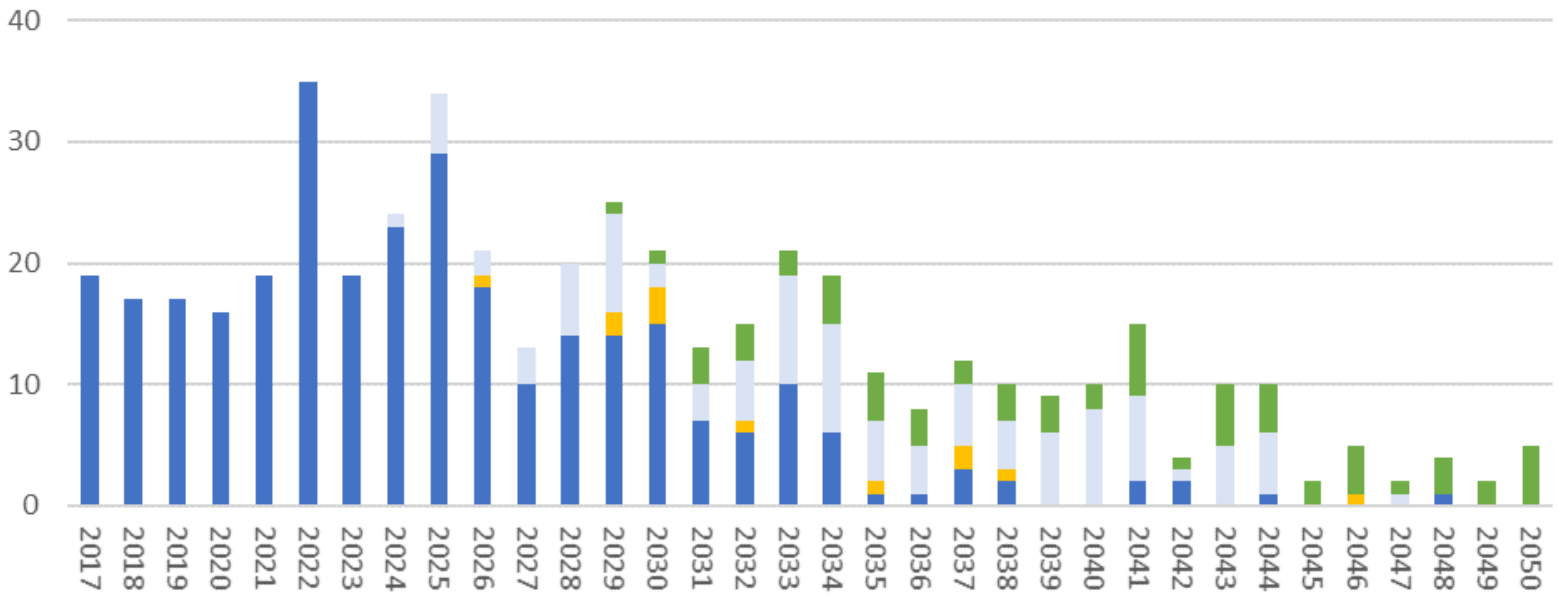

- Sanctioned Future Fields Technical Reserves New Exploration

Chart 24

Potential Number of Fields Decommissioning $\$ 60 / \mathrm{bbl}$ and $50 \mathrm{p} /$ therm

No. of Fields Hurdle : Real NPV @ 10\%/Real Devex @ 10\%>0.3

40

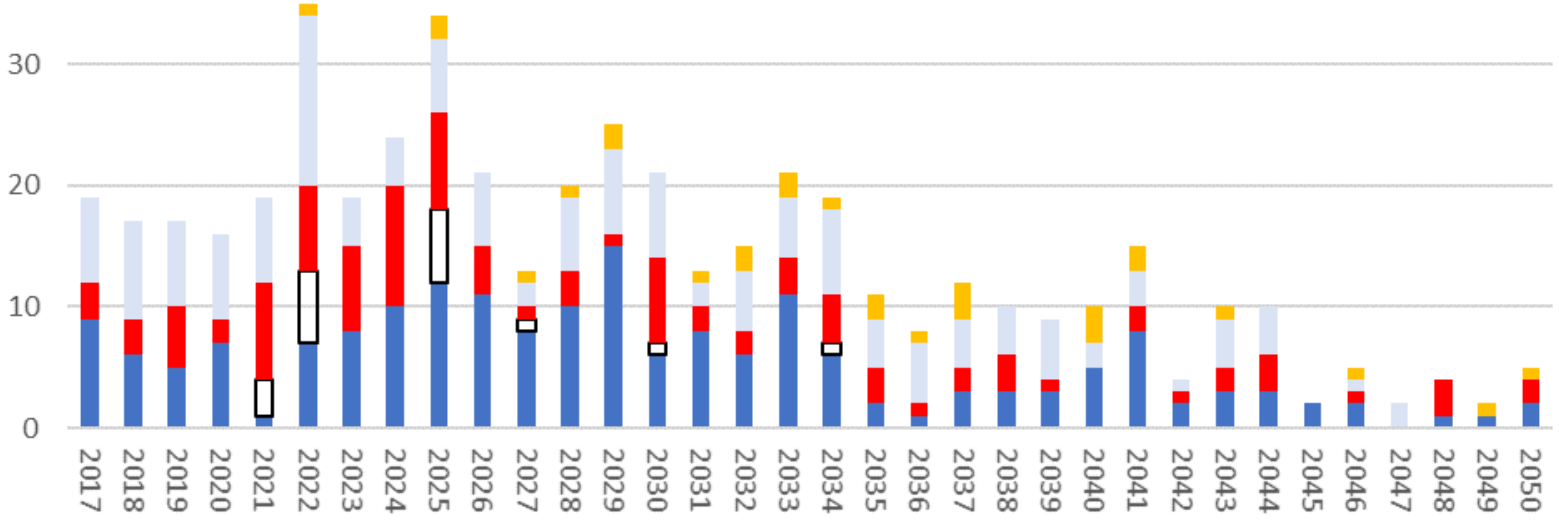

$\because$ CNS $\square$ lrish Sea $\square$ NNS $\square$ SNS $\square$ WOS 
In Chart 25 potential total expenditure is shown under the $\$ 60,50$ pence price case. Over the period to 2050 cumulative total expenditures amount to $£ 267,203$ million at 2017 prices. The sanctioned fields account for $£ 159,726$ million, current incremental projects $£ 5,809$ million, future incremental projects $£ 15,278$ million, probable and possible fields $£ 13,037$ million, technical reserve fields $£ 30,624$ million, and new exploration finds $£ 42,729$ million.

However, had the fields which failed the hurdle rate come into production the total expenditure could have increased by $£ 175,334$ million, with $£ 5,473$ coming from incremental projects, $£ 34,946$ million from probable and possible fields, $£ 117,627$ million from technical reserve fields, and $£ 17,287$ million from new exploration finds.

Chart 26 gives the same information on geographic area basis. The CNS/MF area accounts for $£ 104,249$ million, the SNS $£ 25,503$ million, the NNS $£ 81,694$ million, the WoS $£ 52,279$ million, and the Irish Sea $£ 3,479$ million of total expenditure.

If the fields which fail the hurdle rate had come into production then total expenditure would have been $£ 53,401$ million higher in the CNS/MF area, $£ 17,767$ million higher in the SNS area, $£ 35,097$ million higher in the NNS area , $£ 58,890$ million higher in the WoS, and $£ 10,178$ million higher in the Irish Sea. Further details of the unexploited potential are shown in the Appendix. 


\section{Chart 25}

Potential Total Field Expenditure

$\$ 60 / \mathrm{bbl}$ and $50 \mathrm{p} /$ therm

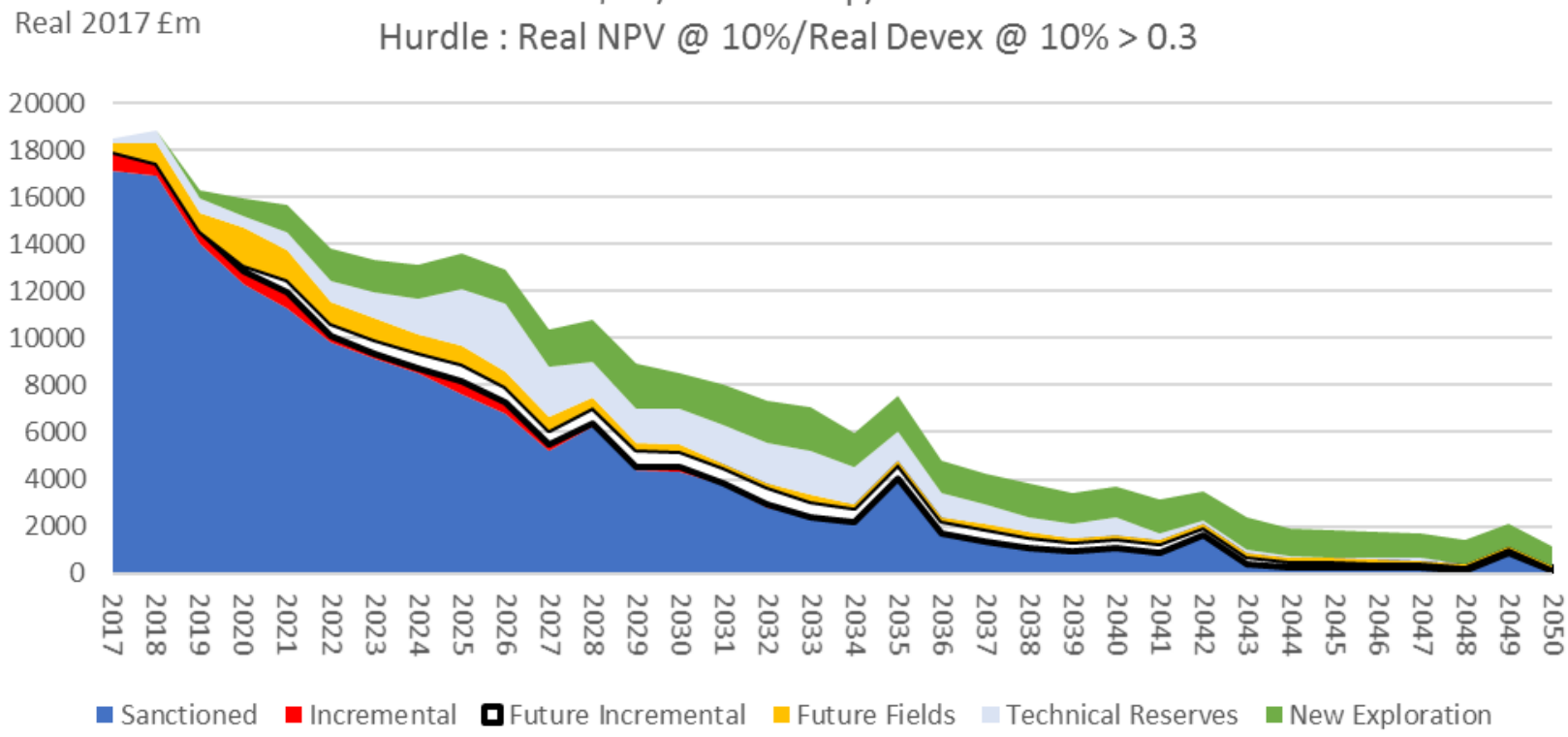

Chart 26

Potential Total Field Expenditure

$\$ 60 / \mathrm{bbl}$ and 50p/therm

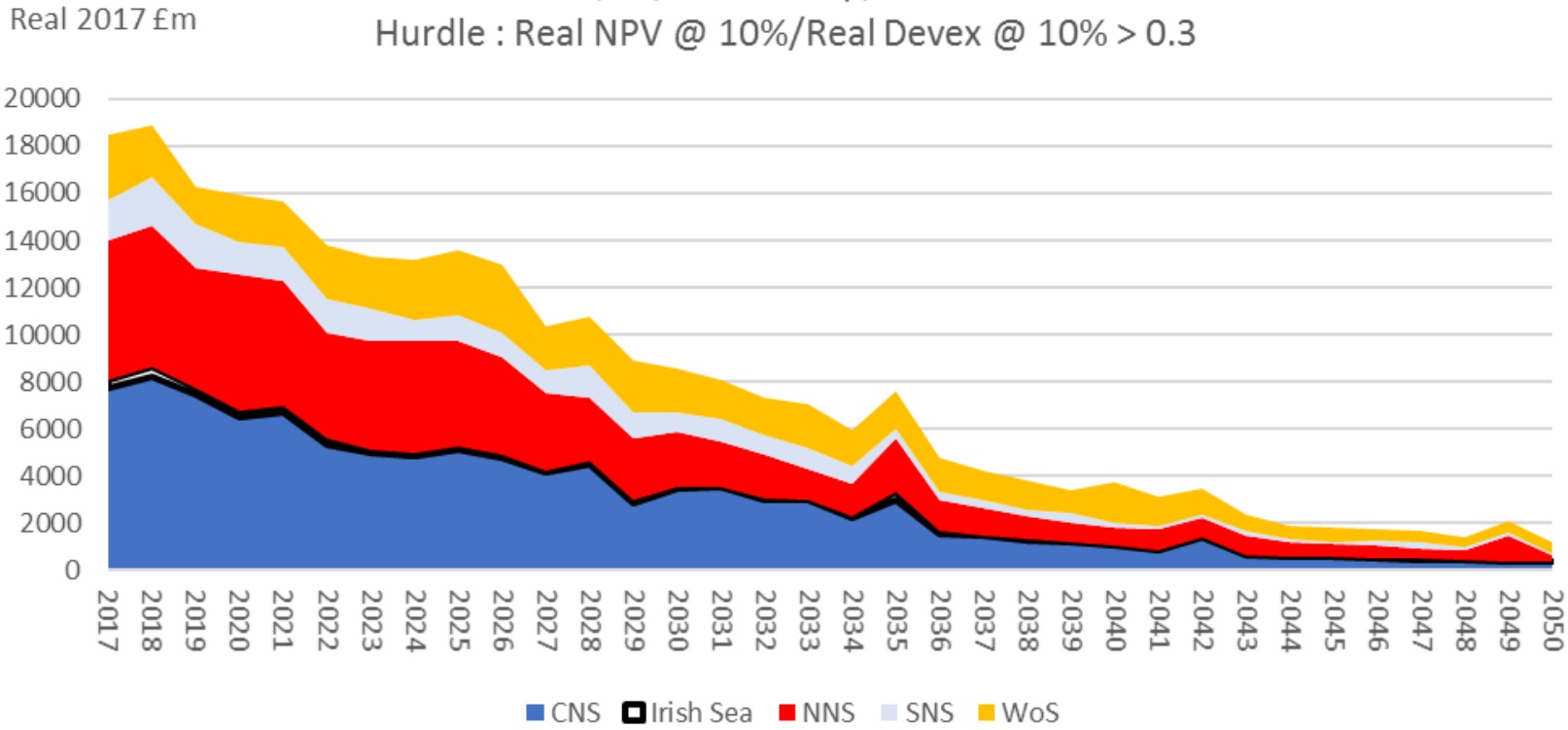

Chart 27 shows that by 2019 operating costs are likely to exceed development costs. By 2023 decommissioning costs could be $22 \%$ of total costs, and in 2035 they could be $48 \%$ of total costs. 


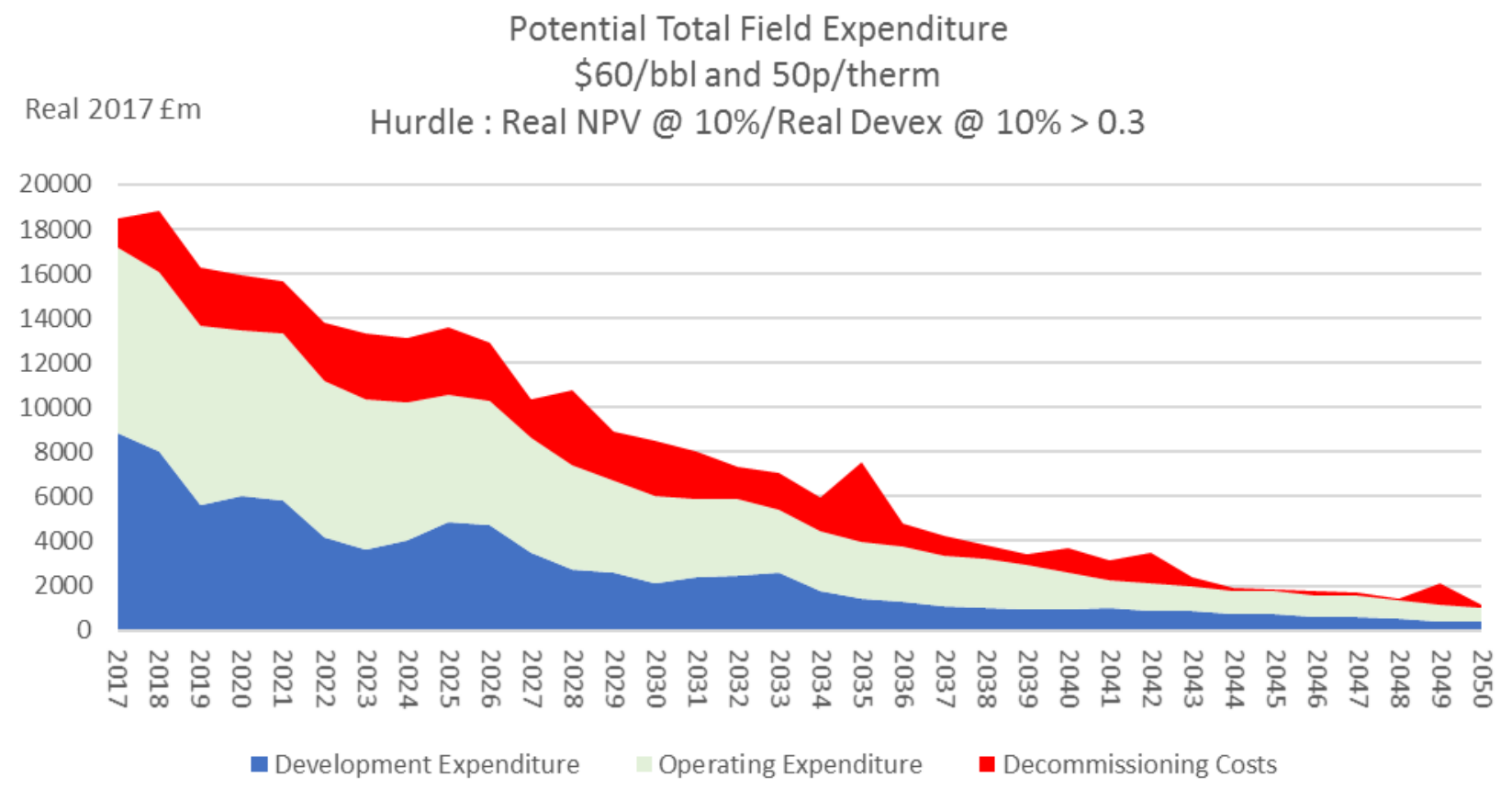

In Chart 28 potential development expenditure is shown under the $\$ 50,40$ pence price case. Over the period to 2050 cumulative development expenditures amount to $£ 63,579$ million at 2017 prices. This is $£ 25,678$ million less than with the $\$ 60$ case. The sanctioned fields contribute to the total until 2043, and eventually $£ 28,017$ million. Current incremental projects account for $£ 3,149$ million, future incremental projects $£ 9,025$ million, probable and possible fields $£ 5,188$ million (which is $£ 1,385$ million less than with the $\$ 60$ case), technical reserve fields $£ 9,338$ million (which is $£ 8,124$ million less than the $\$ 60$ case), and new exploration finds $£ 8,862$ million (which is $£ 14,876$ million less than the $\$ 60$ case).

Chart 29 gives the same information on geographic area basis. The CNS/MF area accounts for $£ 22,434$ million, the SNS $£ 3,779$ million, the NNS $£ 21,383$ million, the WoS $£ 15,736$ million, and the Irish Sea $£ 247$ million of development expenditure. Compared to the $\$ 60,50$ pence case 
this is a reduction of $£ 7,881$ million in the CNS/MF area, $£ 4,994$ million in the SNS area, $£ 6,011$ million in the NNS area, $£ 6,687$ million in the WoS area, and $£ 106$ million in the Irish Sea.

\section{Chart 28}

\section{Potential Development Expenditure}

$\$ 50 / \mathrm{bbl}$ and $40 \mathrm{p} /$ therm 


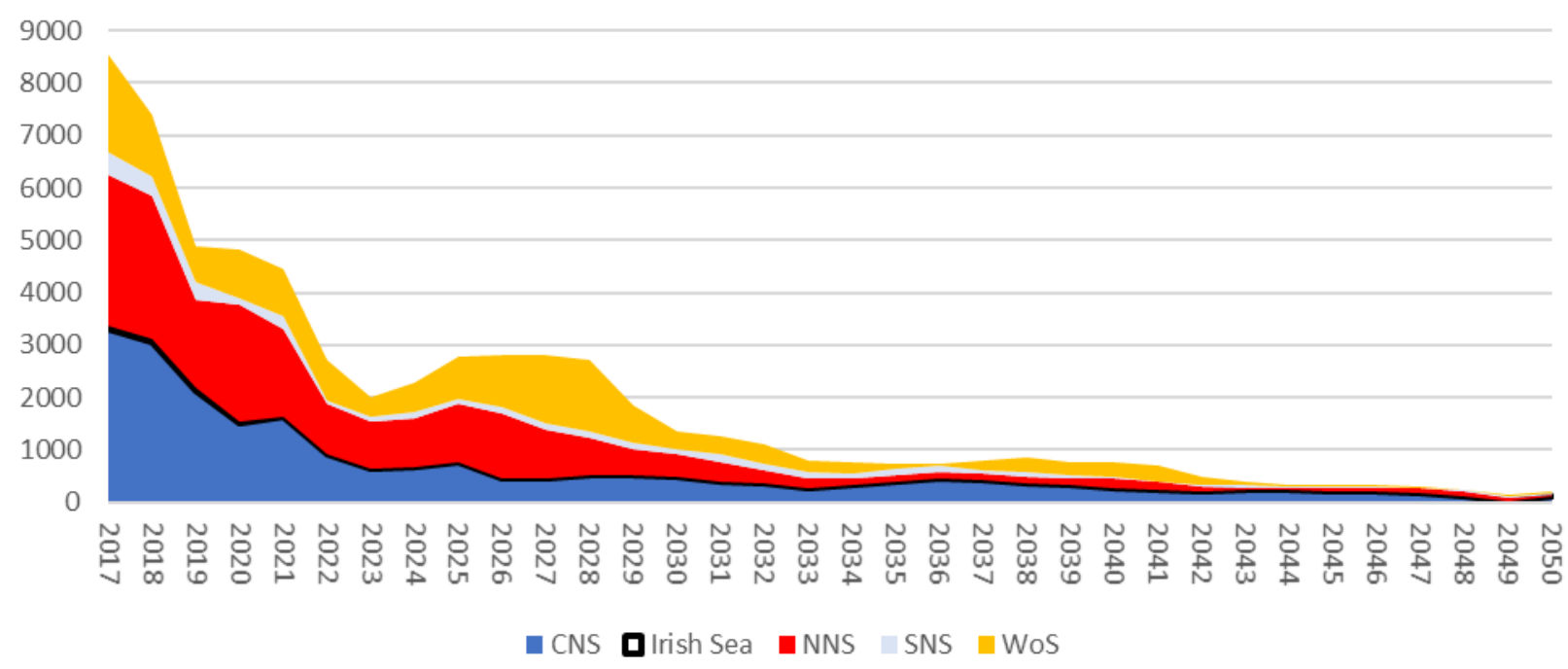

In Chart 30 potential operating expenditure is shown under the $\$ 50,40$ price case. Over the period to 2050 cumulative operating expenditures amount to $£ 101,560$ million at 2017 prices (which is $£ 22,139$ million less than with the $\$ 60$ case). Sanctioned fields account for $£ 79,006$ million, current incremental projects $£ 1,784$ million, future incremental projects $£ 3,890$ million, probable and possible fields $£ 3,993$ million, technical reserve fields $£ 6,706$ million, and new exploration finds $£ 6,181$ million.

This constitutes a reduction of $£ 3,073$ million for the sanctioned fields, $£ 341$ million for the current incremental projects, $£ 912$ million for the future incremental projects, $£ 2,115$ million for the probable and possible fields, $£ 4,710$ million for the technical reserve fields, and $£ 10,987$ million for the new exploration finds.

Chart 31 gives the same information on geographic area basis. The CNS/MF area accounts for $£ 43,096$ million, the SNS $£ 7,165$ million, the 
NNS $£ 30,666$ million, the WoS $£ 18,970$ million, and the Irish Sea $£ 1,663$ million of operating expenditure. Compared to the $\$ 60,50$ pence case this is a reduction of $£ 7,931$ million in the CNS/MF area, $£ 2,289$ million in the SNS area, $£ 5,420$ million in the NNS area, $£ 6,371$ million in the WoS area and $£ 129$ million in the Irish Sea.

\section{Chart 30}

\section{Potential Operating Expenditure}

$\$ 50 / \mathrm{bbl}$ and $40 \mathrm{p} /$ therm

Real $2017 \mathrm{fm}$

Hurdle : Real NPV @ 10\%/Real Devex @ 10\% > 0.3

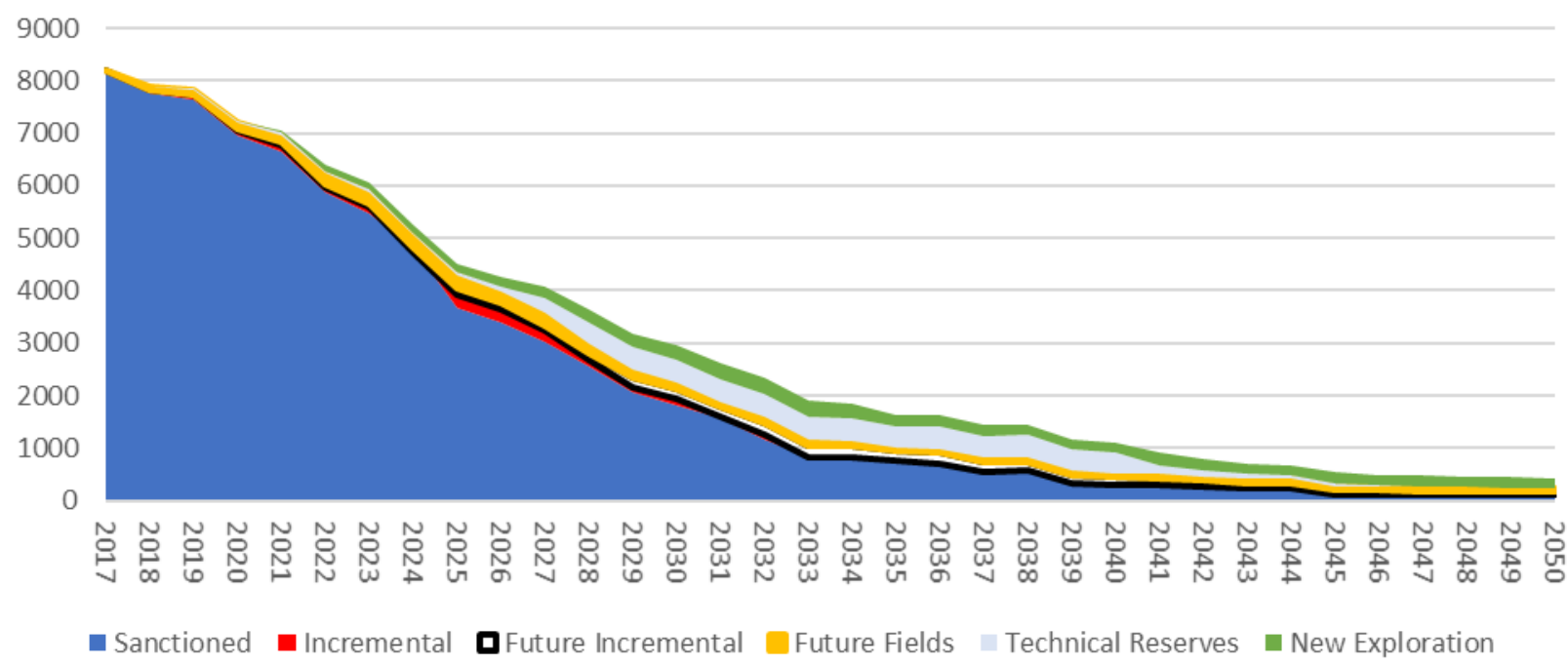




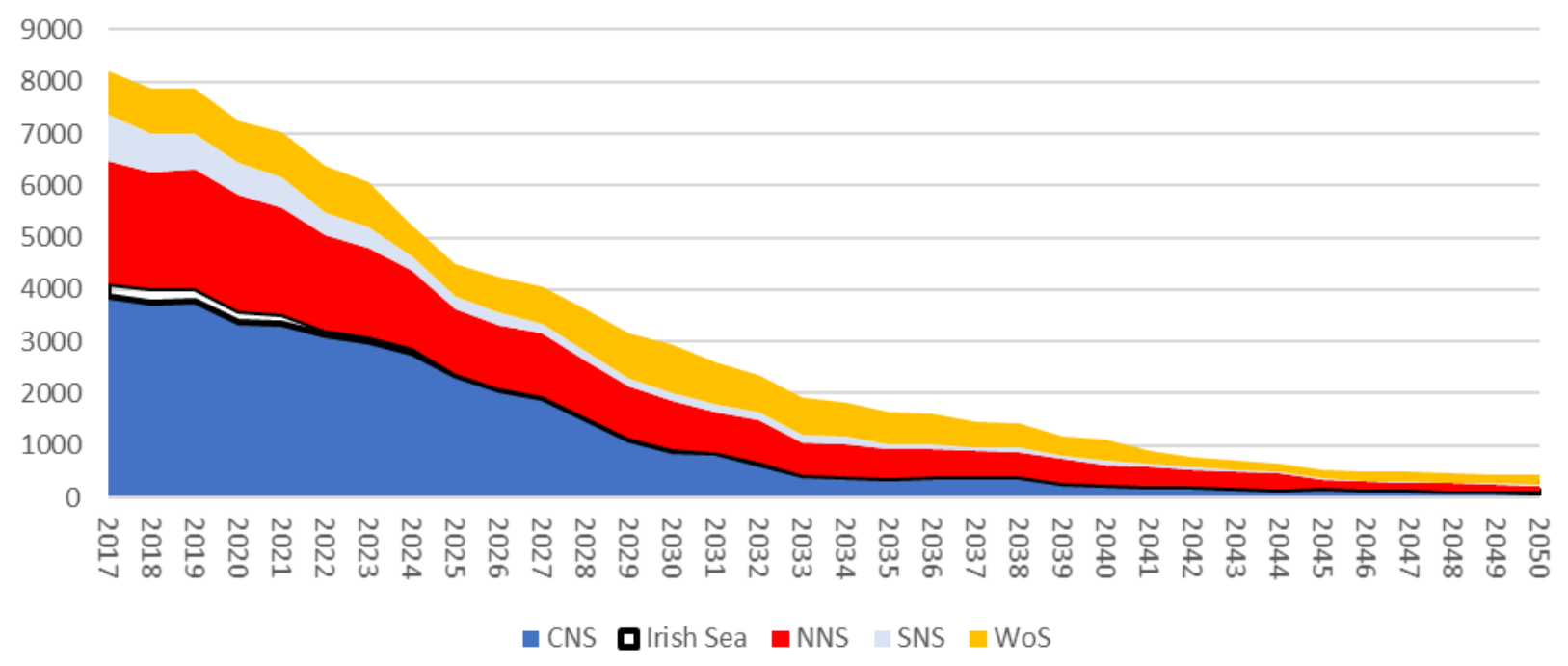

In Chart 32 cumulative potential decommissioning costs are shown under the $\$ 50,40$ price case. Over the period to 2050 cumulative decommissioning costs amount to $£ 52,044$ million at 2017 prices. Sanctioned fields account for $£ 49,599$ million whilst incremental projects account for $£ 236$ million, future incremental projects $£ 424$ million, probable and possible fields $£ 238$ million, technical reserve fields $£ 934$ million, and new exploration finds $£ 614$ million. The bulk of the expenditure occurs before 2035. By 2025 the cumulative decommissioning spend could be $£ 23,222$ million. Although there is no change in cumulative decommissioning costs for the sanctioned fields compared to the $\$ 60$ case the spend occurs earlier.

Compared to the $\$ 60,50$ pence case there is a reduction of $£ 23$ million for the current incremental projects, $£ 40$ million for the future incremental projects, $£ 118$ million for the probable and possible fields, $£ 812$ million for technical reserve fields, and $£ 1,209$ million for new exploration finds 
In the last case there is a reduction in the number of fields which pass the hurdle rate at the lower price.

Chart 33 gives the same information on geographic area basis. The CNS/MF area accounts for $£ 22,190$ million, the SNS $£ 6,809$ million, the NNS $£ 17,717$ million, the WoS $£ 4,006$ million, and the Irish Sea $£ 1,323$ million of decommissioning expenditure.

\section{Chart 32}

Potential Cumulative Decommissioning Expenditure $\$ 50 / \mathrm{bbl}$ and $40 \mathrm{p} /$ therm

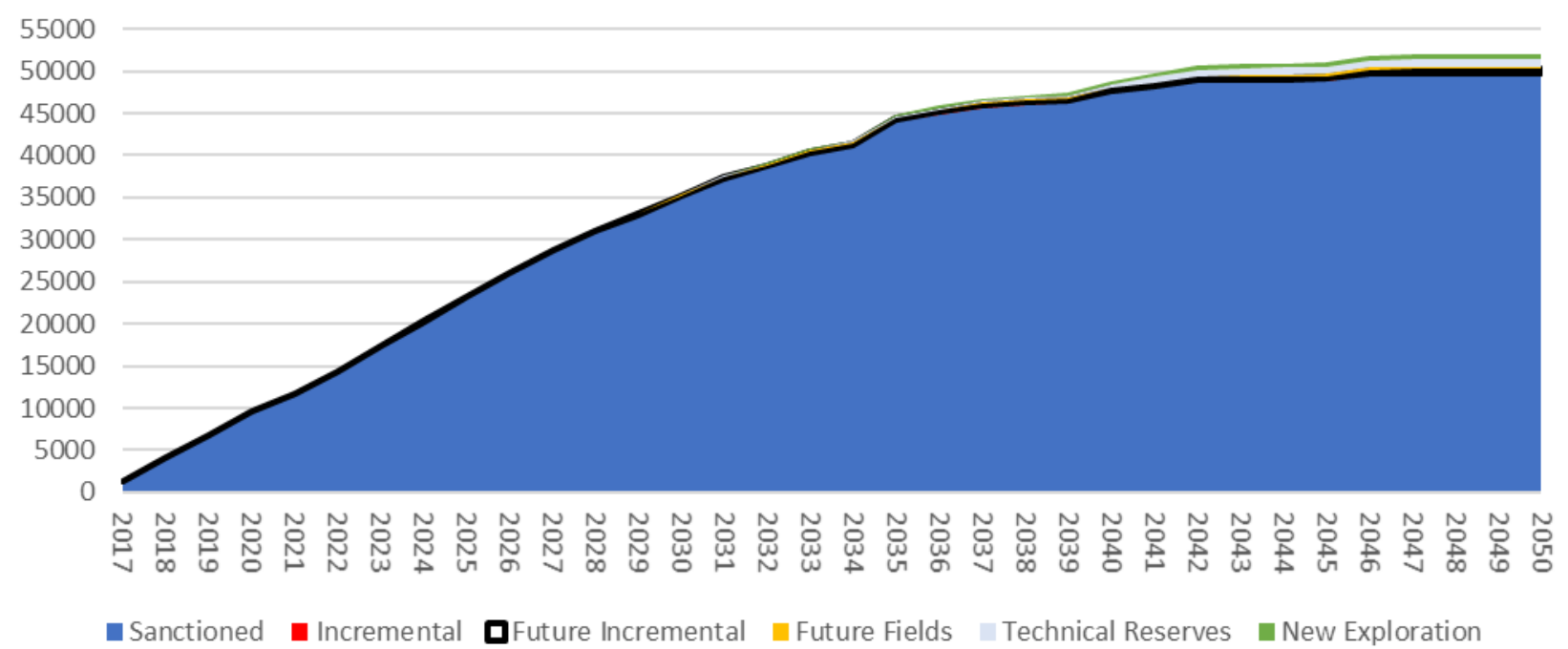




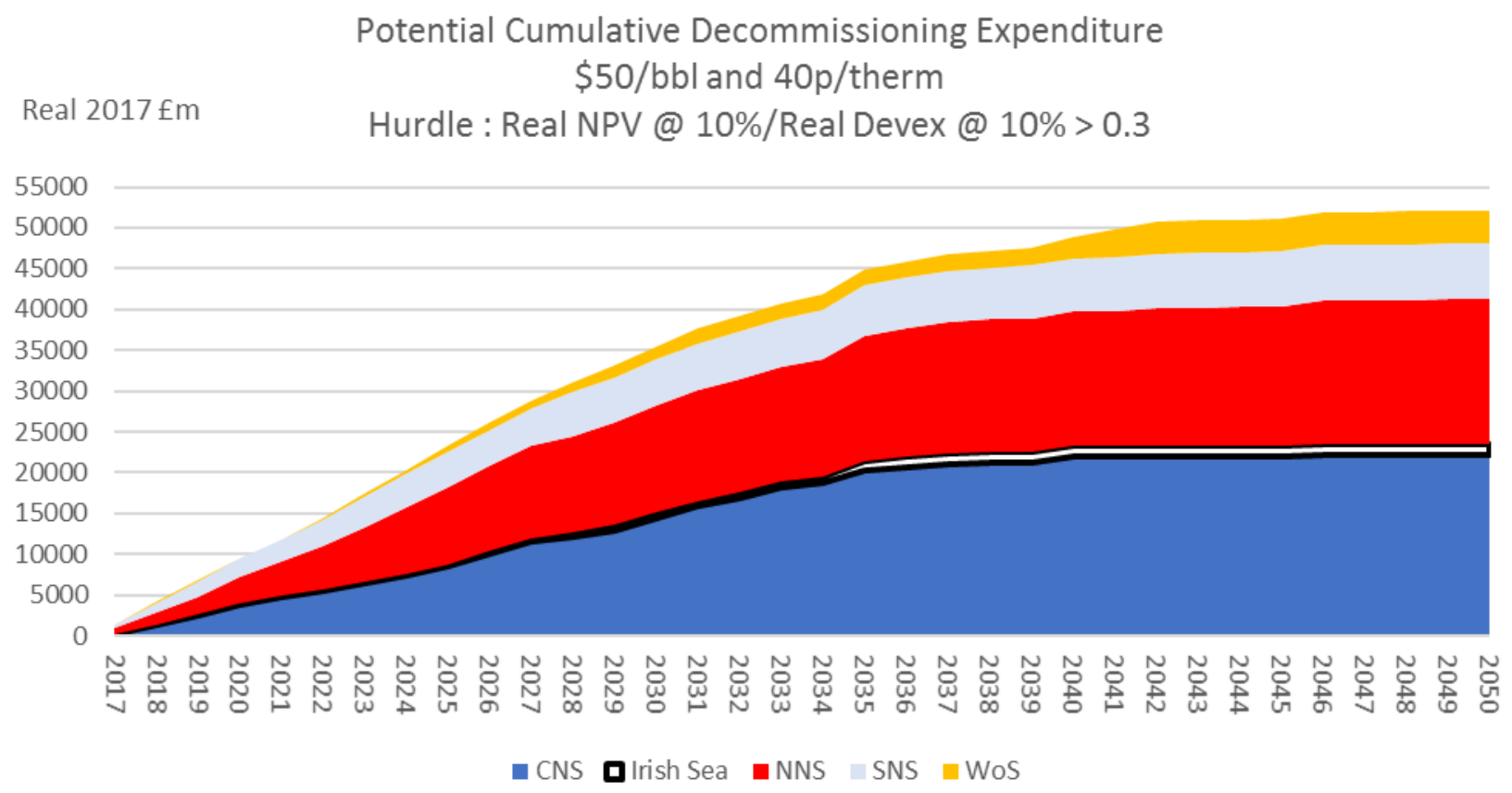

Chart 34 shows the number of fields decommissioning over time under the $\$ 50,40$ price case. By 2025 there could be as many as 205 fields undergoing or having completed decommissioning, and by 2050 there could be 391 fields in this position. By 2025 the sanctioned fields could account for 203 fields, and the technical reserves 2 fields. By 2050 the sanctioned fields could account for 305 fields, the probable and possible ones 6 fields, the technical reserves 51 fields, and new exploration finds 29 of the total. However, at the lower price there are 20 fewer new exploration finds and 48 fewer which pass the hurdle rate. There are also 7 fewer probable and possible fields and 53 fewer technical reserve fields which pass the hurdle rate.

Chart 35 gives the same information on geographic area basis. By 2025 there could be 69 fields in the CNS/MF area undergoing or having completed decommissioning, there could be 65 fields in the SNS, 54 fields in the NNS, 2 fields in the WoS, and 15 fields in the Irish Sea in the same 
position. By 2050 there could be 152 fields in the CNS/MF area undergoing or having completed decommissioning, and there could be 118 fields in the SNS, 87 fields in the NNS, 17 fields in the WoS and 17 fields in the Irish Sea in the same position. However, there are 37 fewer fields passing the hurdle rate in the CNS/MF, 34 fewer in the SNS, 20 fewer in the NNS, 16 fewer in the WoS, and 1 less in the Irish Sea passing the hurdle rate.

\section{Chart 34}

Potential Number of Fields Decommissioning $\$ 50 / \mathrm{bbl}$ and $40 \mathrm{p} /$ therm

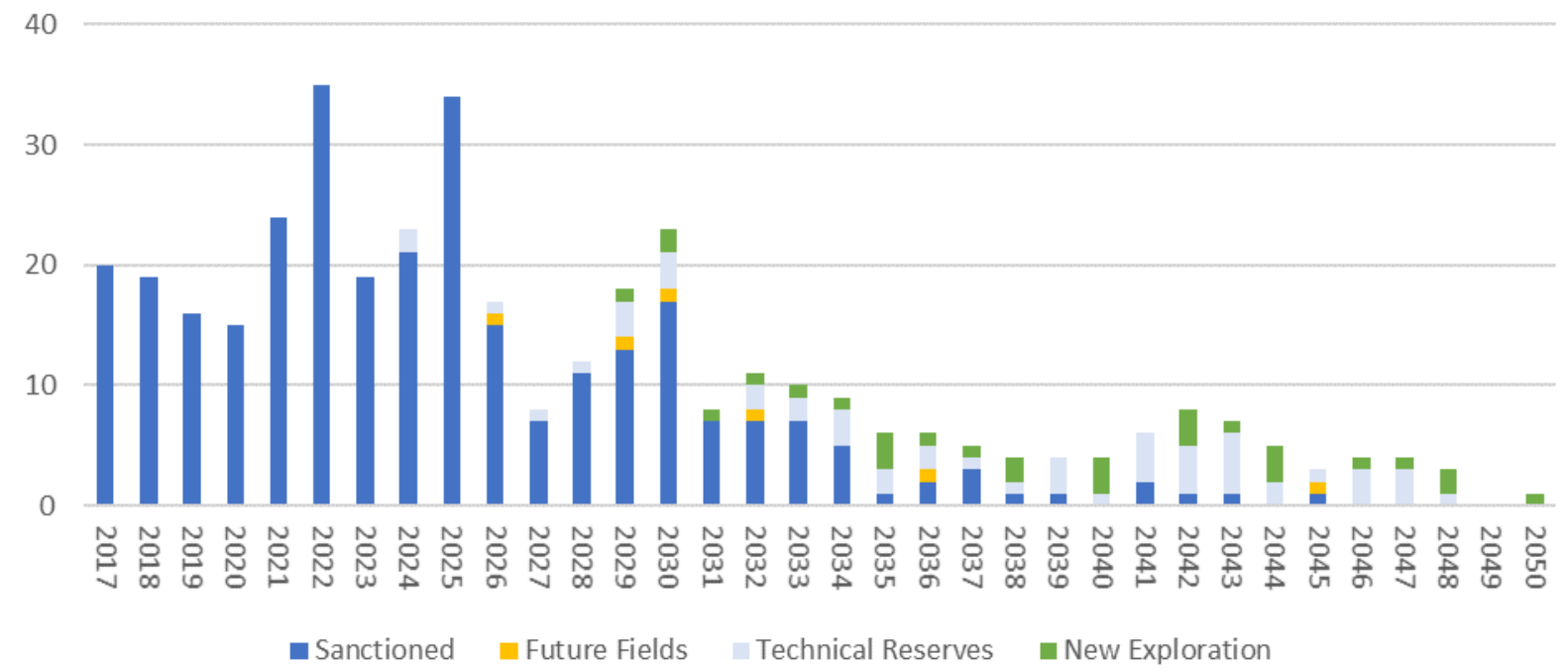


In Chart 36 potential total expenditure is shown under the $\$ 50,40$ price case. Over the period to 2050 cumulative total expenditures amounts to $£ 217,183$ million at 2017 prices. The sanctioned fields account for $£ 156,622$ million, current incremental projects $£ 5,170$ million, future incremental projects $£ 13,338$ million, probable and possible fields $£ 9,419$ million, technical reserve fields $£ 16,977$ million, and new exploration finds $£ 15,657$ million.

However, had all the fields which failed the hurdle rate come into production the total expenditure could have increased by $£ 205,949$ million with $£ 5,612$ coming from the incremental projects, $£ 37,265$ million from the probable and possible fields, $£ 127,926$ million from the technical reserve fields and $£ 35,147$ million from new exploration finds.

Chart 37 gives the same information on geographic area basis. The CNS/MF area accounts for $£ 87,719$ million, the SNS accounts for 
$£ 17,753$ million, the NNS accounts for $£ 69,766$ million, the WoS accounts for $£ 38,711$ million and the Irish Sea accounts for $£ 3,234$ million of total expenditure.

If all the fields which failed the hurdle had come into production then total expenditure from the $\mathrm{CNS} / \mathrm{MF}$ area would have been $£ 63,352$ million higher, the SNS area would have been $£ 24,018$ million higher, the NNS area $£ 42,145$ million higher, the WoS $£ 66,567$ million higher and the Irish Sea $£ 9,867$ million higher. Further details of the unexploited potential are shown in the Appendix.

Chart 36

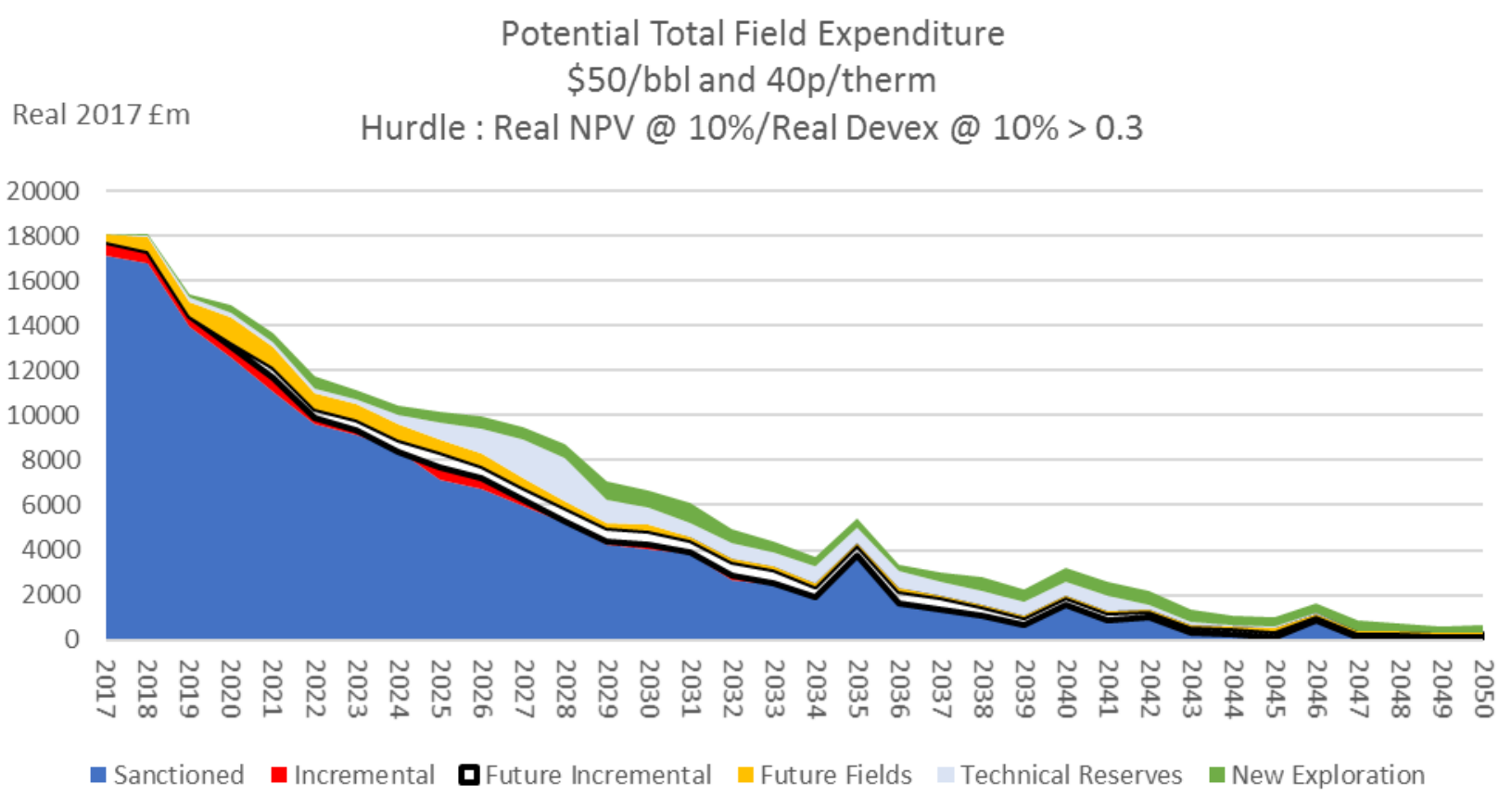




\section{Chart 37}

Potential Total Field Expenditure

$\$ 50 / \mathrm{bbl}$ and $40 \mathrm{p} /$ therm

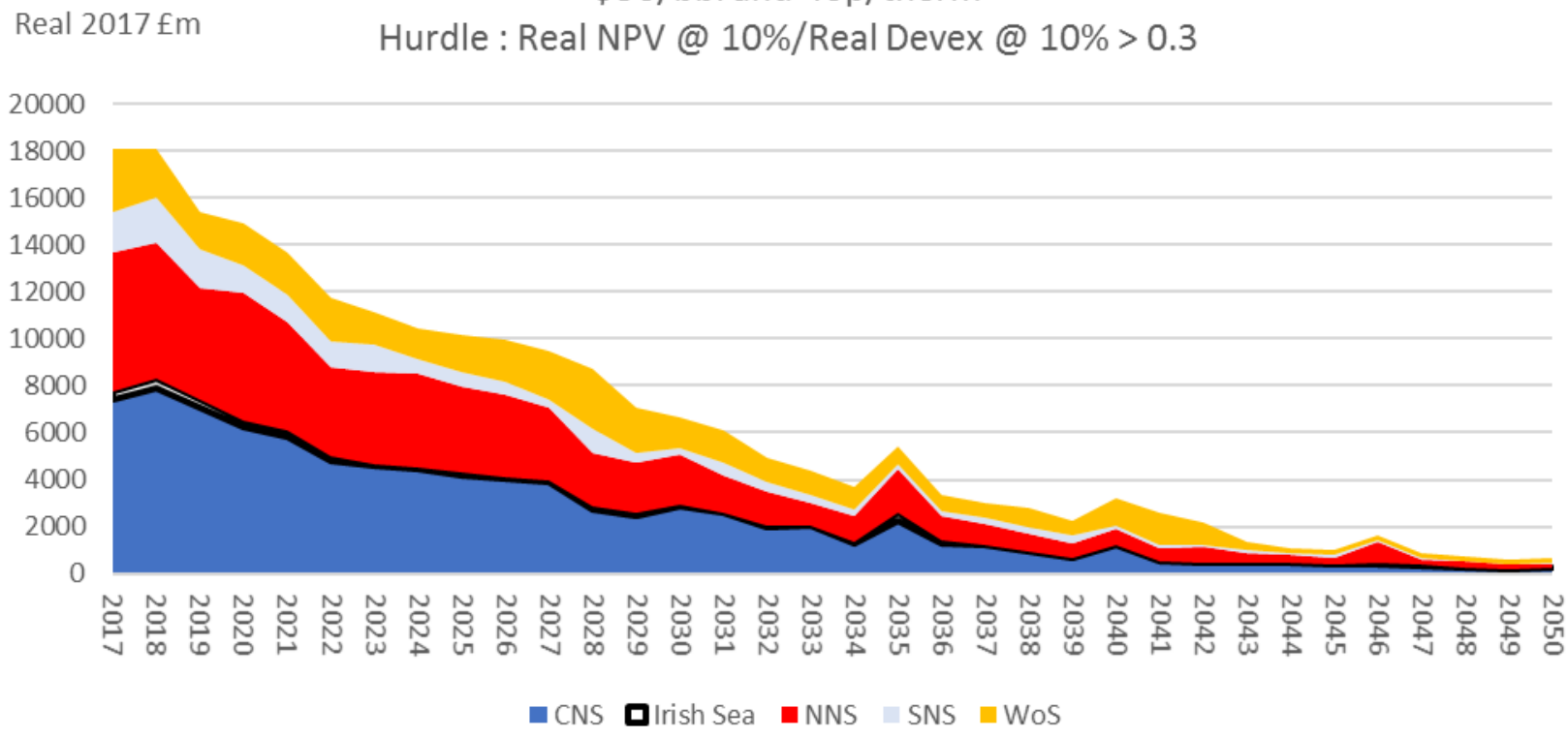

Chart 38 shows that by 2018 operating costs are likely to exceed development costs, and by 2023 decommissioning costs could be $27 \%$ of total costs. In 2035 decommissioning costs could be $56 \%$ of total costs.

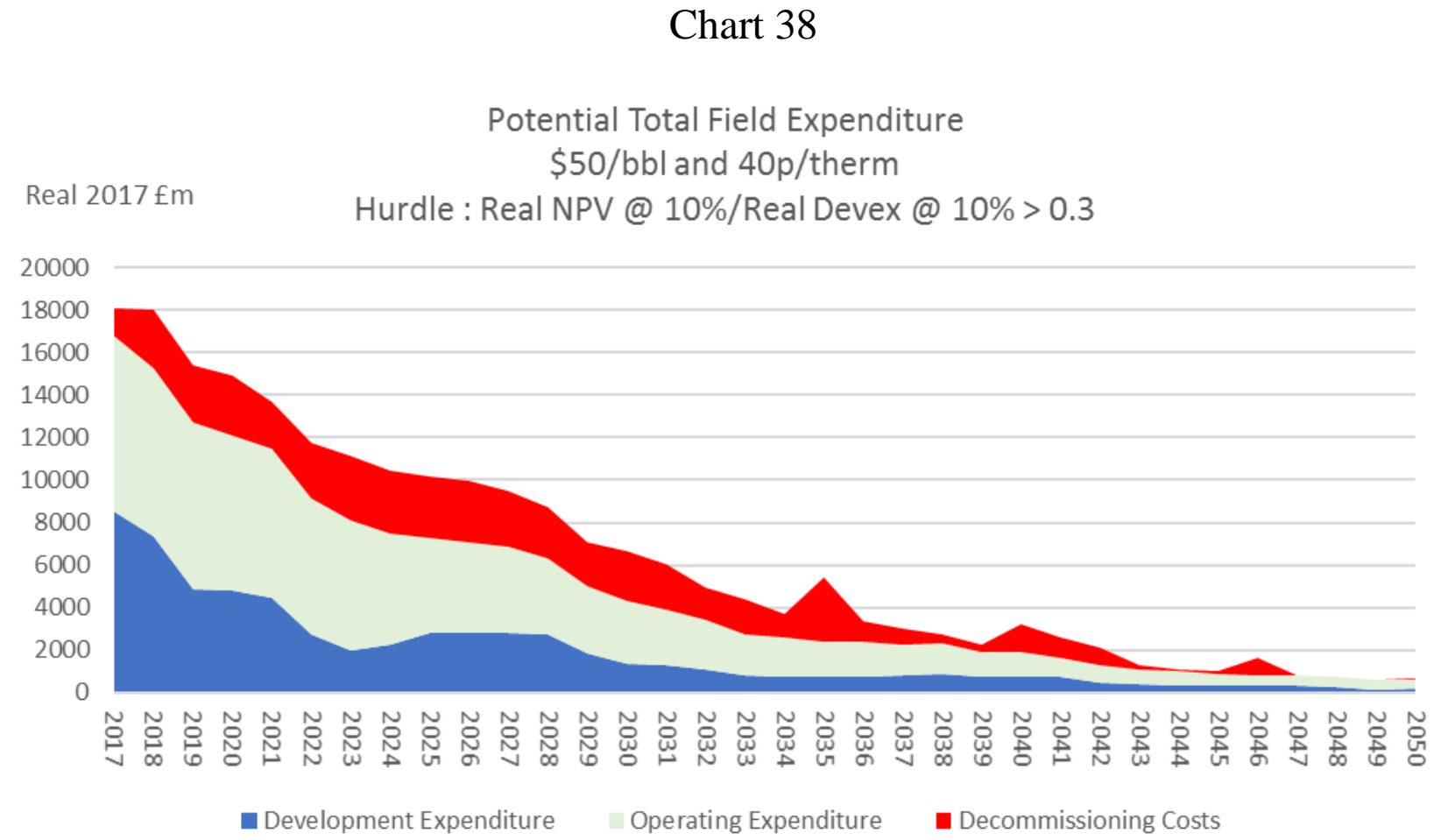




\section{(b) Investment Hurdle NPV/I > 0.5}

\section{(i) Numbers of Producing Fields}

In Chart 39 the numbers of new field developments and COP dates are shown at the $\$ 60,50$ pence price scenario with the NPV/I $\geq 0.5$ investment hurdle. It is seen that the numbers of fields in production fall steadily over the period falling to less than 50 after 2040. Over the period there are 140 new field developments triggered, of which 2 are sanctioned, 5 are in the probable category, 4 in the possible category, 60 in the category of technical reserves, and 69 are future discoveries. With the $\$ 60$ case and a 0.5 hurdle there are 256 fields which fail the hurdle rate, 19 of which are probable or possible fields, 189 are technical reserves, and 48 are new discoveries. There are also 29 incremental projects which fail the hurdle.

In Chart 40 the corresponding results are shown for the $\$ 50,40$ pence price case with the 0.5 hurdle. In this scenario the numbers of new field developments triggered are considerably less, with the number of fields in production falling to less than 30 by 2035 . There are 47 new field developments over the period to 2050, of which 2 are sanctioned, 3 are in the probable category, 2 in the possible category, 18 in technical reserves category, and 22 are new discoveries made in the period. With the $\$ 50$ case and a 0.5 hurdle there are 329 fields which fail the hurdle rate, 23 of which are probable or possible fields, 231 are technical reserves, and 75 are new discoveries. There are also 34 incremental projects which fail the hurdle. 


\section{Chart 39}

Number of Fields in Production

$\$ 60 / \mathrm{bbl}$ and 50p/therm

No. of Fields

Hurdle : Real NPV @10\%/Real Devex @ 10\%>0.5

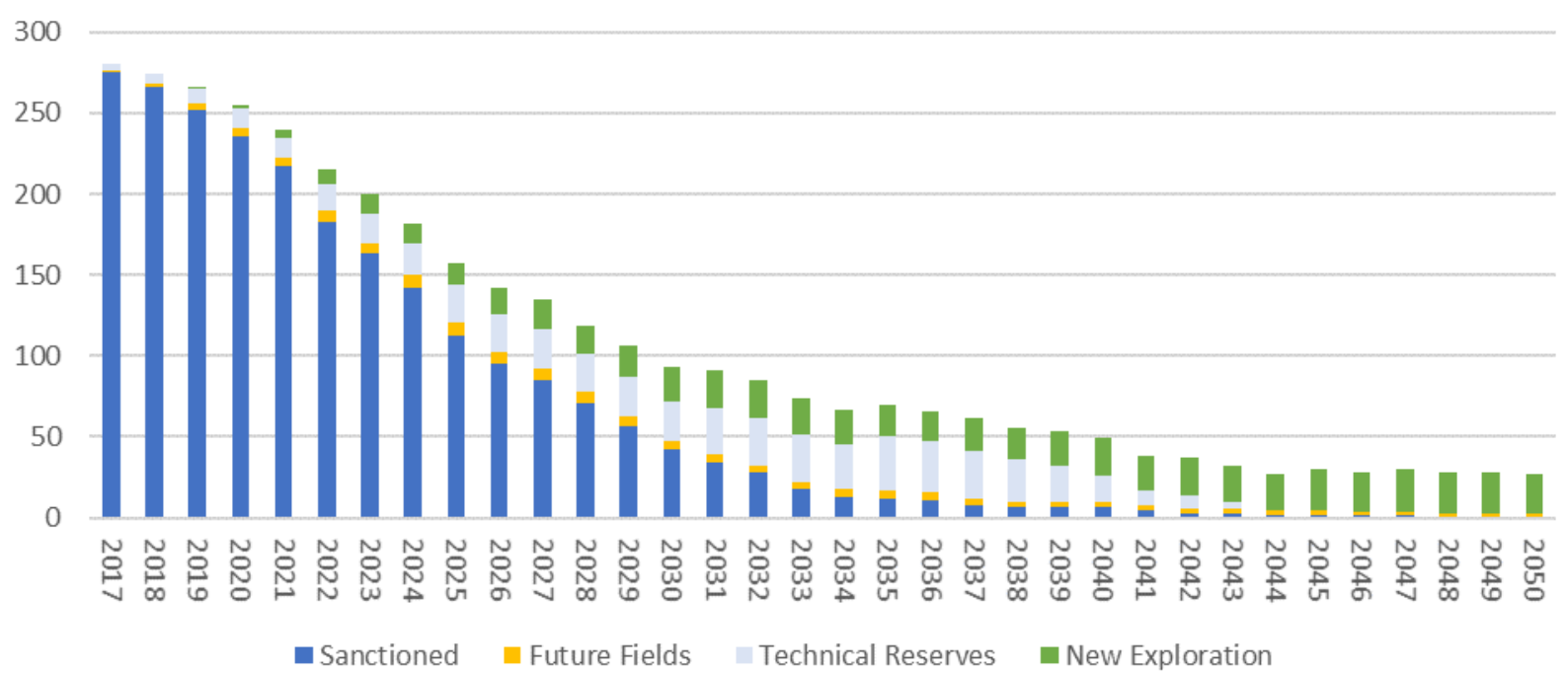

Chart 40

Number of Fields in Production

$\$ 50 / \mathrm{bbl}$ and $40 \mathrm{p} /$ therm

No. of Fields

Hurdle : Real NPV @10\%/Real Devex @ 10\%>0.5

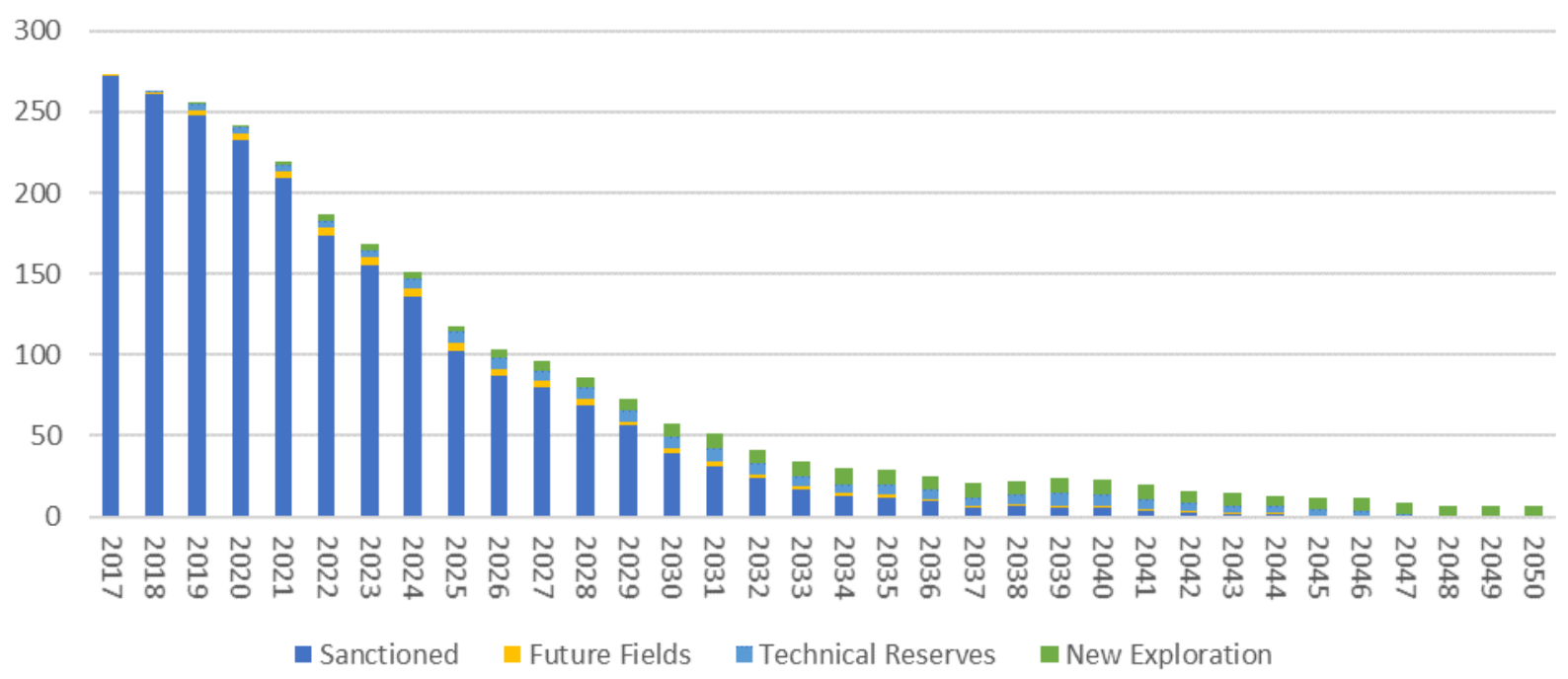

The same results are shown by geographic area in Charts 41 and 42 . 


\section{Chart 41}

Number of Fields in Production

$\$ 60 / \mathrm{bbl}$ and 50p/therm

No. of Fields

Hurdle : Real NPV @10\%/Real Devex @ 10\%>0.5

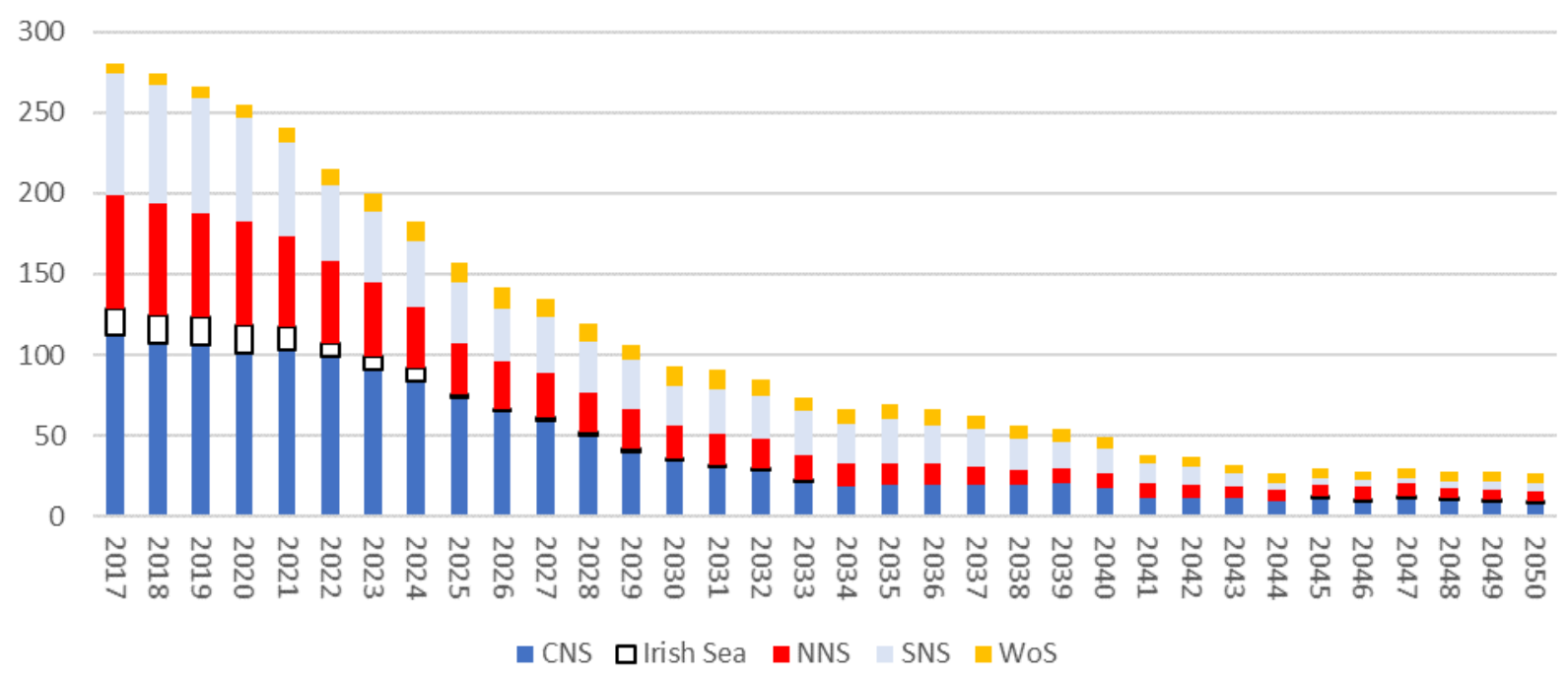

Chart 42

Number of Fields in Production

$\$ 50 / \mathrm{bbl}$ and $40 \mathrm{p} /$ therm

No. of Fields Hurdle : Real NPV @10\%/Real Devex @ $10 \%>0.5$

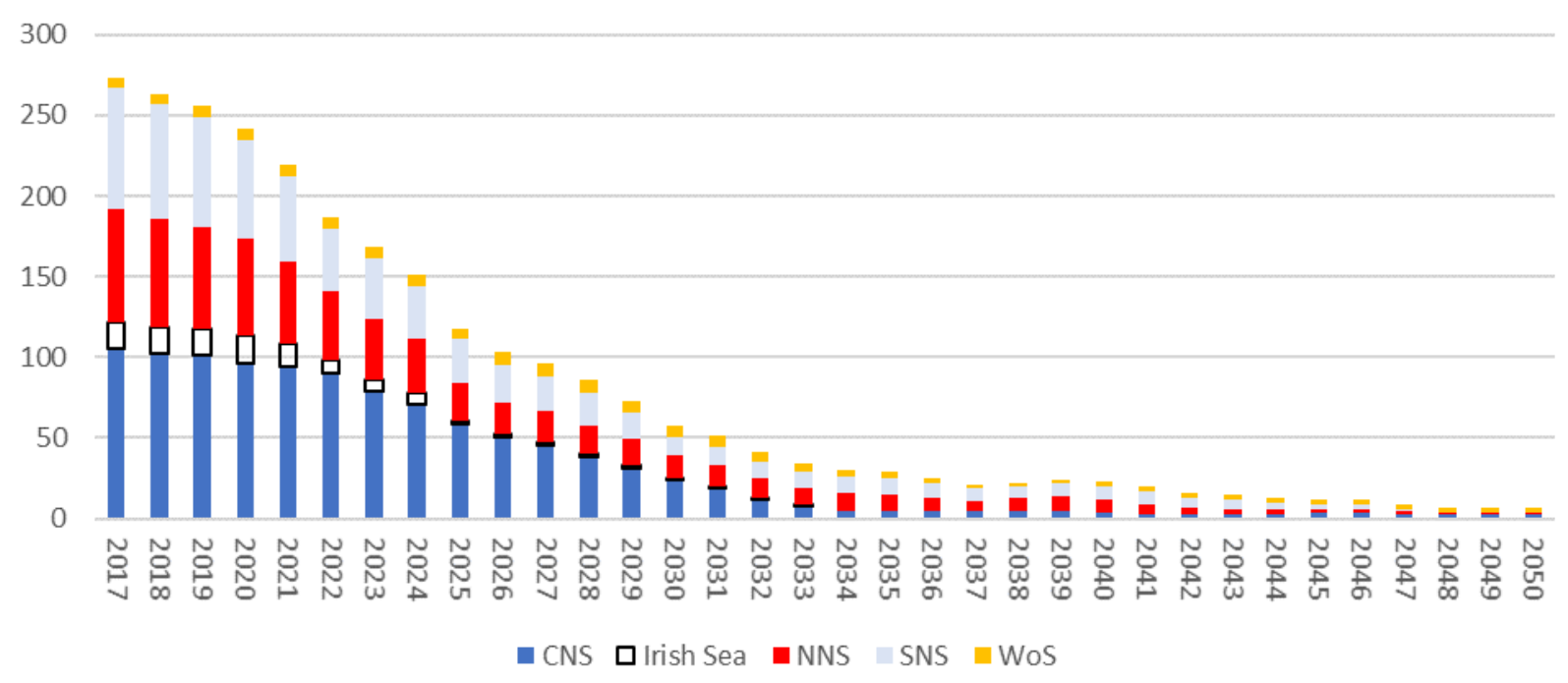


From Chart 41 it is seen that the CNS has the largest number of fields in production followed by the SNS. With the $\$ 60$ case and a 0.5 hurdle, of the 256 fields which fail the hurdle rate, 82 are in the CNS/MF area, 64 are in the SNS, 69 are in the NNS, 26 are in the Wos and 15 are in the Irish Sea. Of the 29 incremental projects which fail the hurdle rate 16 are in the CNS/MF area, 3 are in the SNS, 9 are in the NNS, and 1 is in the Irish Sea. With the $\$ 50$ case and a 0.5 hurdle of the 329 fields which fail the hurdle rate 111 are in the CNS/MF area, 91 are in the SNS, 76 are in the NNS, 35 are in the WoS and 16 are in the Irish Sea. Of the 34 incremental projects which fail the hurdle rate 20 are in the CNS/MF area, 3 are in the SNS, 10 are in the NNS, and 1 is in the Irish Sea.

\section{(ii) Potential Production}

In Chart 43 potential oil production over the period to 2050 is shown for the $\$ 60,50$ pence case with the 0.5 hurdle. Over the period cumulative oil production is just over 6,167 million barrels, of which 3,786 million comes from sanctioned fields, 142 million from current incremental projects, 317 million from future incremental projects, 394 million from probable and possible fields, 642 million from technical reserves, and 886 million from future discoveries.

Chart 44 gives the same information on geographic area basis. It is seen that 2,312 million barrels come from the CNS/MF area, closely followed by 2,078 million barrels from the WoS area. 


\section{Chart 43}

Potential Oil Production

$\$ 60 /$ bbl and 50p/therm

$\mathrm{tb} / \mathrm{d}$

Hurdle : Real NPV @ 10\%/Real Devex @ 10\% > 0.5

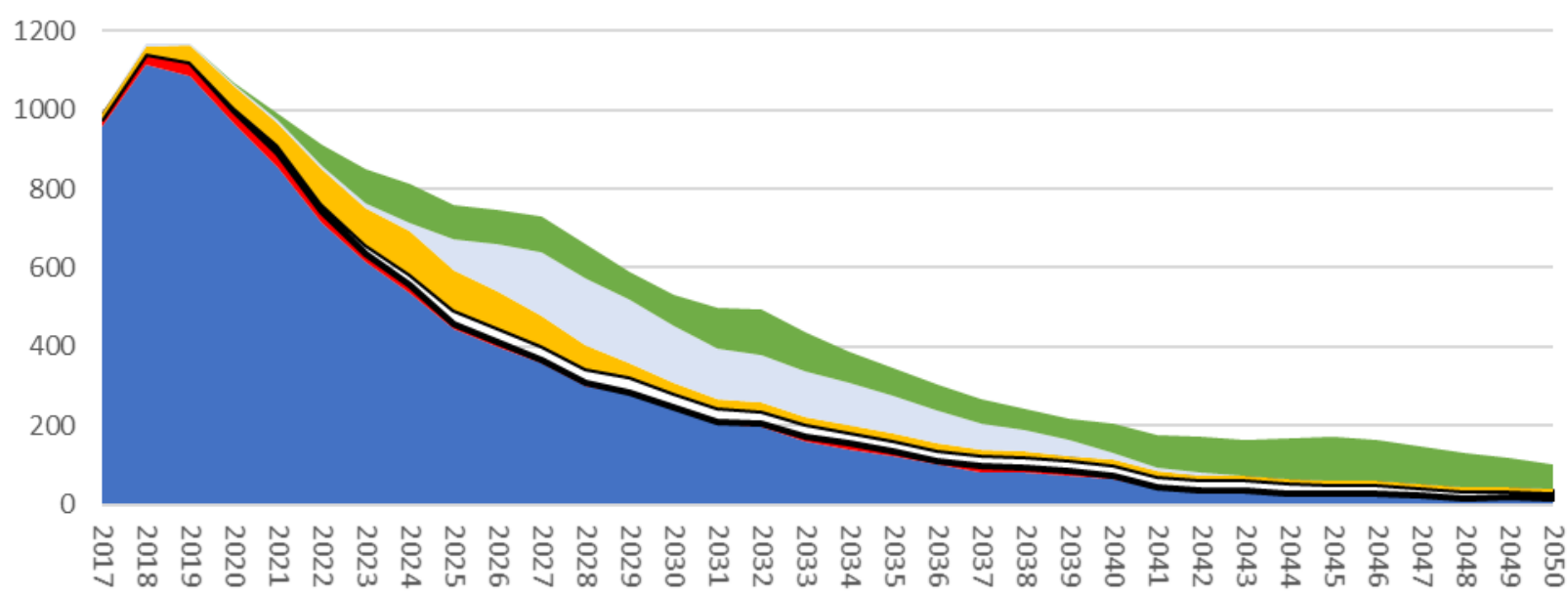

Sanctioned

Incremental

口Future Incremental 1 Future Fields

\section{Chart 44}

Potential Oil Production

$\$ 60 / \mathrm{bbl}$ and 50p/therm

tb/d Hurdle : Real NPV @ 10\%/Real Devex @ 10\% > 0.5

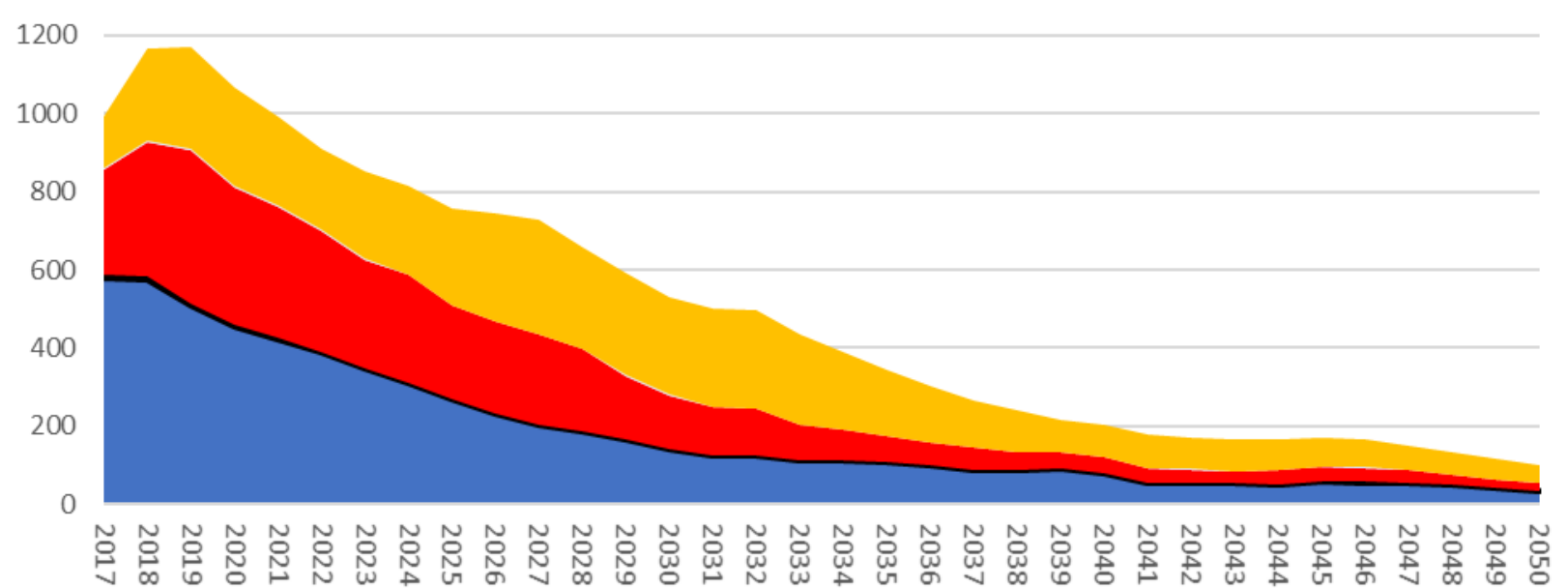

- CNS I Irish Sea anN $\quad$ SNS WoS 
In Chart 45 potential gas production over the period to 2050 is shown for the $\$ 60,50$ pence case with the 0.5 hurdle. Over the period cumulative production is just over 3,069 million barrels of oil equivalent, of which 1,844 mmboe come from sanctioned fields, 171 mmboe from current incremental projects, $371 \mathrm{mmboe}$ from future incremental projects, 165 mmboe from probable and possible fields, $266 \mathrm{mmboe}$ from technical reserves, and 252 mmboe from future discoveries.

Chart 46 gives the same information on geographic area basis. It is seen that 1,006 mmboe comes from the CNS/MF area, 1,002 mmboe comes from the SNS, 604 mmboe comes from the NNS, 361 mmboe from the WoS area, and 96 mmboe from the Irish Sea.

\section{Chart 45}

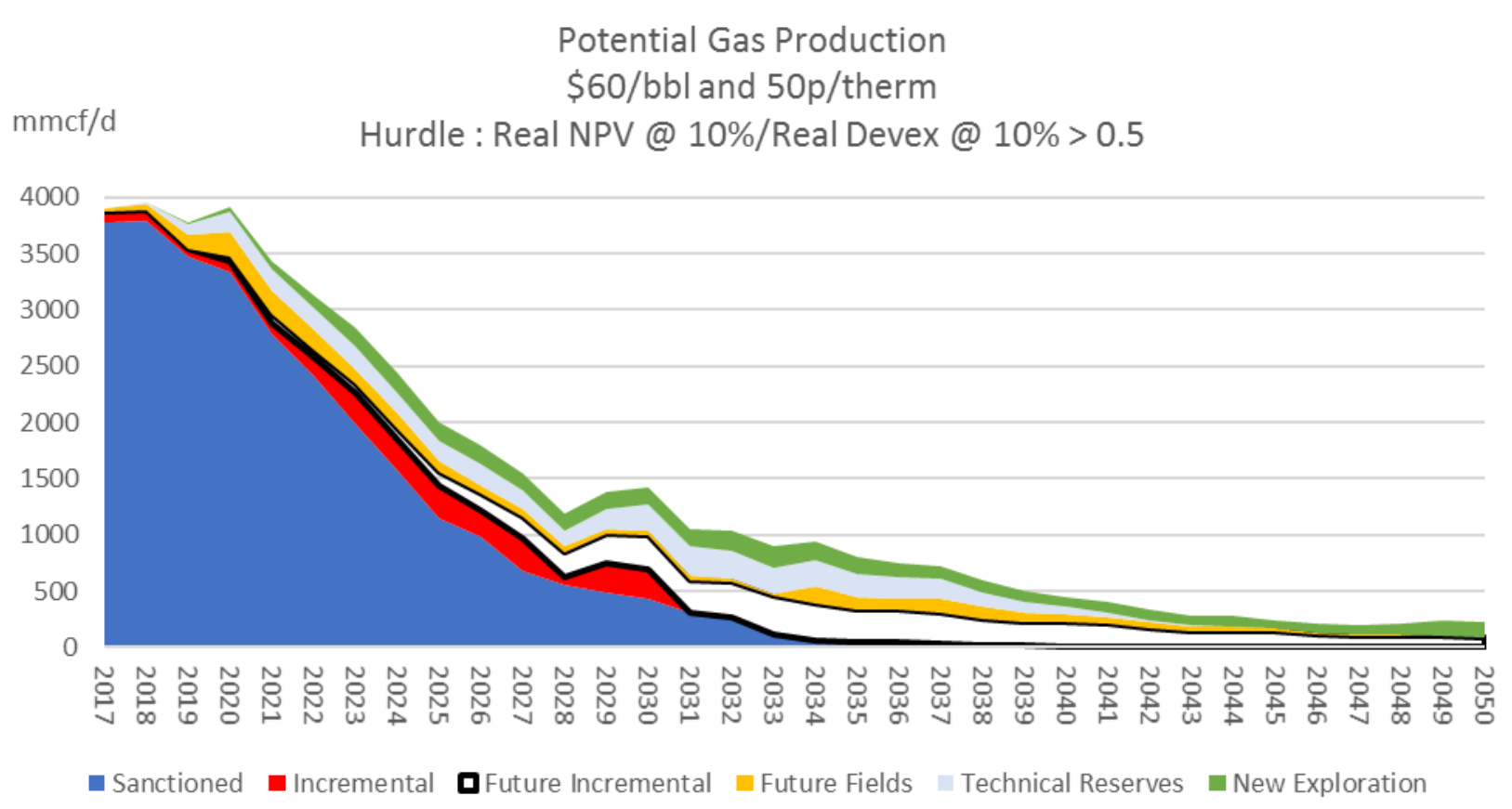




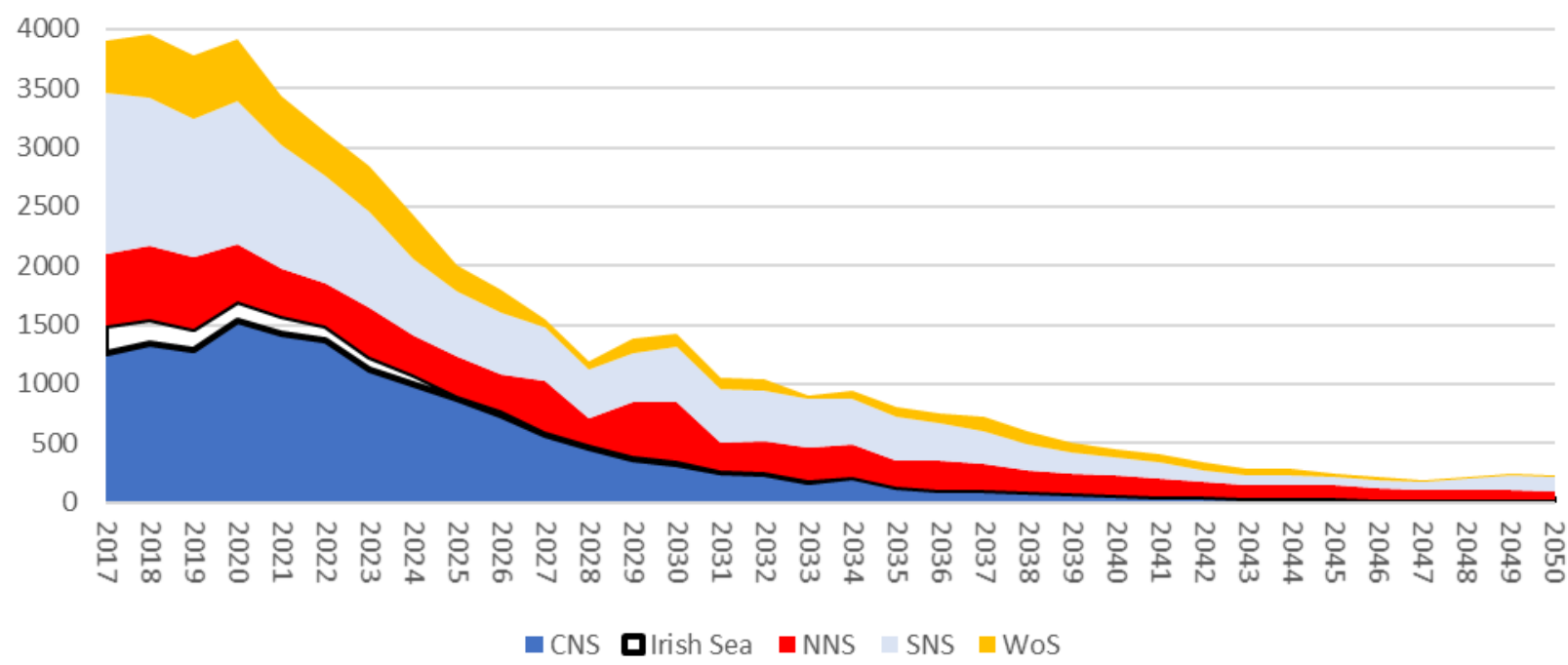

In Chart 47 potential total hydrocarbon production over the period to 2050 is shown for the $\$ 60,50$ pence case with the 0.5 hurdle. Over the period cumulative total hydrocarbon production is just over 9,453 million barrels of oil equivalent, of which 5,792 mmboe comes from sanctioned fields, 325 mmboe from current incremental projects, $722 \mathrm{mmboe}$ from future incremental projects, 565 mmboe from probable and possible fields, 908 mmboe from technical reserves, and 1,141 mmboe from future discoveries. Compared with the $\$ 60$ case with a 0.3 hurdle total production is 1,293 mmboe less, of which 24 mmboe is accounted for by the increment projects, 59 mmboe is accounted for by the future incremental projects, 96 mmboe is accounted for by the probable and possible fields, $501 \mathrm{mmboe}$ is accounted for by the technical reserve fields, and $612 \mathrm{mmboe}$ is accounted for by the new exploration finds.

However, had the fields which failed the hurdle rate come into production total hydrocarbon production could have increased by 6,828 mmboe with 
203 mmboe coming from the incremental projects, 1,304 mmboe from probable and possible fields, 4,214 mmboe from technical reserve fields, and 1,107 from new exploration finds.

Chart 48 gives the same information on geographic area basis. It is seen that 3,484 mmboe comes from the CNS/MF area, 1,015 mmboe comes from the SNS, 2,402 mmboe comes from the NNS, 2,444 mmboe from the WoS area, and 107 mmboe from the Irish Sea.

Compared with the $\$ 60$ case with a 0.3 hurdle total hydrocarbon production is reduced by 338 mmboe in the CNS/MF area, 330 mmboe in the SNS area, 259 mmboe in the NNS area, 360 mmboe in the WoS area, and 6 mmboe in the Irish Sea.

If the fields which failed the 0.5 hurdle had come into production then total hydrocarbon production would be increased by 1,950 mmboe in the CNS/MF area, 1,150 mmboe in the SNS, 1,170 mmboe in the NNS, 2,245 mmboe in the WoS, and 313 mmboe in the Irish Sea. Further details of the unexploited potential are shown in the Appendix. 


\section{Chart 47}

Potential Total Hydrocarbon Production $\$ 60 /$ bbl and 50p/therm

tboe/d

Hurdle : Real NPV @ 10\%/Real Devex @ 10\% > 0.5

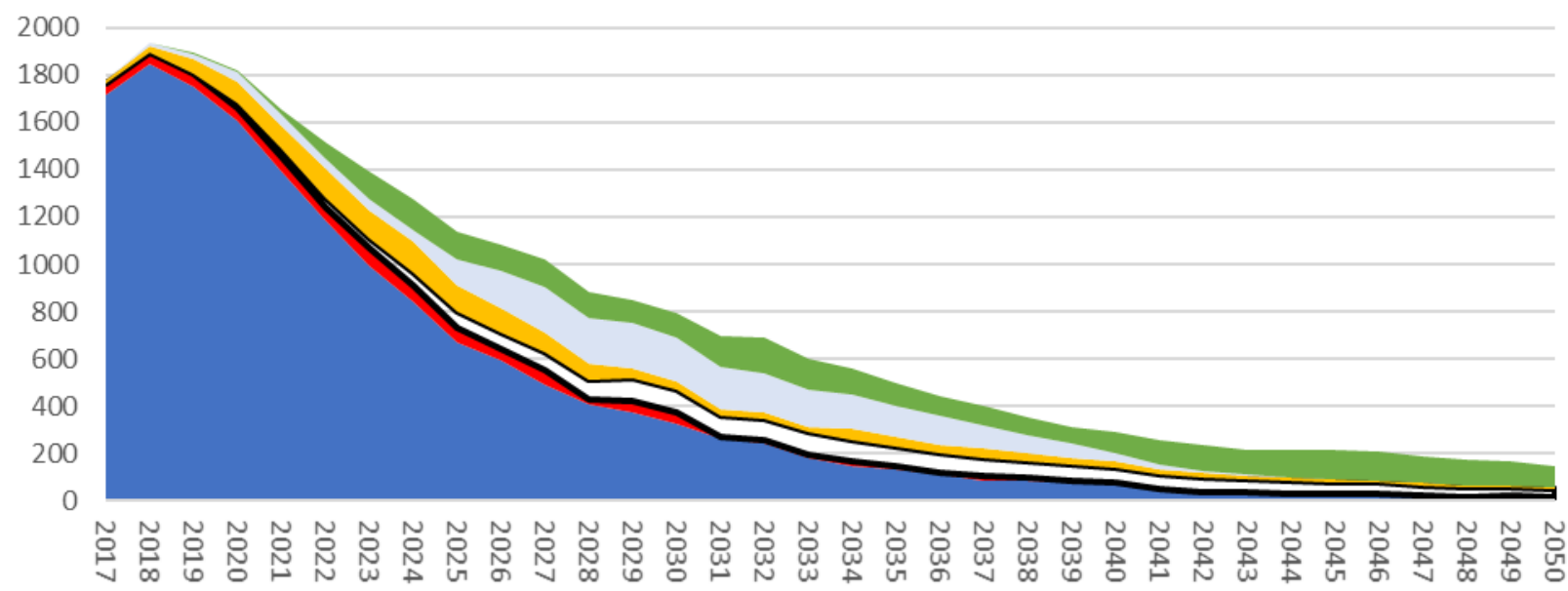

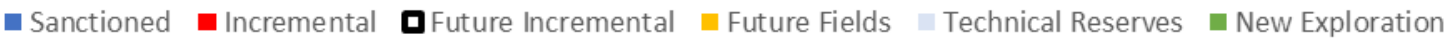

\section{Chart 48}

Potential Total Hydrocarbon Production

$\$ 60 / \mathrm{bbl}$ and 50p/therm

tboe/d $\quad$ Hurdle : Real NPV @ 10\%/Real Devex @ 10\% > 0.5

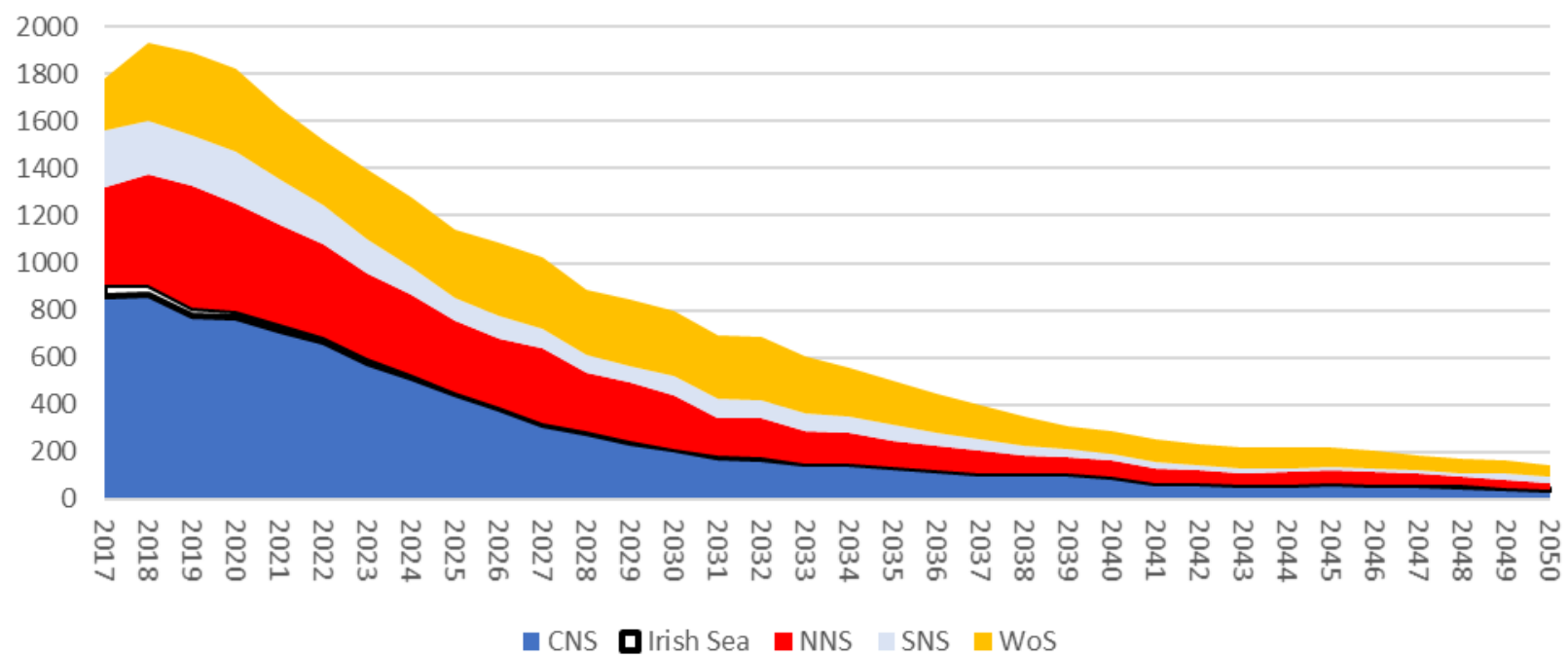


In Chart 49 potential oil production under the $\$ 50,40$ pence scenario and the 0.5 hurdle is shown. Over the period cumulative is 4,648 million barrels, of which 3,733 million comes from sanctioned fields, 107 million from current incremental projects, 242 million from future incremental projects, 60 million from probable and possible fields, 145 million from technical reserves, and 360 million from new discoveries. The reduction in prices from $\$ 60$ to $\$ 50$ results in a potential loss of 1,520 million barrels, 334 million of which are from probable and possible fields, 497 million from technical reserve fields, and 526 million from new discoveries (although there are 20 fewer new exploration finds).

The increase in the hurdle rate results in a loss of 1,121 million barrels, of which 39 million barrels are from current incremental projects, 84 million from future incremental projects, 330 from probable and possible fields, 450 million from technical reserves, and 217 million from the new exploration finds.

Chart 50 gives the same information on geographic area basis. It is seen that 1,798 million barrels comes from the CNS/MF area closely followed by 1,596 million barrels from the WoS area, and 1,230 million barrels from the NNS area. 


\section{Chart 49}

Potential Oil Production

$\$ 50 /$ bbl and 40p/therm

$\mathrm{tb} / \mathrm{d}$

Hurdle : Real NPV @ 10\%/Real Devex @ 10\% > 0.5

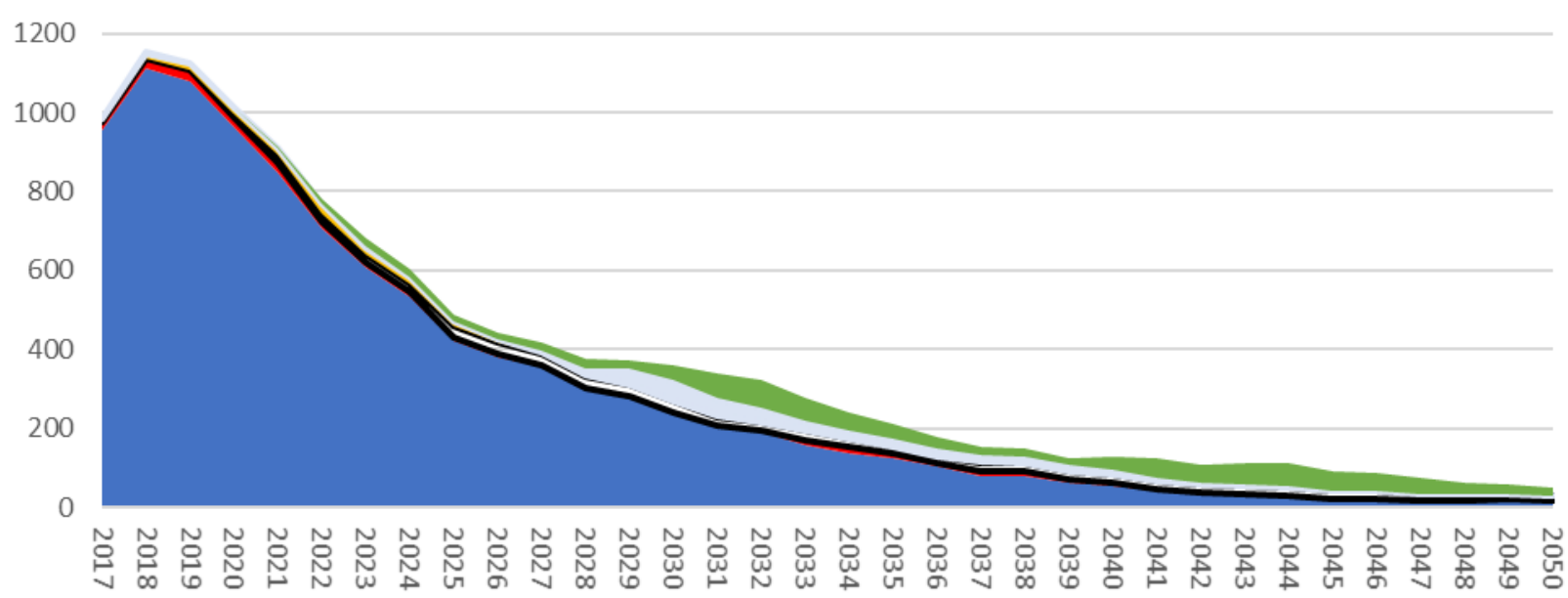

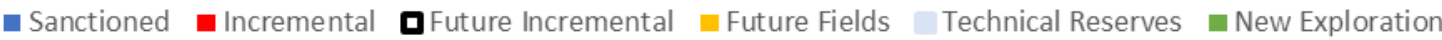

\section{Chart 50}

Potential Oil Production

$\$ 50 / \mathrm{bbl}$ and $40 \mathrm{p} /$ therm

tb/d Hurdle : Real NPV @ $10 \% /$ Real Devex @ $10 \%>0.5$

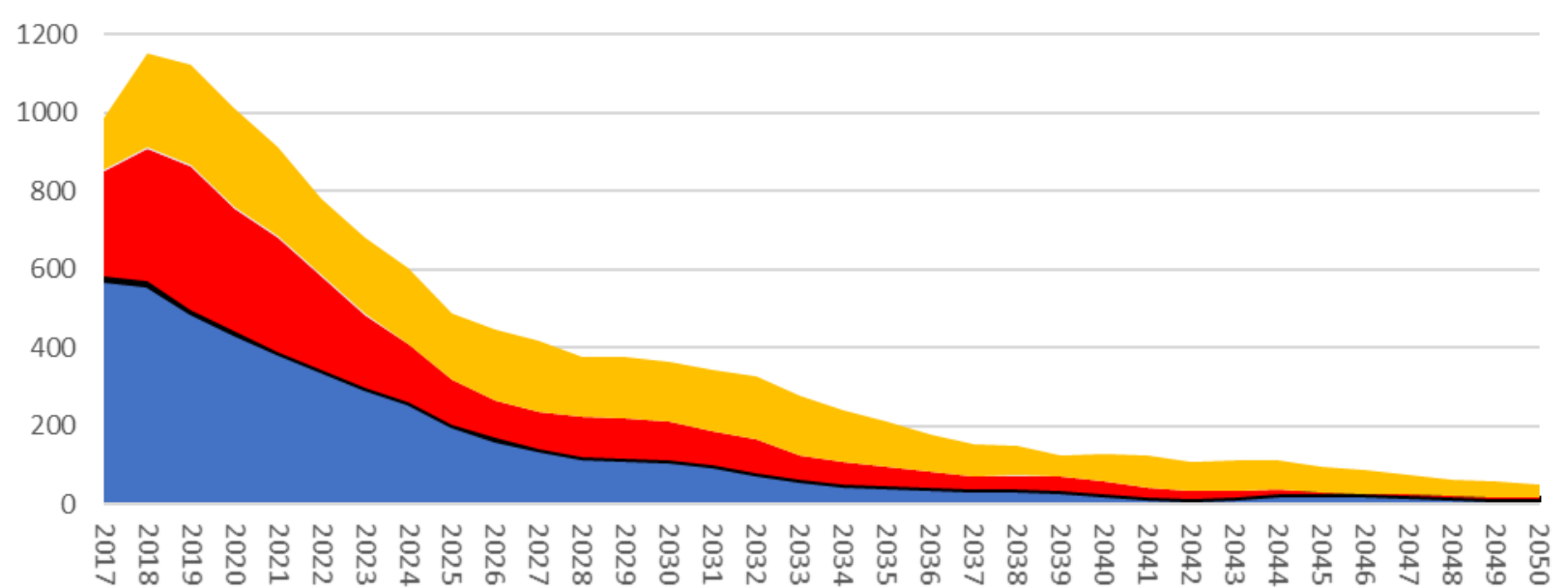

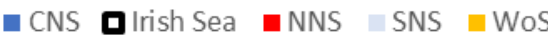


In Chart 51 potential gas production over the period to 2050 is shown for the $\$ 50,40$ pence case with the 0.5 hurdle. Over the period cumulative gas production is just over 2,346 million barrels of oil equivalent, of which 1,817 mmboe comes from sanctioned fields, 84 mmboe from current incremental projects, 195 mmboe from future incremental projects, 104 mmboe from probable and possible fields, $81 \mathrm{mmboe}$ from technical reserves, and 66 mmboe from future discoveries.

The reduction in prices results in a potential loss of $723 \mathrm{mmboe}, 62 \mathrm{mmboe}$ of which is from probable and possible fields, $185 \mathrm{mmboe}$ from technical reserve fields, and 186 mmboe from new discoveries (although there are 20 fewer new exploration finds).

The increase in the hurdle rate results in a loss of 460 mmboe, of which 79 mmboe is from current incremental projects, 159 from future incremental projects, 123 mmboe from technical reserves, and 99 mmboe from new discoveries.

Chart 52 gives the same information on geographic area basis. It is seen that 933 mmboe comes from the CNS/MF area, 695 mmboe comes from the SNS, 362 mmboe comes from the NNS, 262 mmboe from the WoS area, and 94 mmboe from the Irish Sea. 


\section{Chart 51}

Potential Gas Production

$\$ 50 / \mathrm{bbl}$ and $40 \mathrm{p} /$ therm

$\mathrm{mmcf} / \mathrm{d}$

Hurdle : Real NPV @ 10\%/Real Devex @ 10\% > 0.5

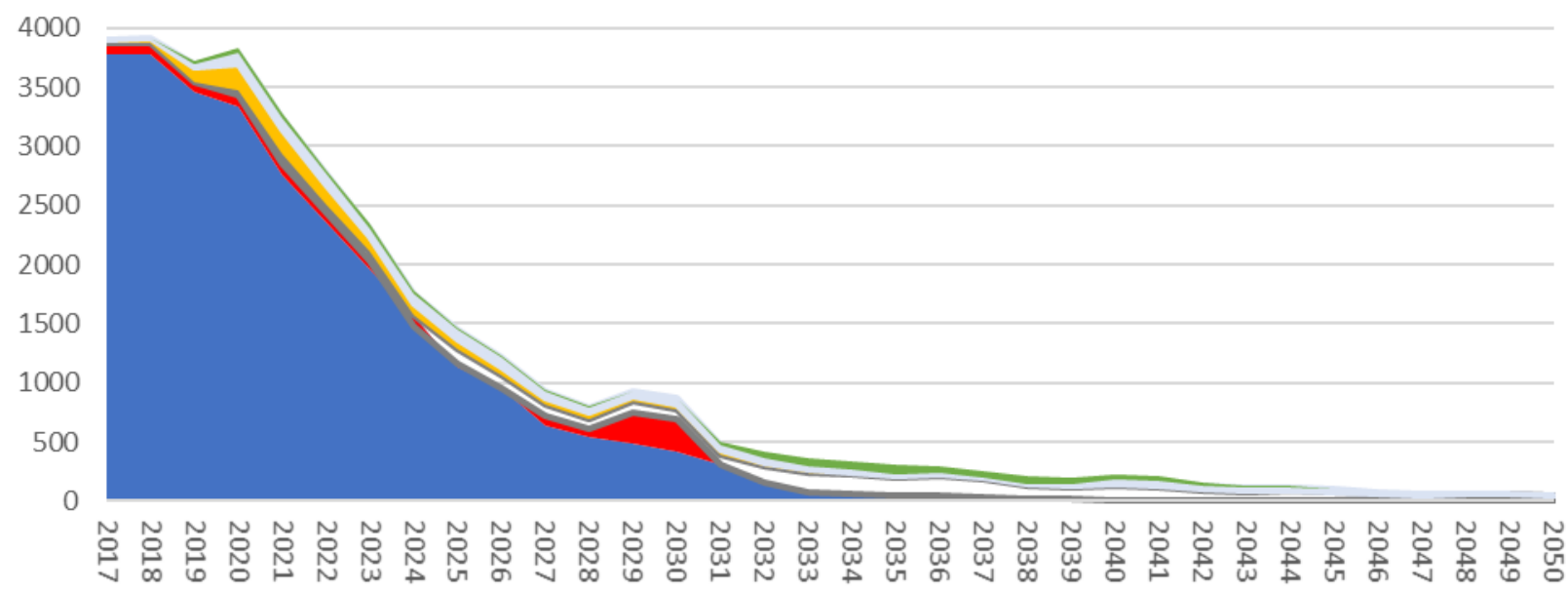

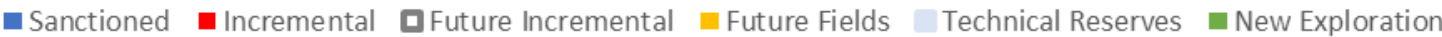

\section{Chart 52}

Potential Gas Production

$\$ 50 / \mathrm{bbl}$ and $40 \mathrm{p} /$ therm

mmcf/d Hurdle : Real NPV @ 10\%/Real Devex @ 10\% > 0.5

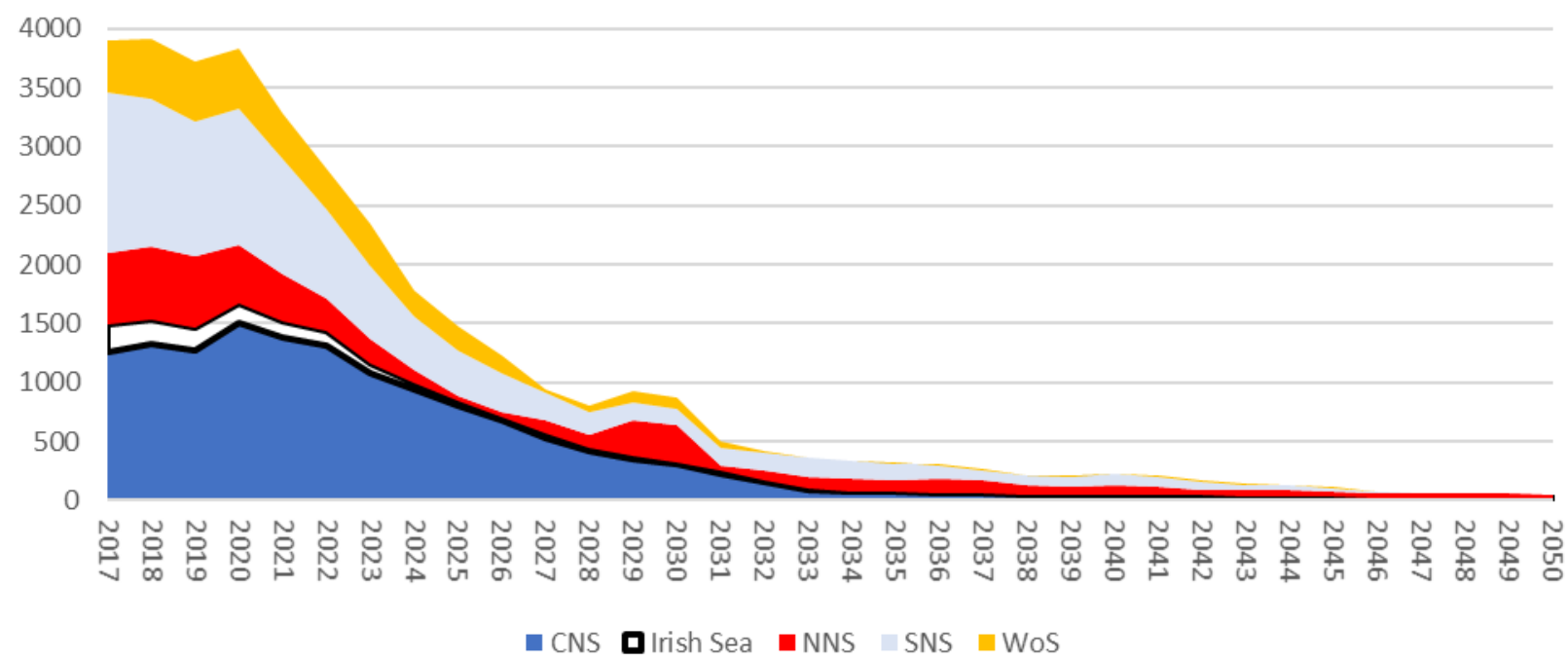


In Chart 53 potential total hydrocarbon production over the period to 2050 is shown for the $\$ 50,40$ pence case with the 0.5 hurdle. Over the period cumulative production is just under 7,202 million barrels of oil equivalent, of which 5,710 mmboe come from sanctioned fields, $202 \mathrm{mmboe}$ from current incremental projects, $470 \mathrm{mmboe}$ from future incremental projects, $167 \mathrm{mmboe}$ from probable and possible fields, $226 \mathrm{mmboe}$ from technical reserves, and 427 mmboe from new discoveries.

The reduction in prices results in a potential loss of 2,251mmboe, 399 mmboe of which is from probable and possible fields, $682 \mathrm{mmboe}$ from technical reserve fields, and 714 mmboe from new discoveries (although there are 20 fewer new exploration finds).

The increase in the hurdle rate from NPV/I $\geq 0.3$ results in a potential loss of 1,583 mmboe, $330 \mathrm{mmboe}$ of which is from probable and possible fields, 574 mmboe from technical reserve fields, and 318 mmboe from new discoveries.

However, had the fields which failed the hurdle rate come into production the total hydrocarbon production could have increased by 8,250 mmboe with 310 mmboe coming from incremental projects, 1,671 mmboe from probable and possible fields, 4,786 mmboe from technical reserve fields, and 1,483 from new exploration finds.

Chart 54 gives the same information on geographic area basis. It is seen that 2,891 mmboe come from the CNS/MF area, $706 \mathrm{mmboe}$ from the SNS, 1,642 mmboe from the NNS, 1,861 mmboe from the WoS area, and 102 mmboe from the Irish Sea. The largest reduction in potential production is from the CNS/MF and the WoS areas. 
If the fields which failed the 0.5 hurdle rate with the $\$ 50$ case had come into production then total hydrocarbon production would have increased by 2,309 mmboe in the CNS/MF area, 1,376 mmboe in the SNS area, 1,652 mmboe in the NNS area, 2,628 mmboe in the WoS area, and 286 mmboe in the Irish Sea.

\section{Chart 53}

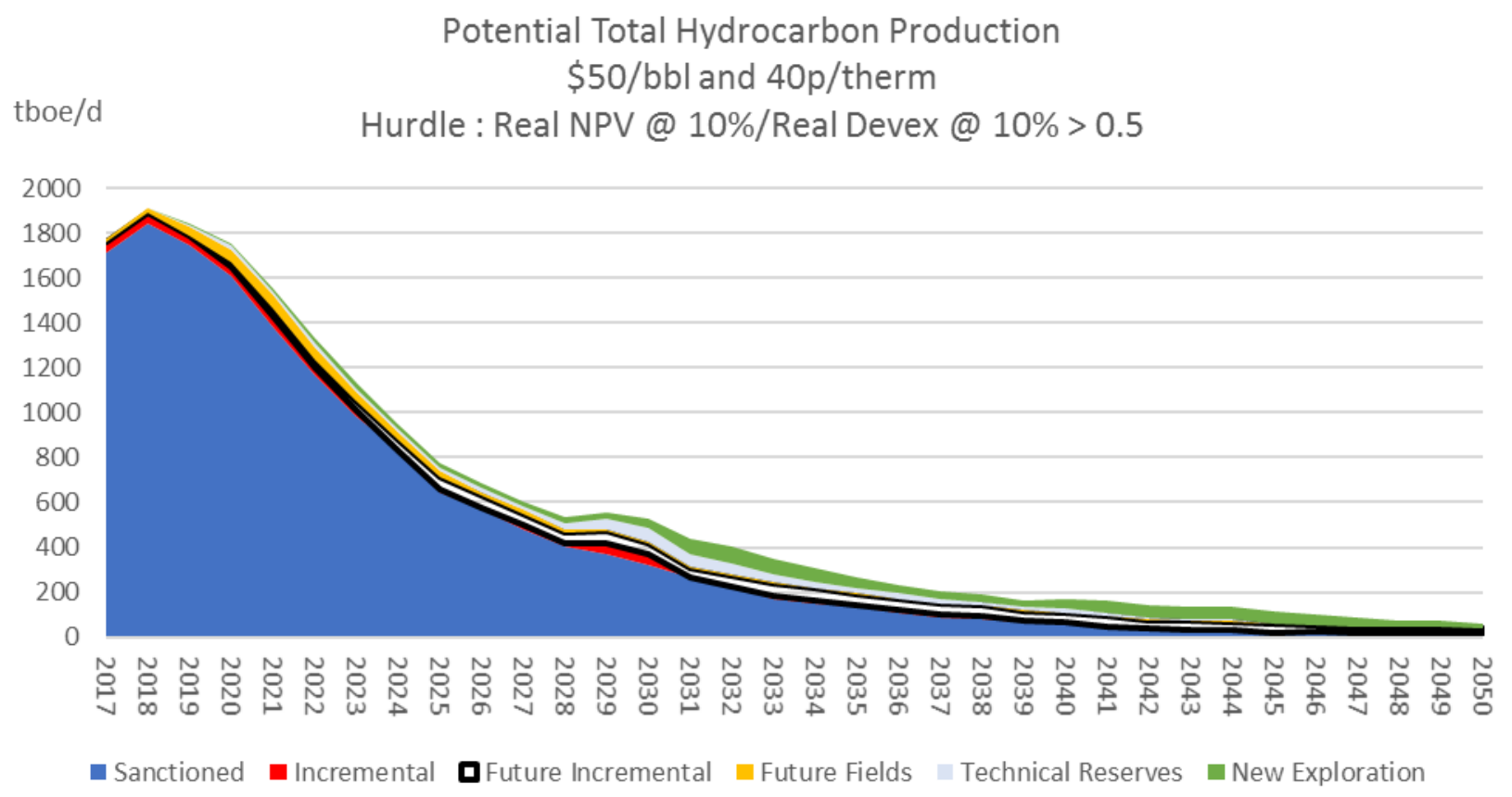




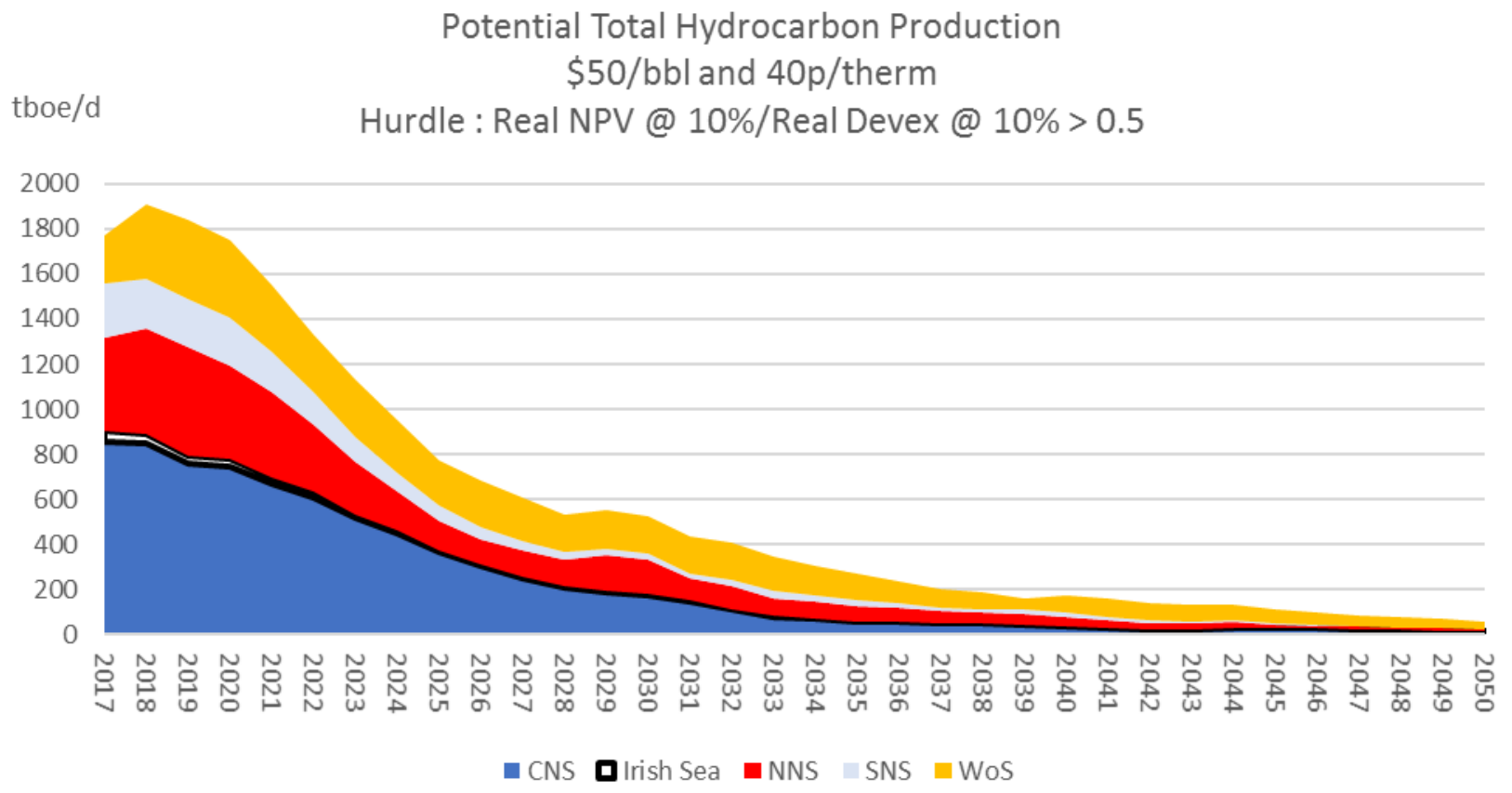

(iii) Field Expenditures by Category and Related Decommissioning Activity

In Chart 55 potential development expenditure is shown under the $\$ 60,50$ price case with the 0.5 hurdle. The decrease from current levels over the next few years is very notable. Over the period to 2050 cumulative development expenditures amount to $£ 70,633$ million at 2017 prices. The sanctioned fields contribute to the total until 2043, and account for $£ 28,049$ million, current incremental projects $£ 3,094$ million, future incremental projects $£ 8,868$ million, probable and possible fields $£ 5,502$ million, technical reserve fields $£ 10,619$ million, and new exploration finds $£ 14,501$ million.

The increase in the hurdle rate results in a reduction of $£ 18,624$ million in development expenditure with current incremental projects accounting for $£ 331$ million, future incremental projects $£ 1,144$ million, probable and 
possible fields $£ 1,071$ million, technical reserves $£ 6,842$ million, and new exploration finds $£ 9,237$ million.

Chart 56 gives the same information on geographic area basis. The CNS/MF area accounts for $£ 25,044$ million, the SNS $£ 5,024$ million, the NNS $£ 23,210$ million, the WoS $£ 17,107$ million, and the Irish Sea $£ 247$ million of development expenditure. The increase in the hurdle rate results in a reduction of $£ 5,271$ million in the CNS/MF area, $£ 3,749$ million in the SNS, $£ 4,184$ million in the NNS, $£ 5,315$ million in the WoS area, and $£ 106$ million from the Irish Sea.

Chart 55

Potential Development Expenditure

$\$ 60 / \mathrm{bbl}$ and $50 \mathrm{p} /$ therm

Real $2017 \mathrm{fm}$ Hurdle : Real NPV @ 10\%/Real Devex @ 10\% > 0.5

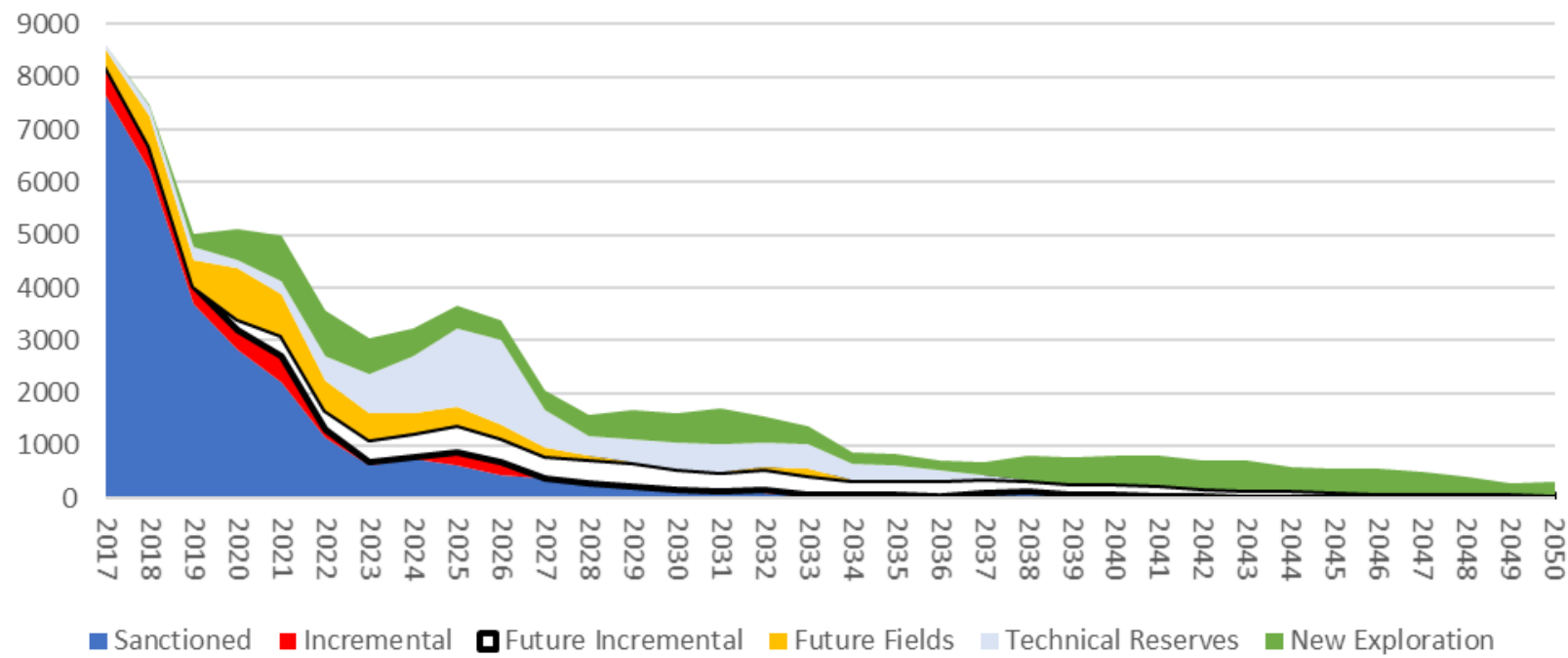




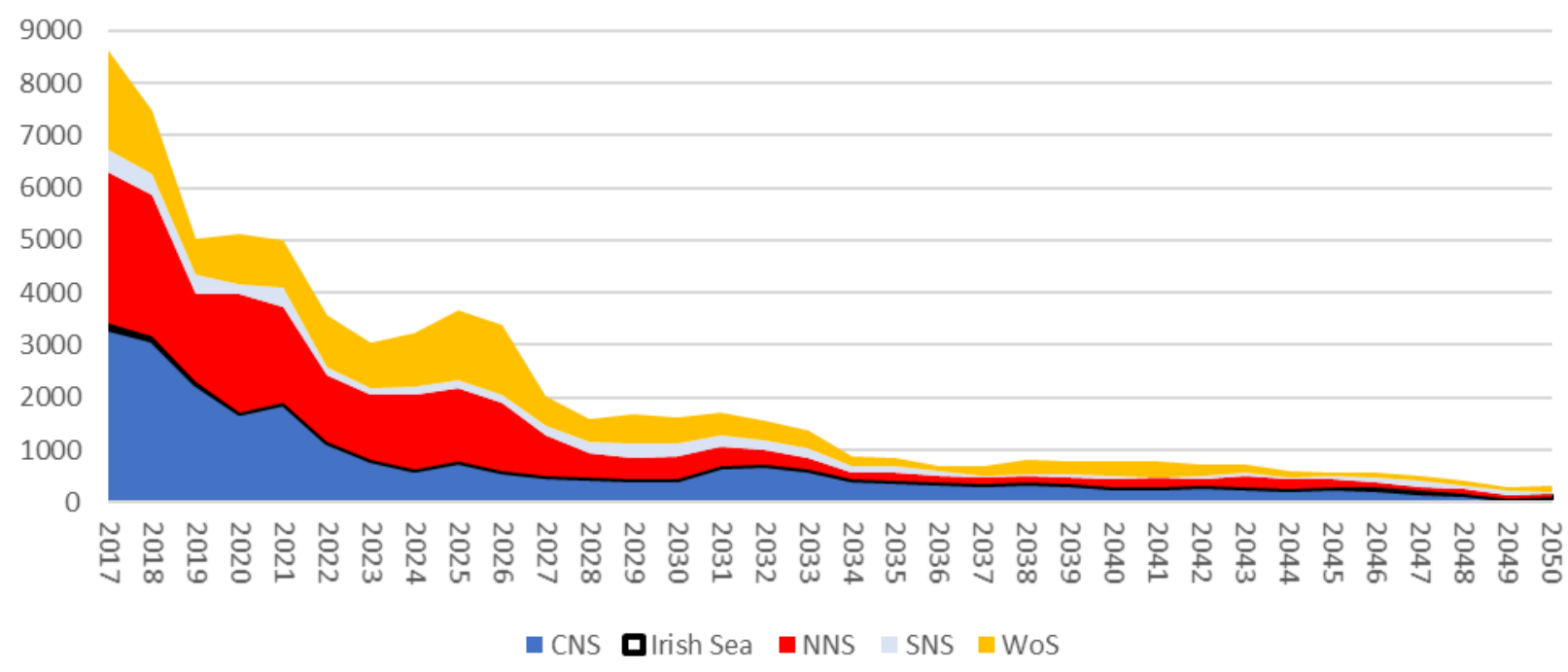

In Chart 57 potential operating expenditure is shown under the $\$ 60,50$ price case with the 0.5 hurdle. Over the period to 2050 cumulative operating expenditures amount to $£ 111,214$ million at 2017 prices. The sanctioned fields account for $£ 82,079$ million, current incremental projects $£ 2,005$ million, future incremental projects $£ 4,333$ million, probable and possible fields $£ 4,868$ million, technical reserve fields $£ 7,745$ million, and new exploration finds $£ 10,185$ million.

The increase in the hurdle rate results in a reduction of $£ 12,486$ million, $£ 121$ million from current incremental projects, $£ 470$ million from future incremental projects, $£ 1,240$ million from probable and possible fields, $£ 3,672$ million from technical reserves, and $£ 6,983$ million from new exploration finds.

Chart 58 gives the same information on geographic area basis. The CNS/MF area accounts for $£ 47,216$ million, the SNS $£ 7,891$ million, the 
NNS $£ 32,664$ million, the WoS $£ 21,718$ million, and the Irish Sea $£ 1,724$ million of operating expenditure. The increase in the hurdle rate results in a reduction of $£ 3,810$ million from the $\mathrm{CNS} / \mathrm{MF}$ area, $£ 1,563$ million from the SNS, $£ 3,422$ million from the NNS, $£ 3,623$ million from the WoS area, and $£ 68$ million from Irish Sea

Chart 57

\section{Potential Operating Expenditure} $\$ 60 /$ bbl and 50p/therm

Real $2017 \mathrm{fm} \quad$ Hurdle : Real NPV @ 10\%/Real Devex @ 10\% > 0.5

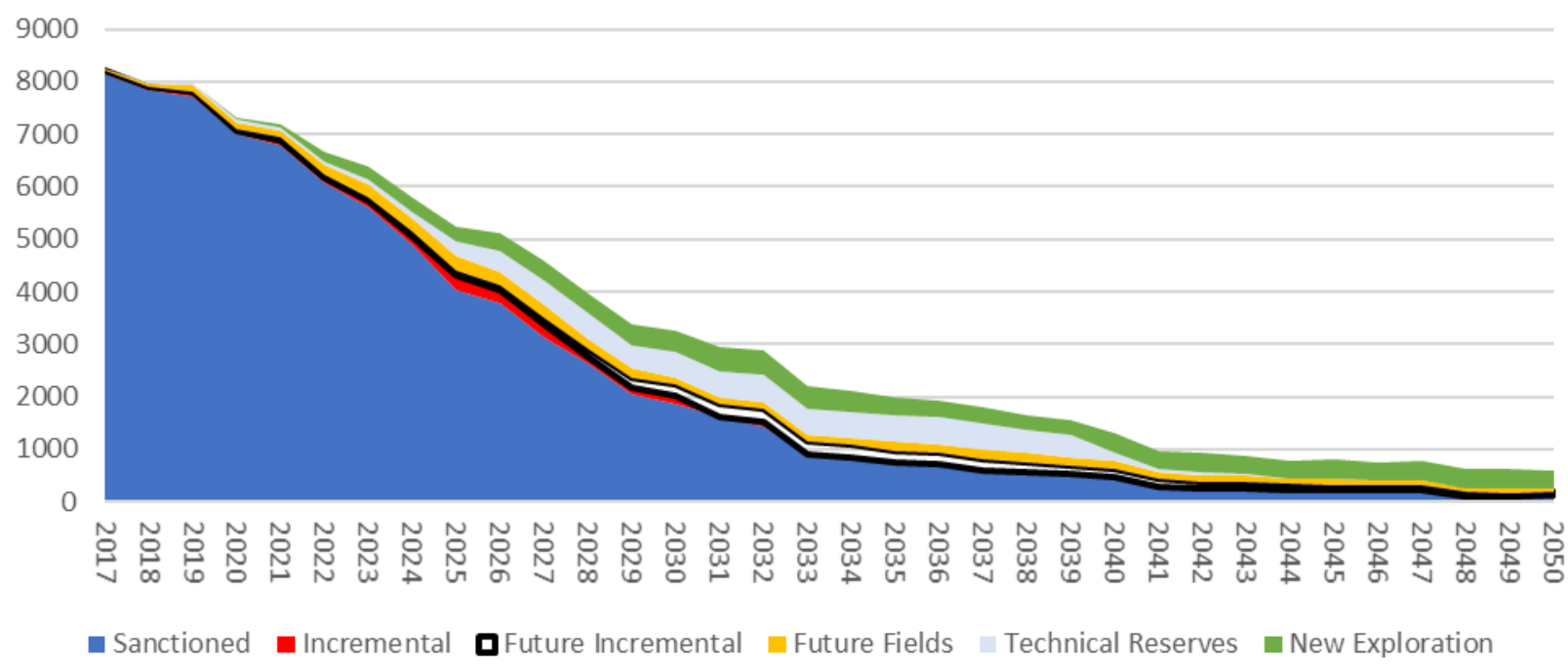


In Chart 59 cumulative potential decommissioning costs are shown under the $\$ 60,50$ price case with the 0.5 hurdle. Over the period to 2050 cumulative decommissioning costs amount to £52,518 million at 2017 prices. The sanctioned fields account for $£ 49,599$ million, current incremental projects $£ 209$ million, future incremental projects $£ 441$ million, probable and possible fields $£ 257$ million, technical reserve fields $£ 1,062$ million, and new exploration finds $£ 980$ million with the bulk of the expenditure occurring before 2035. By 2025 the cumulative decommissioning spend could be $£ 22,980$ million. The increase in the hurdle rate reduces the decommissioning costs by $£ 1728$ million because of fewer new fields passing the investment hurdle rate.

Chart 60 gives the same information on geographic area basis. The CNS/MF area accounts for $£ 22,386$ million, the SNS $£ 6,893$ million, the NNS $£ 17,853$ million, the WoS $£ 4,063$ million, and the Irish Sea $£ 1,323$ million of decommissioning costs. 


\section{Chart 59}

Potential Cumulative Decommissioning Expenditure $\$ 60 / \mathrm{bbl}$ and $50 \mathrm{p} /$ therm

Real $2017 \mathrm{fm}$

Hurdle : Real NPV @ 10\%/Real Devex @ 10\% > 0.5

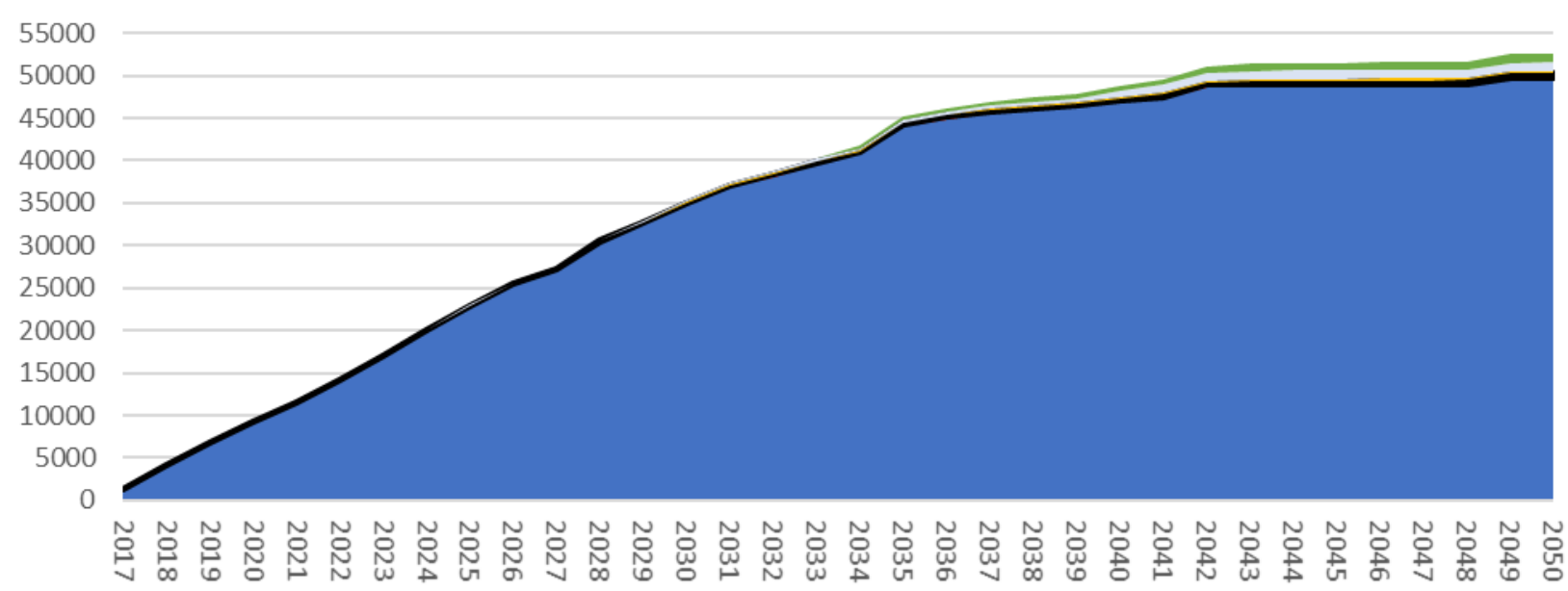

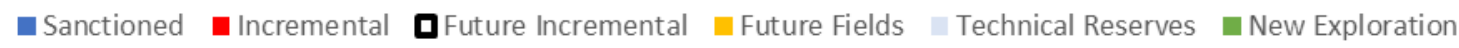

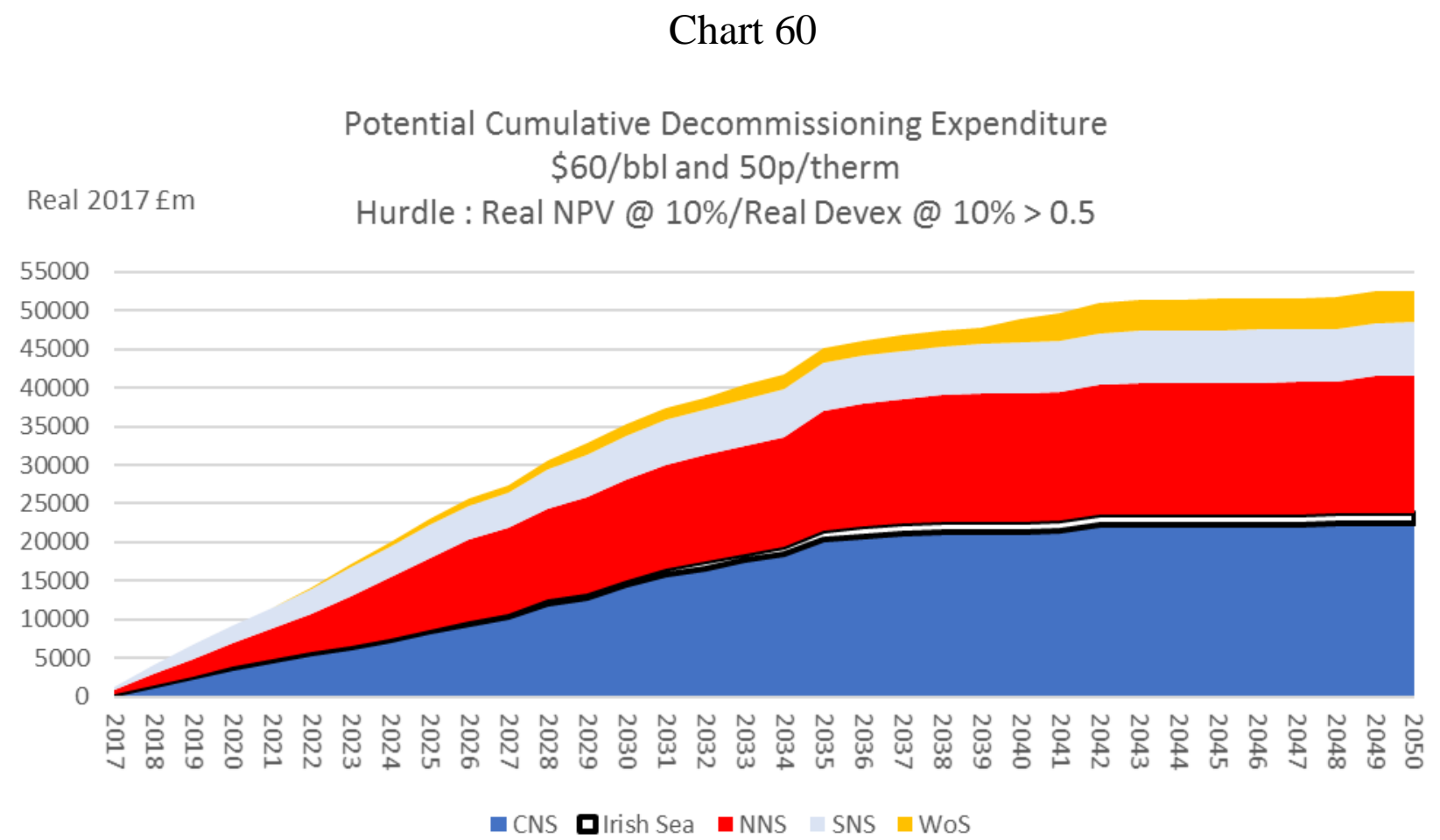


Chart 61 shows the number of fields decommissioning over time under the $\$ 60,50$ price case with the 0.5 hurdle. By 2025 there could be as many as 198 fields undergoing or having completed decommissioning, and by 2050 there could be 417 fields in this position. By 2025 sanctioned fields could account for 194 fields, and technical reserves could account for 4 fields. By 2050 sanctioned fields could account for 307 fields, technical reserves could account for 60 fields, and new exploration finds could account for 43 fields.

Chart 62 gives the same information on geographic area basis. By 2025 there could be 65 fields in the CNS/MF area undergoing or having completed decommissioning, and there could be 64 fields in the SNS, 52 fields in the NNS, 2 fields in the WoS, and 15 fields in the Irish Sea in the same position. By 2050 there could be 165 fields in the CNS/MF area undergoing or having completed decommissioning, of which there could be 125 fields in the SNS, 91 fields in the NNS, 19 fields in the WoS and 17 fields in the Irish Sea in the same position.

Chart 61

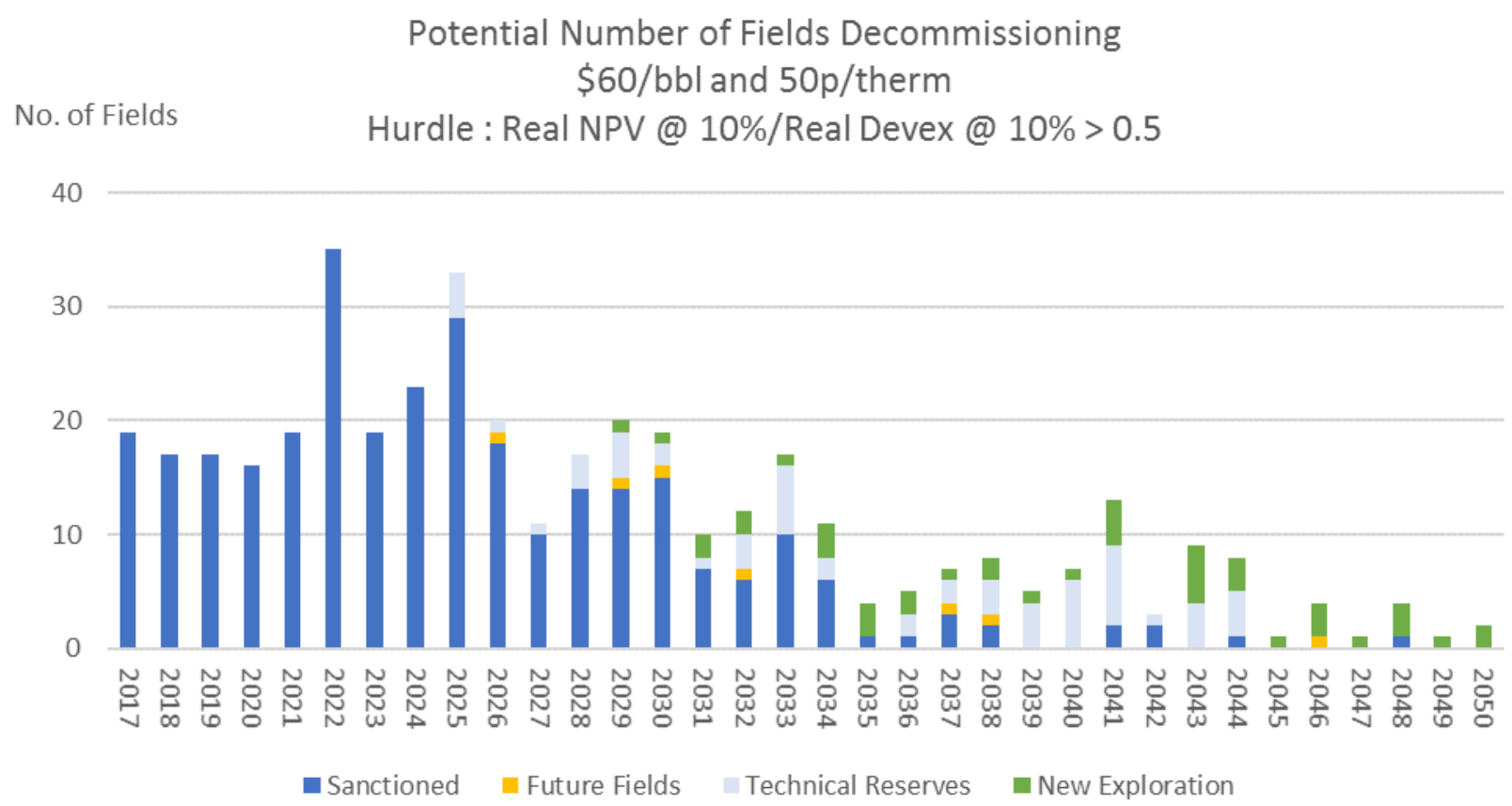




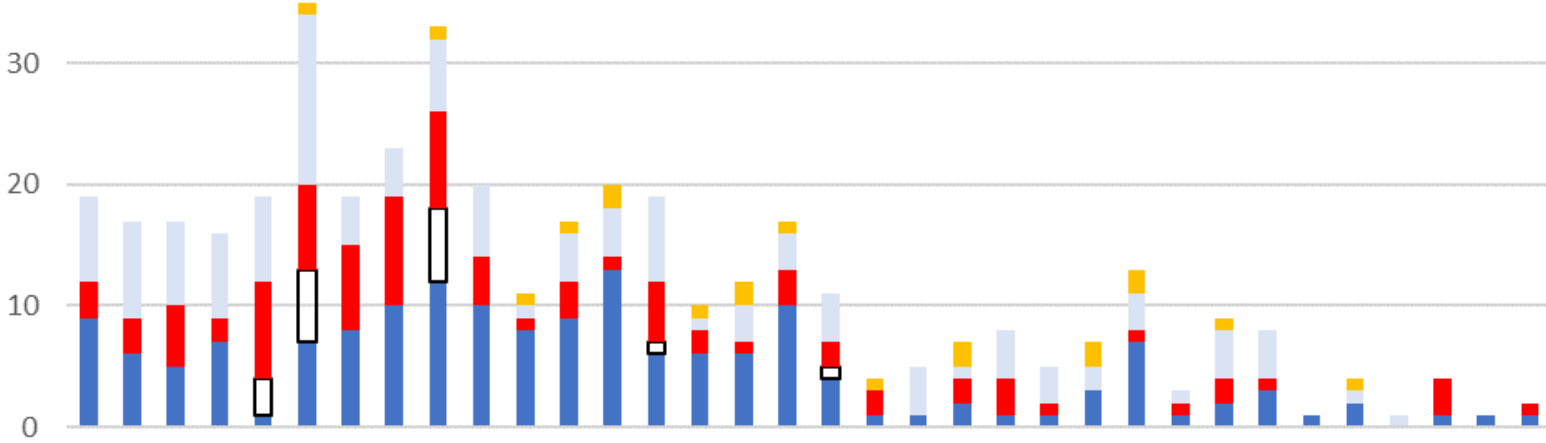

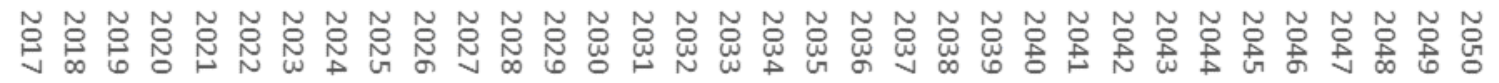

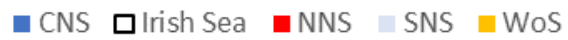

In Chart 63 potential total expenditure is shown under the $\$ 60,50$ price case with the 0.5 hurdle. Over the period to 2050 cumulative total expenditures amount to $£ 234,365$ million at 2017 prices. The sanctioned fields account for $£ 159,726$ million, current incremental fields $£ 5,308$ million, future incremental $£ 13,612$ million, probable and possible fields $£ 10,627$ million, technical reserve fields $£ 19,426$ million, and new exploration finds $£ 25,666$ million.

The increase in the hurdle rate results is a reduction in total expenditure of $£ 32,838$ million, $£ 501$ million being from current incremental projects, $£ 1,665$ million from future incremental projects, $£ 2,410$ million from probable and possible fields, $£ 11,198$ million from technical reserves, and $£ 17,063$ million from new exploration finds. 
However, had the fields which failed the 0.5 hurdle rate come into production the total expenditure could have increased by $£ 206,506$ million with $£ 5,974$ coming from incremental projects, $£ 37,357$ million from probable and possible fields, $£ 128,825$ million from technical reserve fields, and $£ 34,351$ million from new exploration finds.

Chart 64 gives results on geographic area basis. The CNS/MF area accounts for $£ 94,647$ million, the SNS $£ 19,808$ million, the NNS $£ 73,727$ million, the WoS $£ 42,888$ million, and the Irish Sea $£ 3,294$ million of total expenditure. The increase in the hurdle rate results is a reduction in total expenditure of $£ 9,602$ million from the CNS/MF area, $£ 5,696$ million from the SNS area, $£ 7,966$ million from the NNS area, $£ 9,391$ million from the WoS area, and $£ 184$ million from the Irish Sea.

If the fields which failed the 0.5 hurdle rate had come into production the total expenditure could have increased by $£ 61,998$ million from the CNS/MF area, $£ 23,463$ million from the SNS area, $£ 42,402$ million from the NNS area, $£ 68,280$ million from the WoS area, and $£ 10,362$ million from the Irish Sea. Further details of the unexploited potential are shown in the Appendix. 


\section{Chart 63}

Potential Total Field Expenditure

$\$ 60 / \mathrm{bbl}$ and 50p/therm

Real $2017 \mathrm{fm}$

Hurdle : Real NPV @ 10\%/Real Devex @ 10\% > 0.5

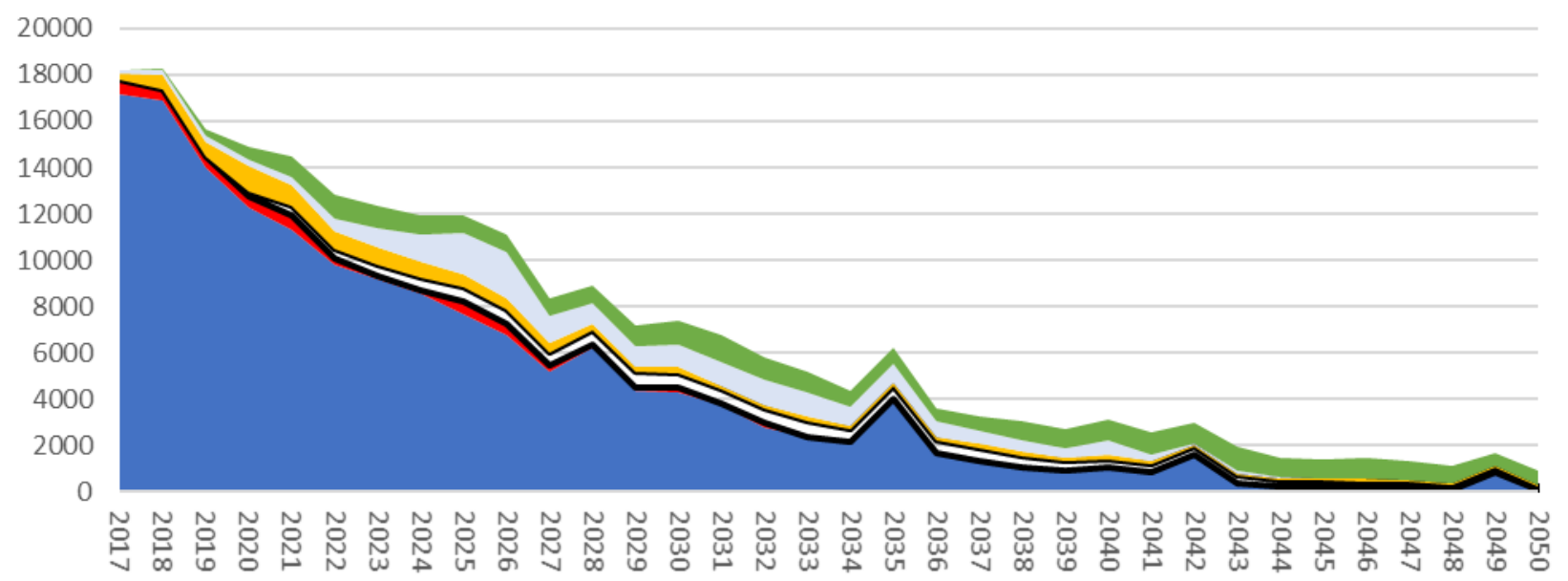

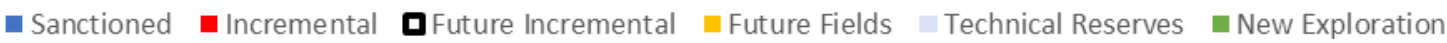

\section{Chart 64}

Potential Total Field Expenditure

$\$ 60 / \mathrm{bbl}$ and 50p/therm

Real $2017 \mathrm{fm} \quad$ Hurdle : Real NPV @ 10\%/Real Devex @ 10\% $>0.5$

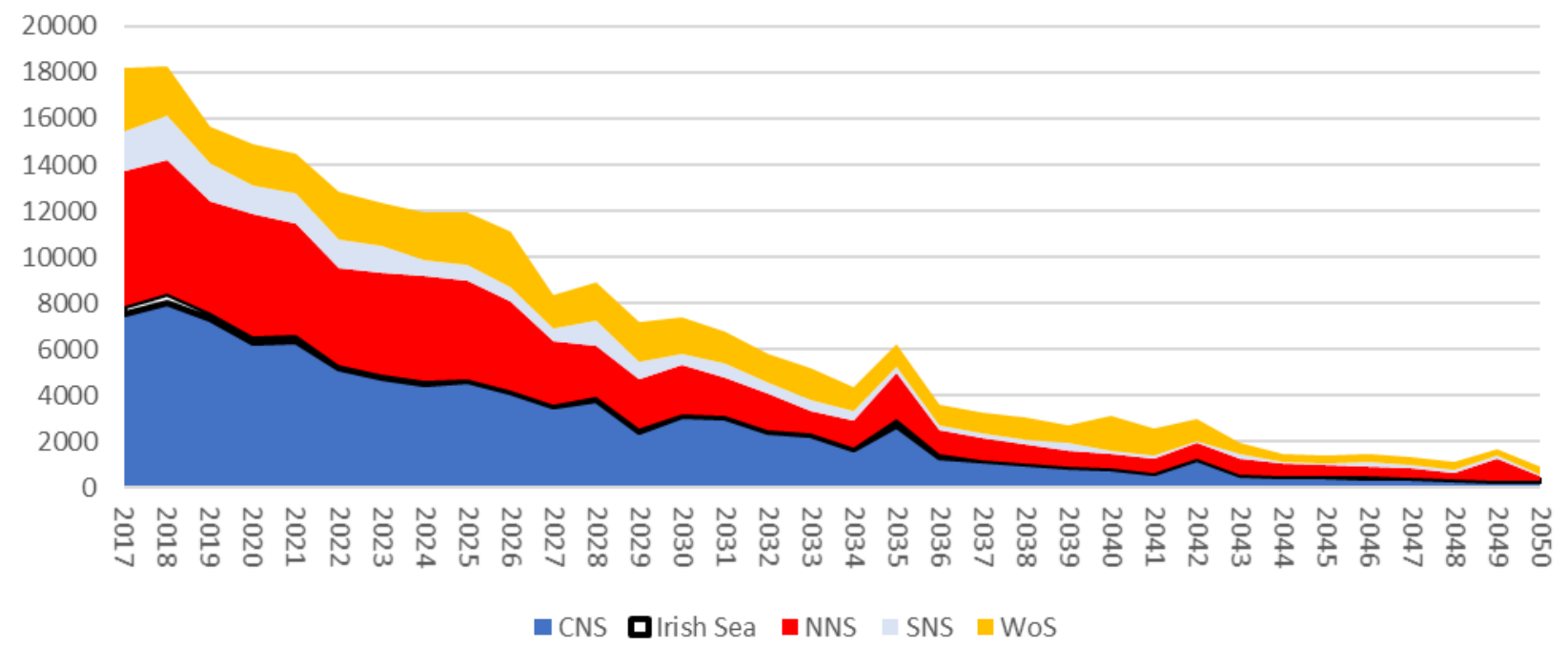


Chart 65 shows that by 2018 operating costs are likely to exceed development costs, and by 2025 decommissioning costs could be $25 \%$ of total costs and in 2035 they could be $55 \%$ of total costs.

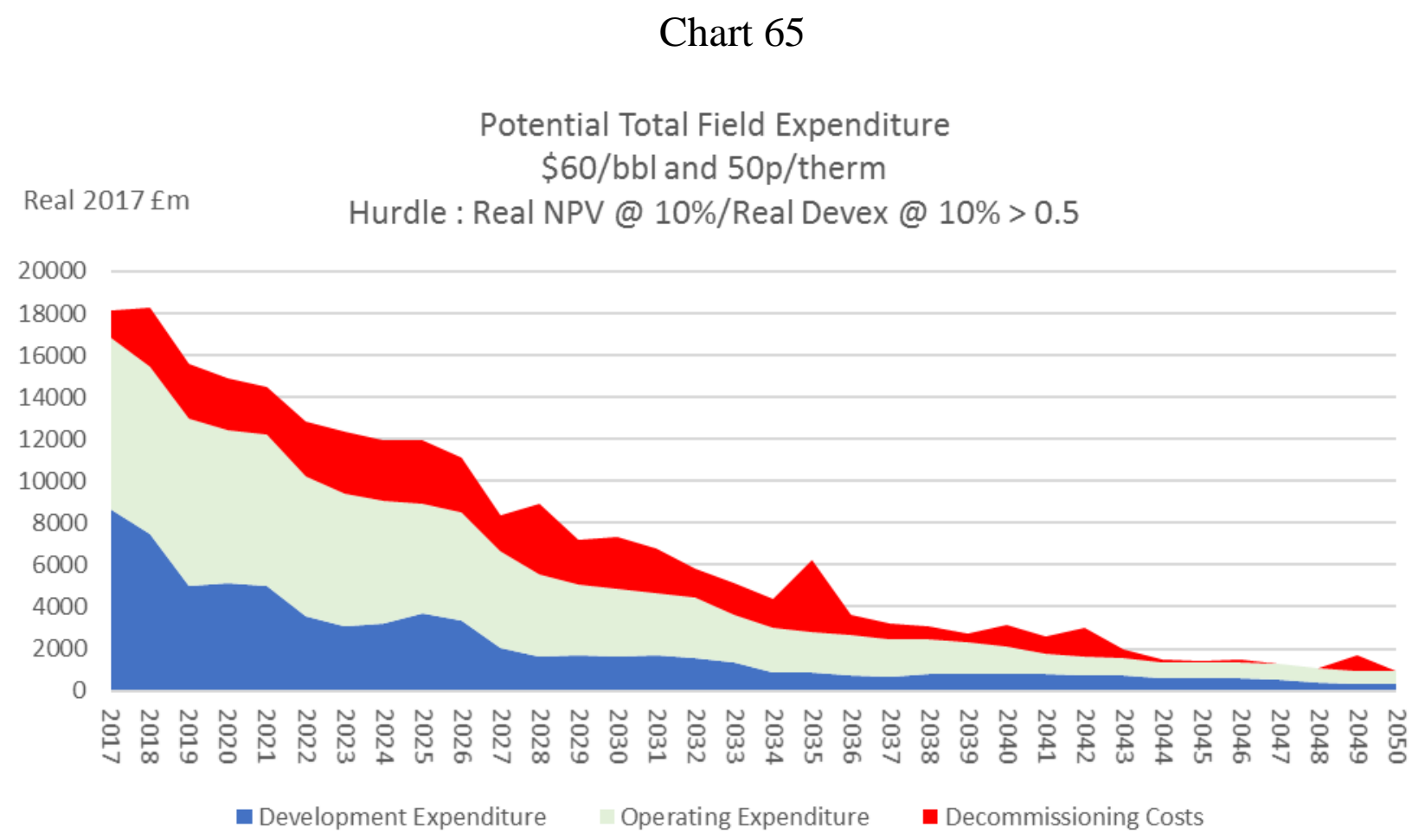

In Chart 66 potential development expenditure is shown under the $\$ 50,40$ price case with the 0.5 hurdle. Over the period to 2050 cumulative development expenditures amount to $£ 44,076$ million at 2017 prices. This is $£ 26,557$ million less than with the $\$ 60$ case with the 0.5 hurdle. Sanctioned fields still contribute to the total until 2043, and account for $£ 28,017$ million. Current incremental projects account for $£ 1,986$ million, future incremental $£ 5,993$ million, probable and possible fields $£ 1,256$ million (which is $£ 4,247$ million less than with the $\$ 60$ case), technical reserve fields $£ 2,150$ million (which is $£ 8,470$ million less than the $\$ 60$ case), and new exploration finds $£ 4,675$ million (which is $£ 9,826$ million less than the $\$ 60$ case). 
When the hurdle rate is increased development expenditure is $£ 19,503$ million less.

Chart 67 gives the same information on geographic area basis. The CNS/MF area accounts for development expenditure of $£ 17,404$ million, the SNS $£ 1,960$ million, the NNS $£ 14,135$ million, the WoS $£ 10,378$ million, and the Irish Sea accounts for $£ 199$ million. Compared to the $\$ 60$ case there is a reduction of $£ 7,641$ million in the CNS/MF area, $£ 3,065$ million in the SNS area, $£ 9,075$ million in the NNS area, $£ 6,729$ million in the WoS area, and $£ 48$ million in the Irish Sea.

Chart 66

Potential Development Expenditure

$\$ 50 / \mathrm{bbl}$ and $40 \mathrm{p} /$ therm

Real 2017 fm Hurdle : Real NPV @ 10\%/Real Devex @ 10\% > 0.5

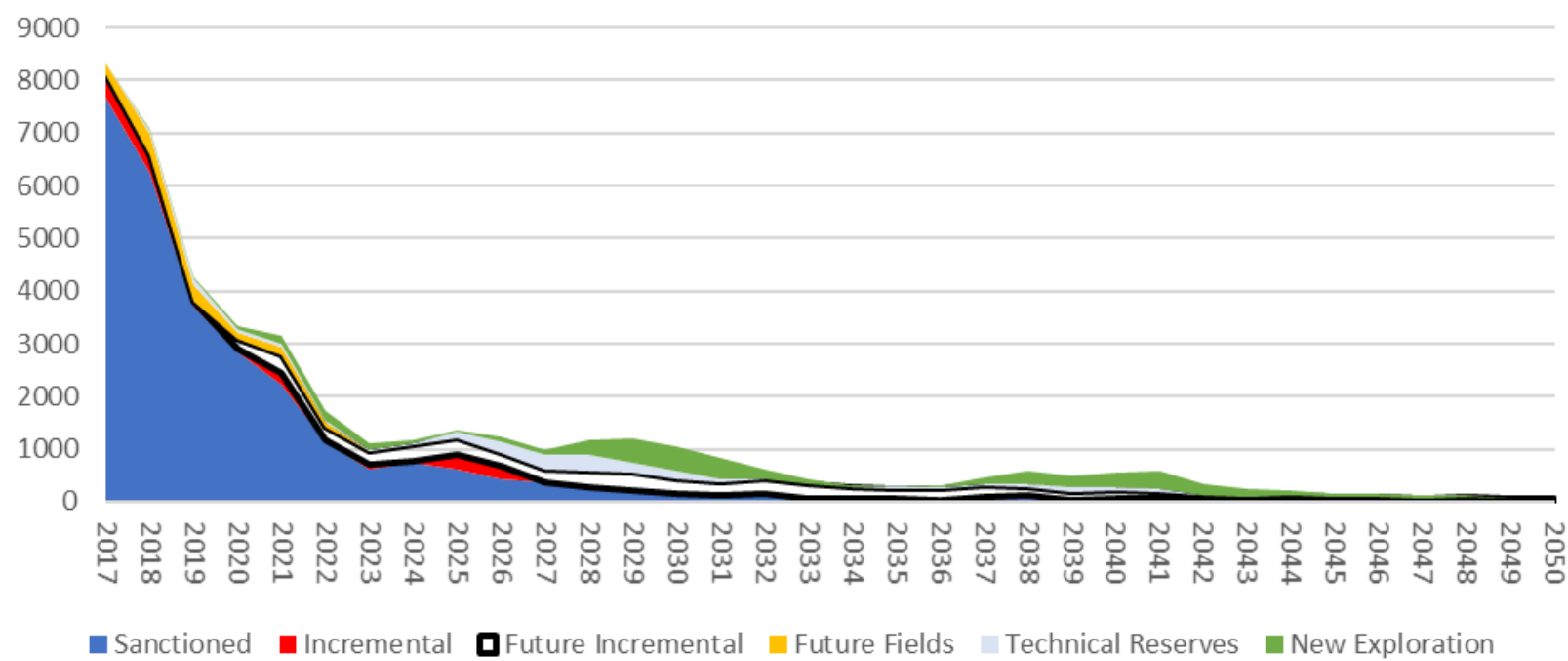




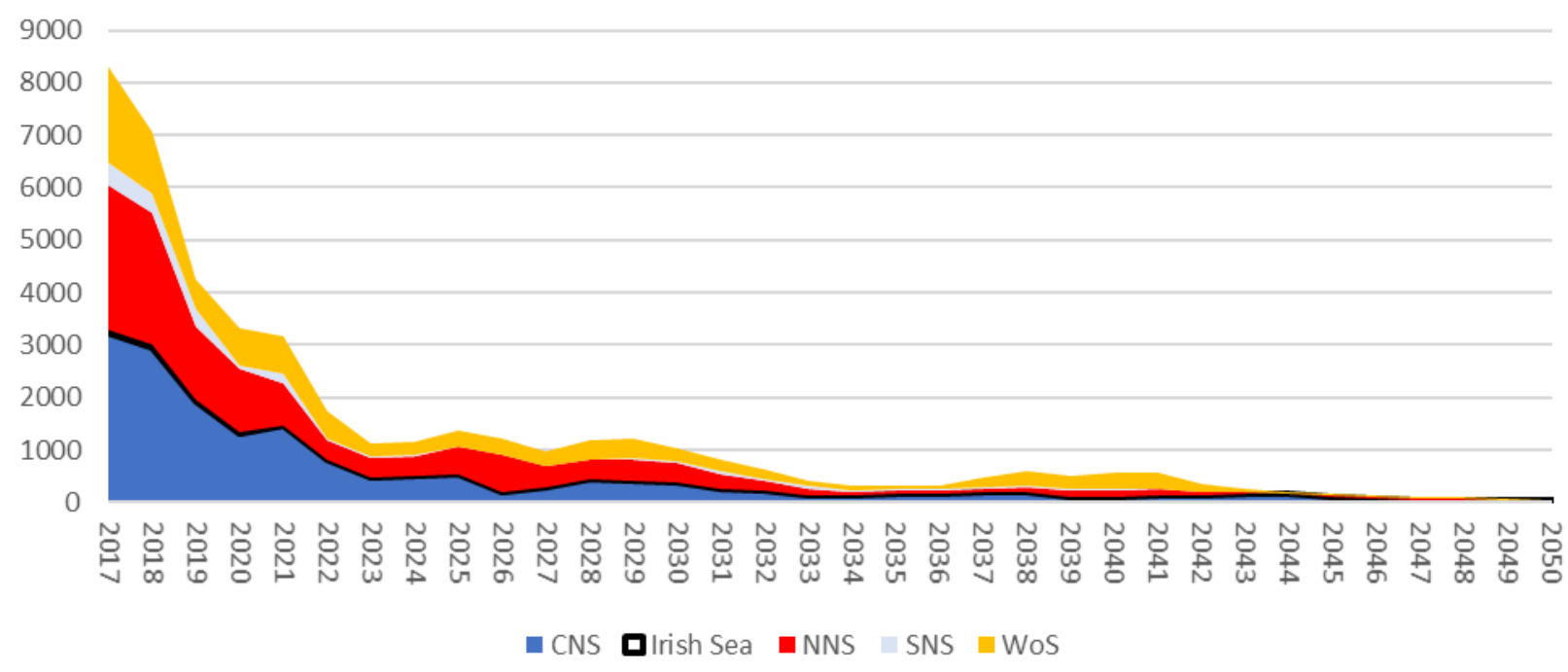

In Chart 68 potential operating expenditure is shown under the $\$ 50,40$ price case with the 0.5 hurdle. Over the period to 2050 cumulative operating expenditures amount to $£ 87,106$ million at 2017 prices which is $£ 24,108$ million less than the $\$ 60$ case with the 0.5 hurdle. Sanctioned fields account for $£ 79,006$ million. Current incremental projects account for $£ 807$ million, future incremental ones $£ 1,837$ million, probable and possible fields $£ 544$ million, technical reserve fields $£ 1,461$ million, and new exploration finds $£ 3,451$ million. This is a reduction of $£ 3,073$ million for sanctioned fields, $£ 1,198$ million for current incremental projects, $£ 2,496$ million for future incremental projects, $£ 4,323$ million for probable and possible fields, $£ 6,284$ million for technical reserve fields, and $£ 6,734$ million for the new exploration finds compared to the $\$ 60$ case. With the $\$ 50$ case and a higher hurdle there is a potential $£ 14,455$ million reduction in operating costs compared to the 0.3 hurdle. 
Chart 69 gives the same information on geographic area basis. The CNS/MF area accounts for $£ 39,357$ million, the SNS $£ 6,420$ million, the NNS $£ 25,014$ million, the WoS $£ 14,676$ million, and the Irish Sea $£ 1,638$ million. This constitutes a reduction of $£ 7,859$ million in the CNS/MF area, $£ 1,471$ million in the SNS area, $£ 7,650$ million in the NNS area, $£ 7,042$ million in the WoS area, and $£ 86$ million in the Irish Sea compared to the $\$ 60$ case with the 0.5 hurdle.

\section{Chart 68}

Potential Operating Expenditure

$\$ 50 / \mathrm{bbl}$ and $40 \mathrm{p} /$ therm

Real $2017 \mathrm{fm}$

Hurdle : Real NPV @ 10\%/Real Devex @ 10\% > 0.5

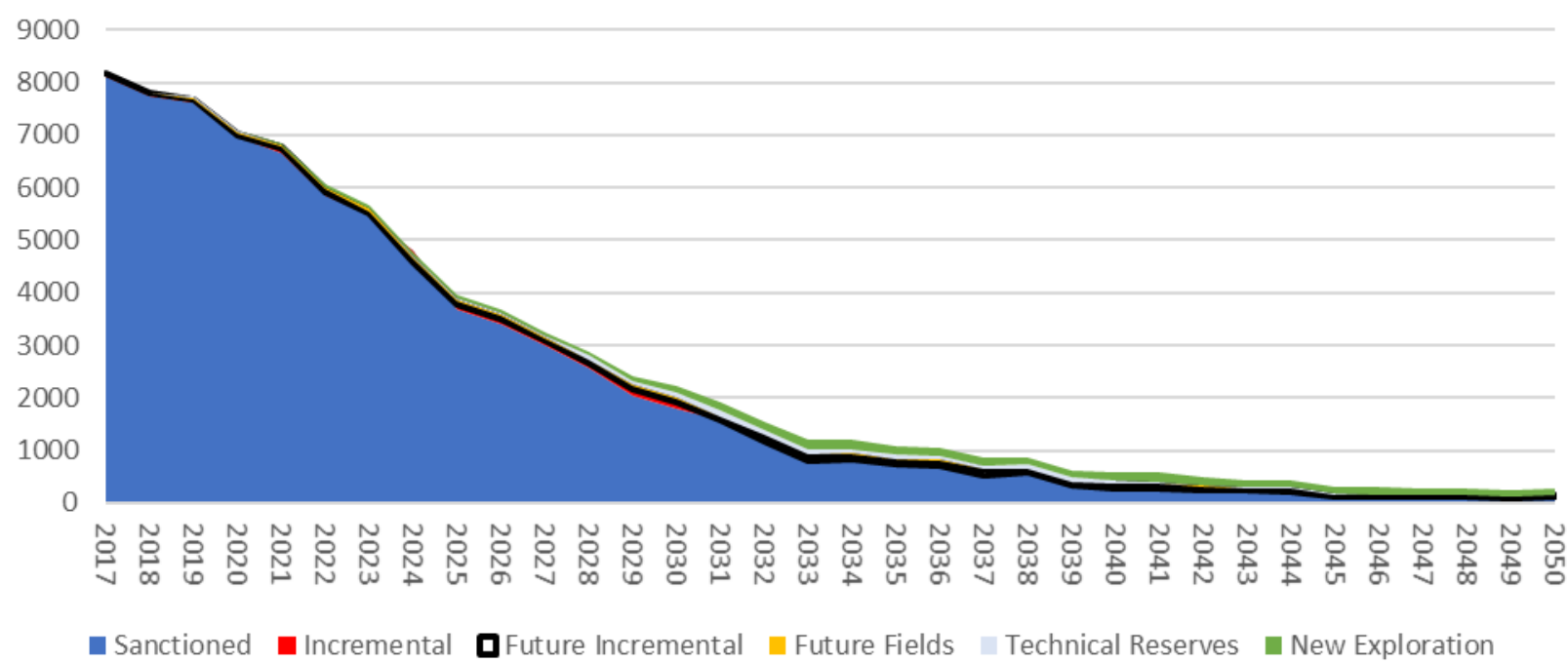




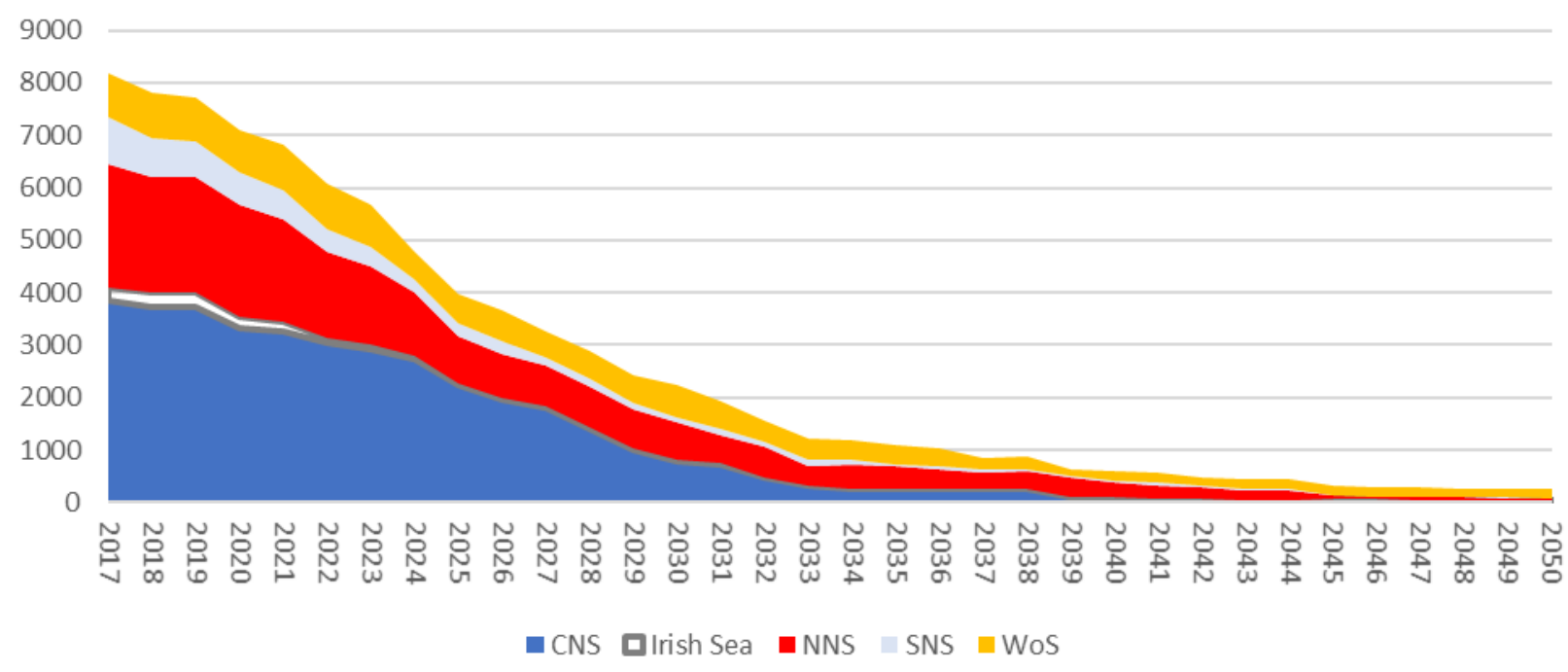

In Chart 70 cumulative potential decommissioning costs are shown under the $\$ 50,40$ price case with the 0.5 hurdle. Over the period to 2050 they amount to $£ 50,485$ million at 2017 prices. Sanctioned fields account for $£ 49,599$ million. Current incremental fields account for $£ 84$ million, future incremental $£ 188$ million, probable and possible fields $£ 106$ million, technical reserve fields $£ 215$ million, and new exploration finds $£ 293$ million. The bulk of the expenditure occurs before 2035. By 2025 the cumulative decommissioning spend could be $£ 23,216$ million.

Compared to the $\$ 60$ case there is a reduction of $£ 125$ million for current incremental projects, £224 million for future ones, £151 million for probable and possible fields, $£ 847$ million for technical reserve fields, and $£ 687$ million for the new exploration finds.

Compared to the $\$ 50$ with a 0.3 hurdle case there is a reduction of $£ 152$ million for current incremental projects, $£ 236$ million for future ones, $£ 132$ 
million for probable and possible fields, $£ 719$ million for technical reserve fields, and $£ 321$ million for the new exploration finds.

Chart 71 gives the same information on geographic area basis. The CNS/MF area accounts for $£ 21,849$ million, the SNS $£ 6,657$ million, the NNS $£ 17,187$ million, the WoS $£ 3,470$ million, and the Irish Sea $£ 1,323$ million.

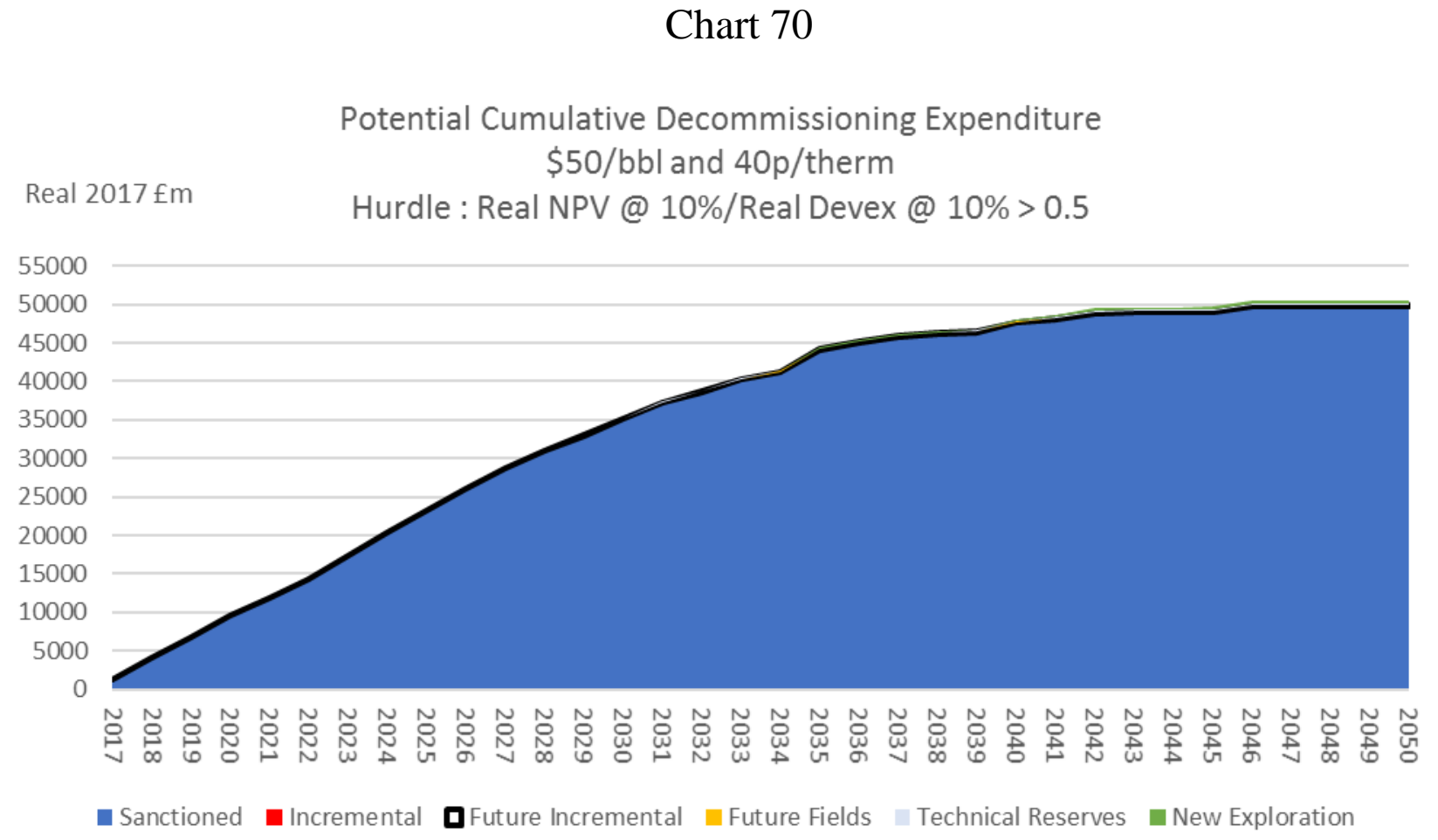




\section{Chart 71}

Potential Cumulative Decommissioning Expenditure

$\$ 50 / \mathrm{bbl}$ and $40 \mathrm{p} /$ therm

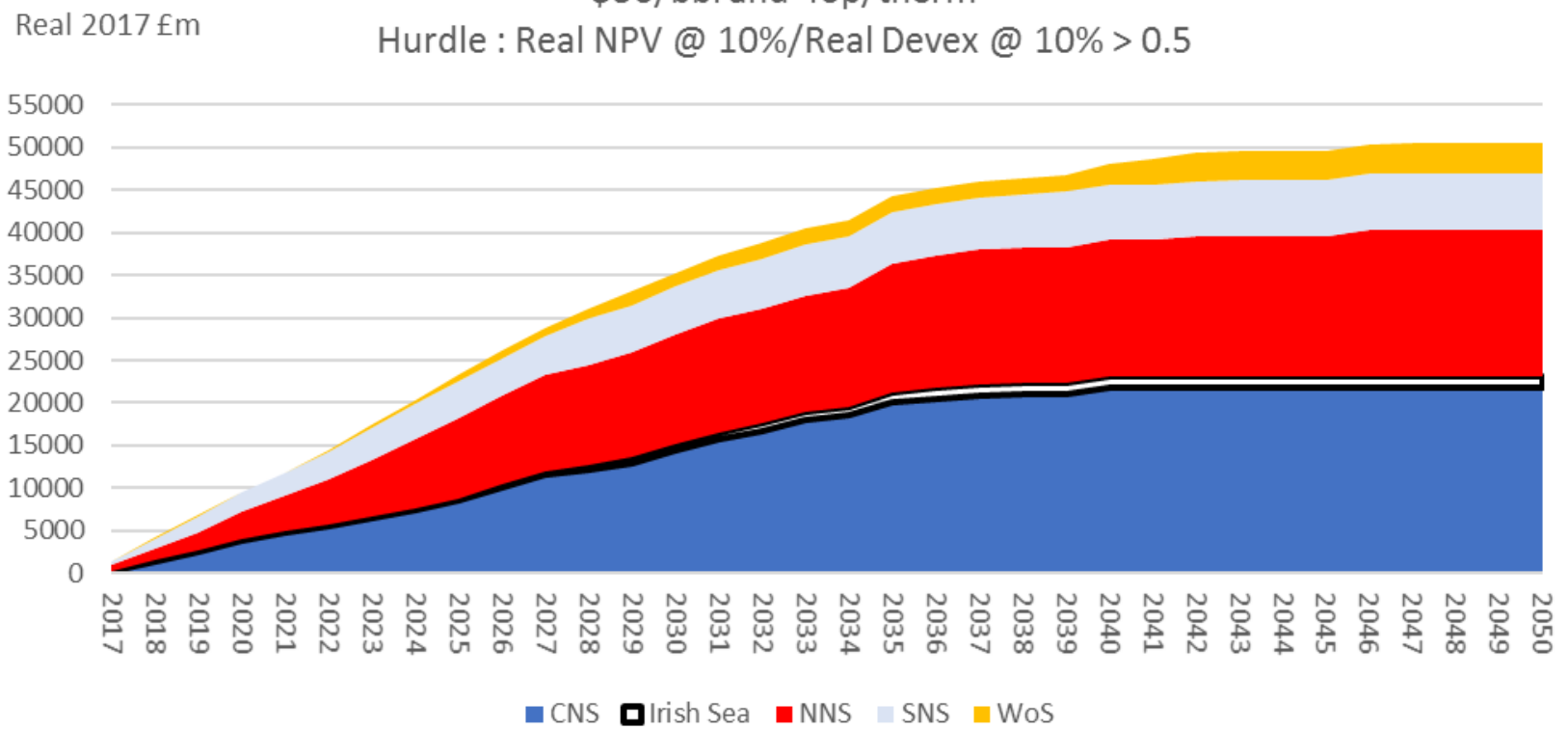

Chart 72 shows the number of fields decommissioning over time under the $\$ 50,40$ price case with a 0.5 hurdle. By 2025 there could be as many as 203 fields, all of which are in the sanctioned category, undergoing or having completed decommissioning, and by 2050 there could be 344 fields in this position. By 2050 sanctioned fields could account for 305 fields, probable and possible fields could account for 5 fields, technical reserves could account for 18 fields, and new exploration finds could account for 16.

However, compared to the $\$ 60$ case with a 0.5 hurdle, at the lower price there are 20 fewer new exploration finds and 47 fewer fields which pass the hurdle. There are also 5 fewer incremental projects, 4 fewer probable and possible fields and 42 fewer technical reserve fields which pass the hurdle. Compared to the $\$ 50$ case with a 0.3 hurdle rate there are 6 fewer incremental projects, 2 less probable and possible fields, 33 less technical reserves and 23 less new exploration finds. 
Chart 73 gives the same information on geographic area basis. By 2025 there could be 67 fields in the CNS/MF area undergoing or having completed decommissioning. There could be 65 fields in the SNS, 54 fields in the NNS, 2 fields in the WoS, and 15 fields in the Irish Sea in the same position. By 2050 there could be 133 fields in the CNS/MF area undergoing or having completed decommissioning, and there could be 100 fields in the SNS, 83 fields in the NNS, 11 fields in the WoS, and 17 fields in the Irish Sea in the same position.

However, compared to the $\$ 60$ case with a 0.5 hurdle there are 37 fewer fields passing the hurdle in the CNS/MF, 30 fewer in the SNS, 13 fewer in the NNS, 12 fewer in the WoS, and 1 less in the Irish Sea passing the hurdle. Compared to the $\$ 50$ case with a 0.3 hurdle there are 23 fewer fields in CNS/MF passing the hurdle, 21 fewer in the SNS, 7 fewer in the NNS, 6 fewer in the WoS, and 1 less in the Irish Sea.

\section{Chart 72}
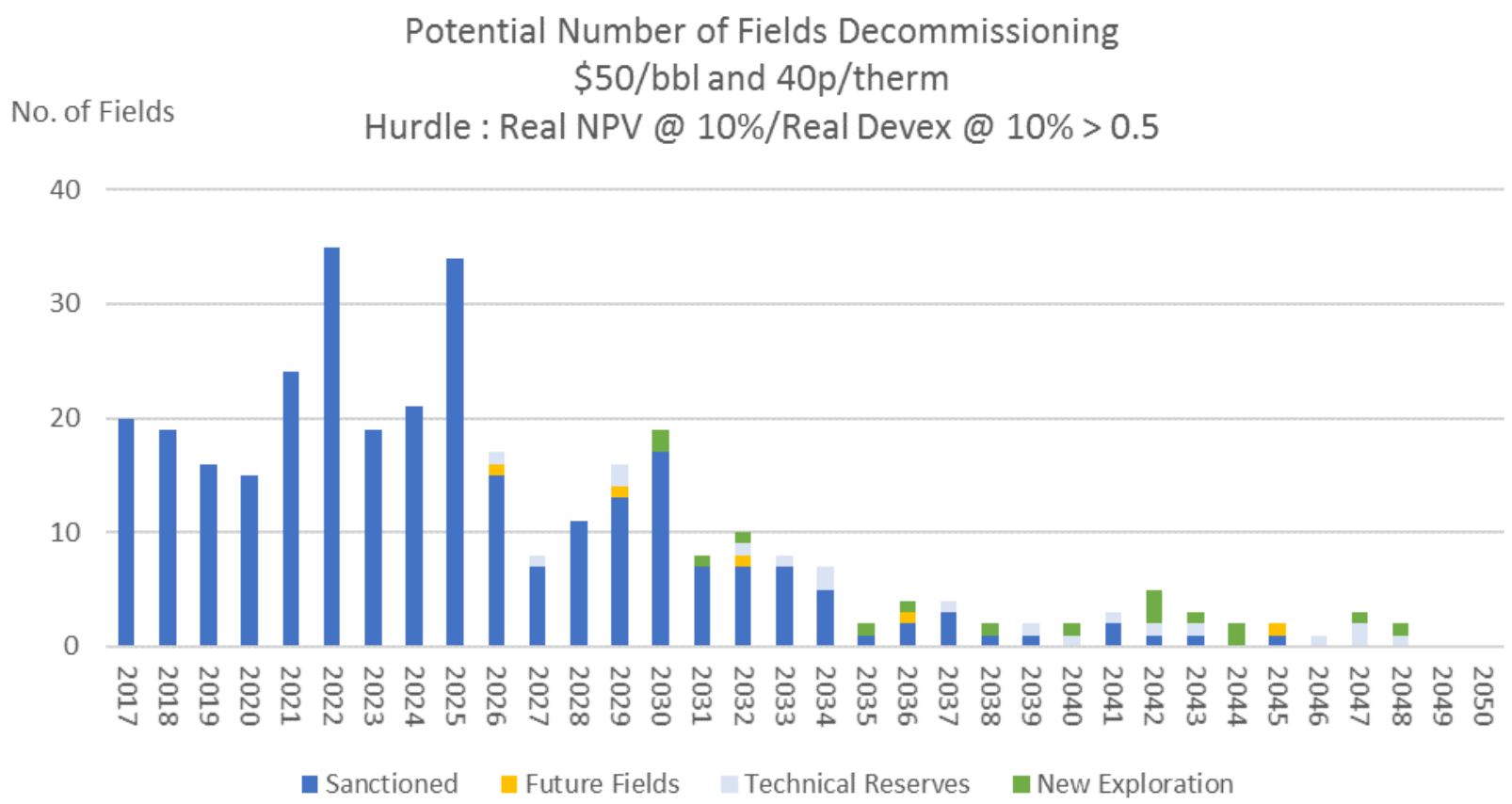


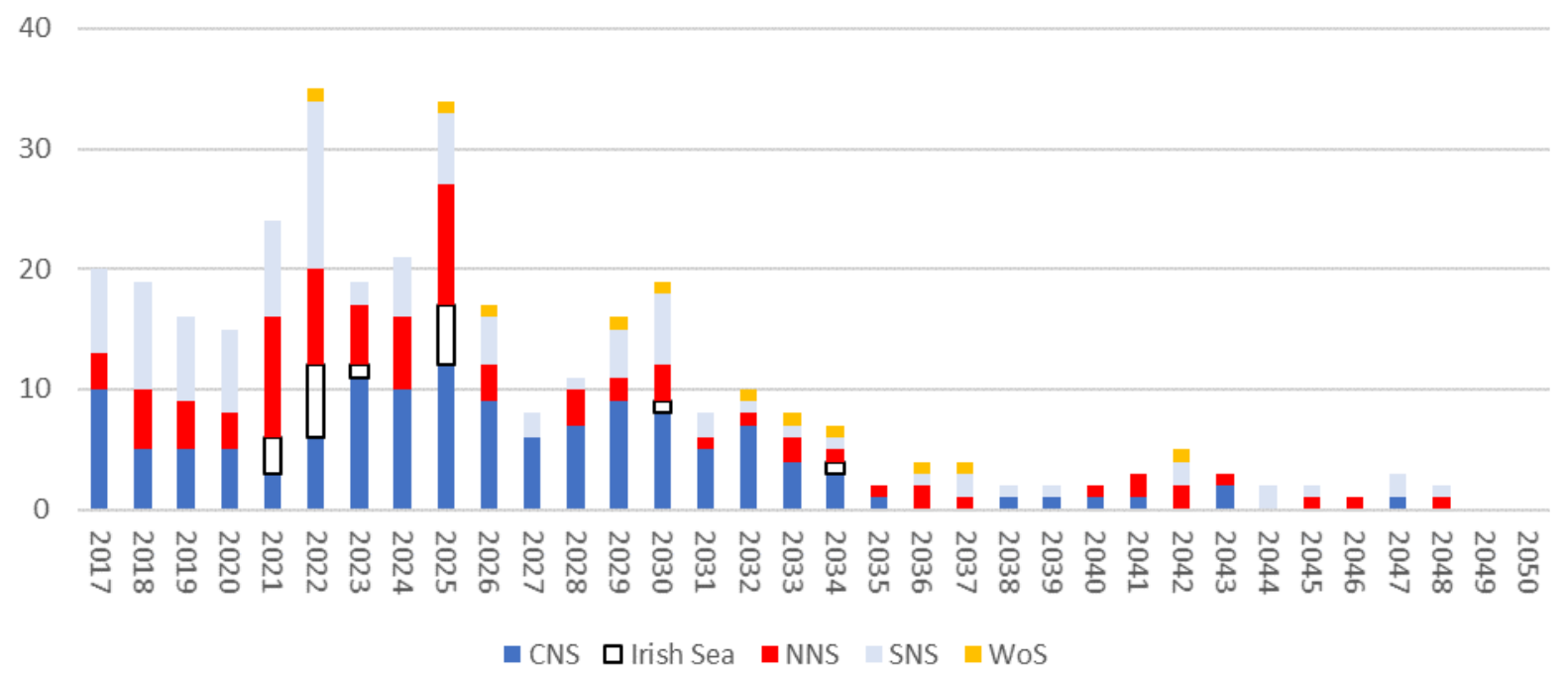

In Chart 74 potential total expenditure is shown under the $\$ 50,40$ price case with the 0.5 hurdle. Over the period to 2050 cumulative total expenditures amount to $£ 181,667$ million at 2017 prices. Sanctioned fields account for $£ 156,622$ million. Current incremental fields $£ 2,876$ million, future incremental ones $£ 8,018$ million, probable and possible fields $£ 1,906$ million, technical reserve fields $£ 3,825$ million, and new exploration finds $£ 8,419$ million.

The increase in the hurdle rate results is a reduction in total expenditure of $£ 35,517$ million, $£ 2,293$ million from current incremental projects, $£ 5,320$ million from future incremental ones, £7,513 million from probable and possible fields, $£ 13,152$ million from technical reserves, and $£ 7,238$ million from new exploration finds.

Compared with the $£ 60$ case with a 0.5 hurdle the total expenditure is reduced by $£ 52,698$ million, $£ 3,105$ million of which is accounted for by 
the sanctioned fields, $£ 2,431$ million by current incremental projects, $£ 5,594$ million by future ones, $£ 8,721$ million by probable and possible fields, $£ 15,601$ million by technical reserves, and $£ 17,246$ million by new exploration finds.

Had the fields which failed the 0.5 hurdle rate come into production the total expenditure could have increased by $£ 236,146$ million, with $£ 7,905$ coming from incremental projects, $£ 44,778$ million from probable and possible fields, $£ 141,078$ million from technical reserve fields, and $£ 42,385$ million from new exploration finds.

Chart 75 gives the same information on geographic area basis. The CNS/MF area accounts for $£ 78,610$ million, the SNS $£ 15,036$ million, the NNS $£ 56,336$ million, the WoS $£ 28,524$ million, and the Irish Sea $£ 3,160$ million.

If the fields which failed the 0.5 hurdle rate had come into production the total expenditure could have increased by $£ 70,076$ million in the CNS/MF area, $£ 26,735$ million in the SNS, $£ 52,641$ million in the NNS area, $£ 76,754$ million in the WoS, and $£ 9,940$ million in the Irish Sea. 


\section{Chart 74}

Potential Total Field Expenditure

$\$ 50 / \mathrm{bbl}$ and $40 \mathrm{p} /$ therm

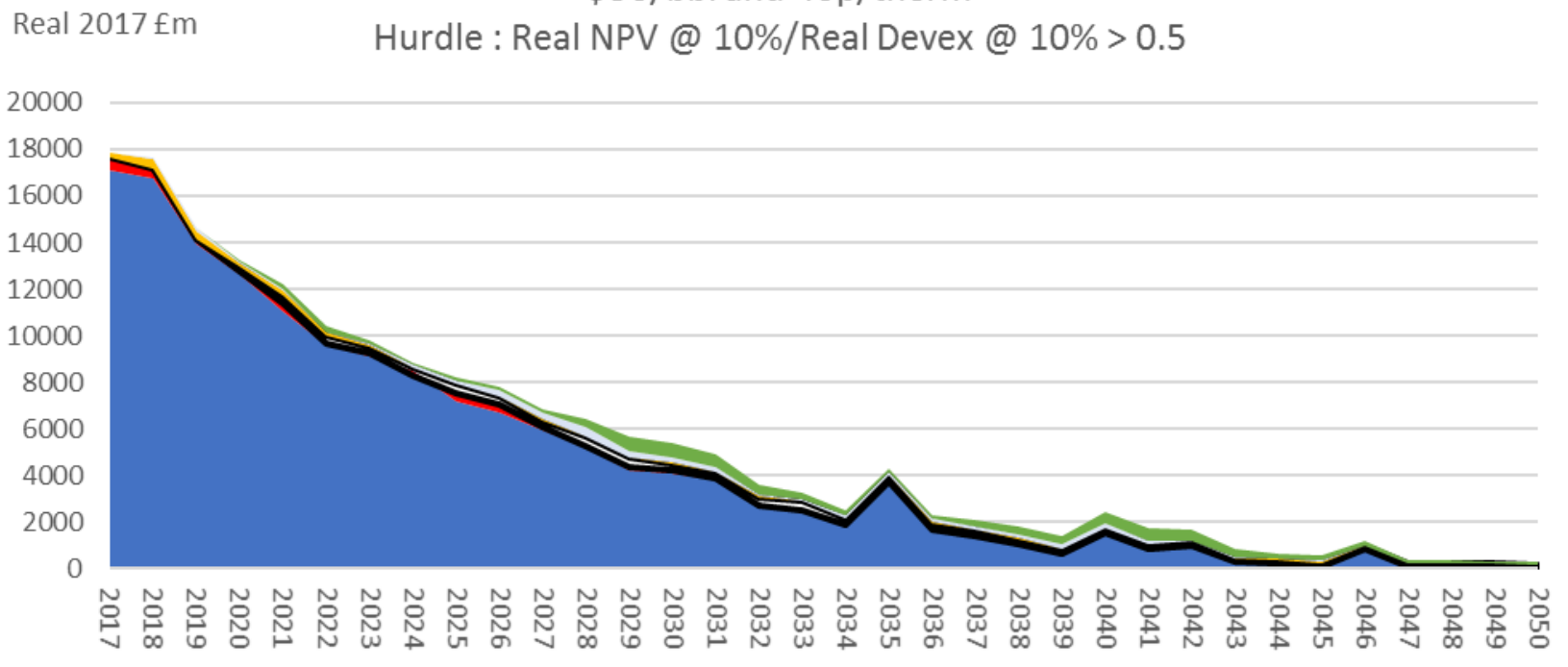

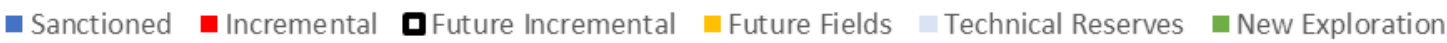

\section{Chart 75}

Potential Total Field Expenditure

$\$ 50 / \mathrm{bbl}$ and $40 \mathrm{p} /$ therm

Real $2017 \mathrm{fm}$

Hurdle : Real NPV @ 10\%/Real Devex @ 10\% > 0.5

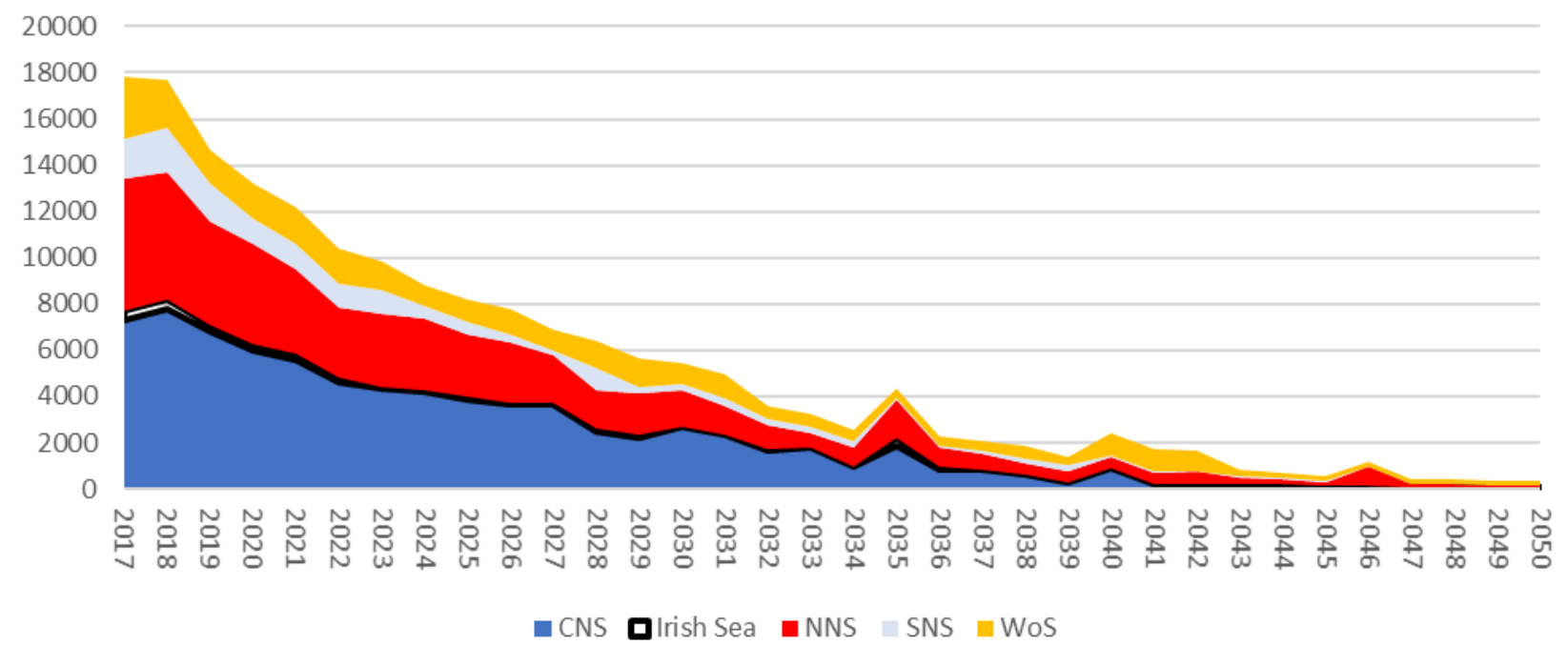


Chart 76 shows that by 2018 operating costs are likely to exceed development costs, and by 2023 decommissioning costs could be $31 \%$ of total costs and in 2035 they could be $68 \%$ of total costs.

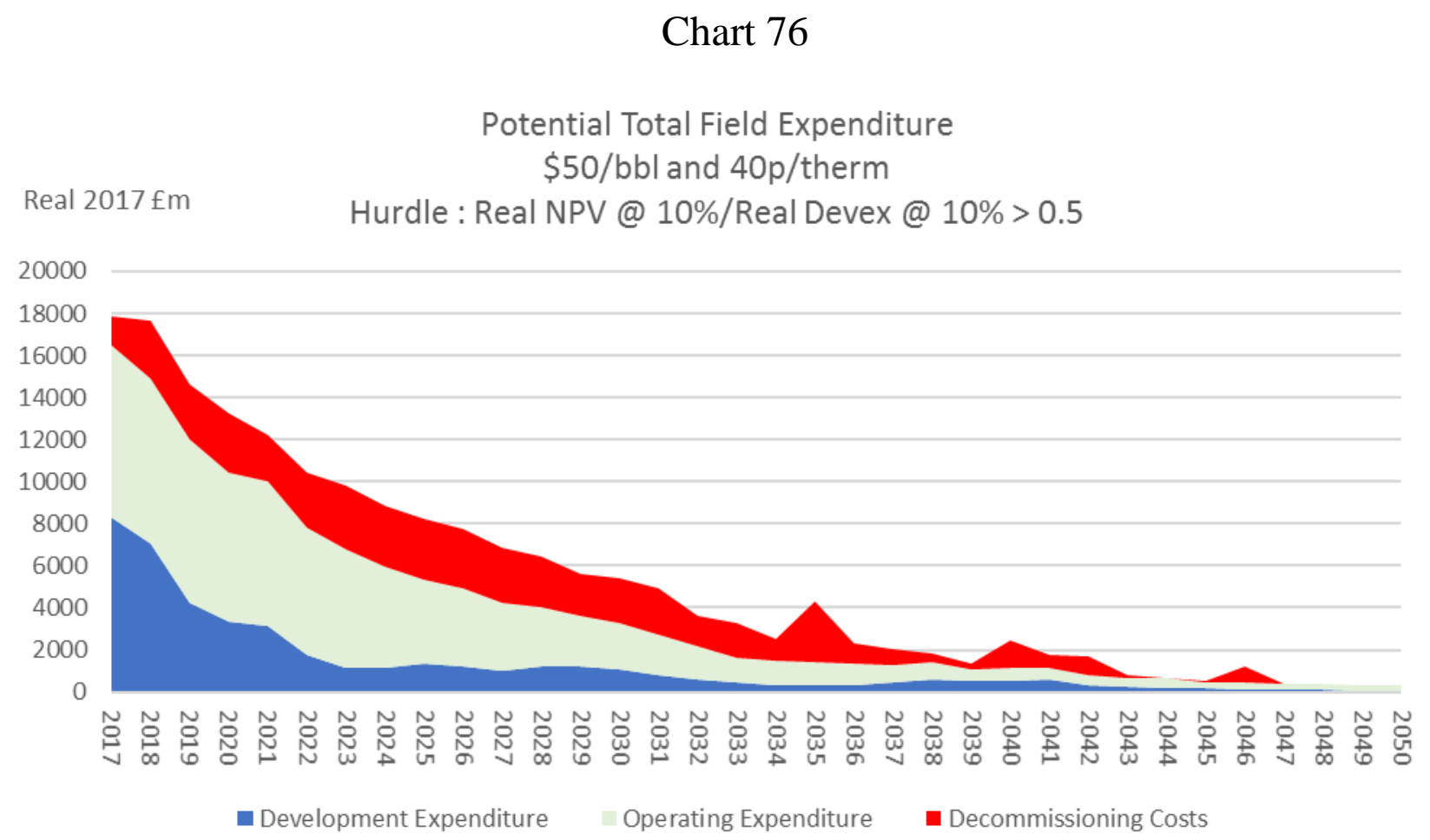

\section{Summary and Conclusions}

In this study the prospects for activity in the UKCS to 2050 have been examined under "lower for longer" investment screening oil and gas real prices scenarios of (1) $\$ 50$ and 40 pence and (2) $\$ 60$ and 50 pence. It should be noted that the oil prices in 2050 in money-of-the-day (MOD) terms become $\$ 96$ in the first scenario and $\$ 115.3$ in the second one. The modelling also incorporates two scenarios of (1) significant, and (2) very serious capital rationing.

The modelling was undertaken separately for the five main geographic regions of the UKCS namely (1) Southern North Sea (SNS), (2) Central North Sea/Moray Firth (CNS/MF), (3) Northern North Sea (NNS), (4) West of Shetlands (WoS), 
and (5) the Irish Sea (IS). The overall prospectivity, costs, and distribution of size and type of discoveries (according to oil, gas, or condensate) vary across the five regions and the modelling reflects these differences. The modelling of the exploration effort reflects the substantial reduction in wells drilled over the past few years. The assumptions regarding development and operating costs reflect the substantial reductions achieved over the past two years. The effects of the substantial depreciation of sterling against the dollar have been taken into account in the modelling of costs and revenues.

Key findings of the study are that in the period 2017-2050 cumulative production under the $\$ 60$ price scenario and significant capital rationing will be 10.75 bn boe. With (less likely) very serious capital rationing cumulative recovery would be 9.45 bn boe. Under the $\$ 50$ price scenario with significant capital rationing total recovery over the period $2017-2050$ is only 8.79 bn boe, and with very serious capital rationing is only 7.2 bn boe.

The modelling also enabled the size of the unexploited potential to be calculated. Under the $\$ 60$ price and significant capital rationing this was found to be $5.6 \mathrm{bn}$ boe. With very serious capital rationing it is as much as $6.83 \mathrm{bn}$ boe. Under the $\$ 50$ price scenario with significant capital rationing becomes 6.9 bn boe, and, with very serious capital rationing, becomes as much as 8.25 bn boe. The very large unexploited potential indicates both the challenges and opportunities facing the industry, the OGA, the OGTC and the OGIC. It is clear that a combination of further productivity improvements and oil/gas price increases can make a major difference to the overall economic recovery from the UKCS.

Development of the unexploited potential would also greatly enhance the fortunes of the supply chain. With "lower for longer" prices at the $\$ 60$ price and significant capital rationing total field related expenditures in the period 2017- 
2050 amount to $£ 267$ billion at 2017 prices of which development expenditures account for $£ 89.3$ billion, operating costs $£ 123.7$ billion, and decommissioning costs $£ 54.2$ billion. In the (extremely unlikely) event that all the unexploited discoveries were developed by 2050 a further $£ 100$ billion of field investment would result, and total expenditures could be increased by over $£ 175$ billion. Even the development of, say, $50 \%$ of the undeveloped discoveries would make a major difference to the fortunes of the supply chain as well as the economic recovery from the province.

An increase in the exploration effort could also have a significant effect on longer term activity and economic recovery from the UKCS. The modelling in this study reflects the reality of the low effort in recent years. A significant increase would be likely to result in increased discoveries on the basis of the success rates achieved in recent years.

A noteworthy feature of the results is the growing relative and absolute importance of decommissioning activity. Largely because of the noteworthy decline in new field investment activity decommissioning expenditures constitute an increasing share of total industry expenditures over the next two decades. The findings of the study also highlight the acceleration of the dates at which the economic limit of fields is reached. It is noticeable that there is a substantial acceleration of COP dates at the $\$ 50$ price compared to $\$ 60$.

Overall the study provides a quantification of the current challenges and opportunities facing the UKCS. If productivity can be significantly enhanced the economic recovery from the province can be greatly increased and the supply chain can benefit from a greatly expanded market. But if these productivity improvements are not achieved the prospect is for long term decline at a brisk pace. 


\section{$\underline{\text { Appendix }}$}

\section{Table A1}

The Unexploited Potential in the UKCS in Context (bn boe)

$1 \$ 50,40$ pence real prices $\underline{\mathrm{NPV} / \mathrm{I}>0.3}$

$\underline{\mathrm{NPV} / \mathrm{I}>0.5}$
(a) Current Expectation
(b) Unexploited Potential

8.79

7.2

6.9

8.25

$2 \$ 60,50$ pence real prices
(a) Current Expectation
10.75
9.45
(b) Unexploited Potential
5.6
6.83

\section{Chart A1}

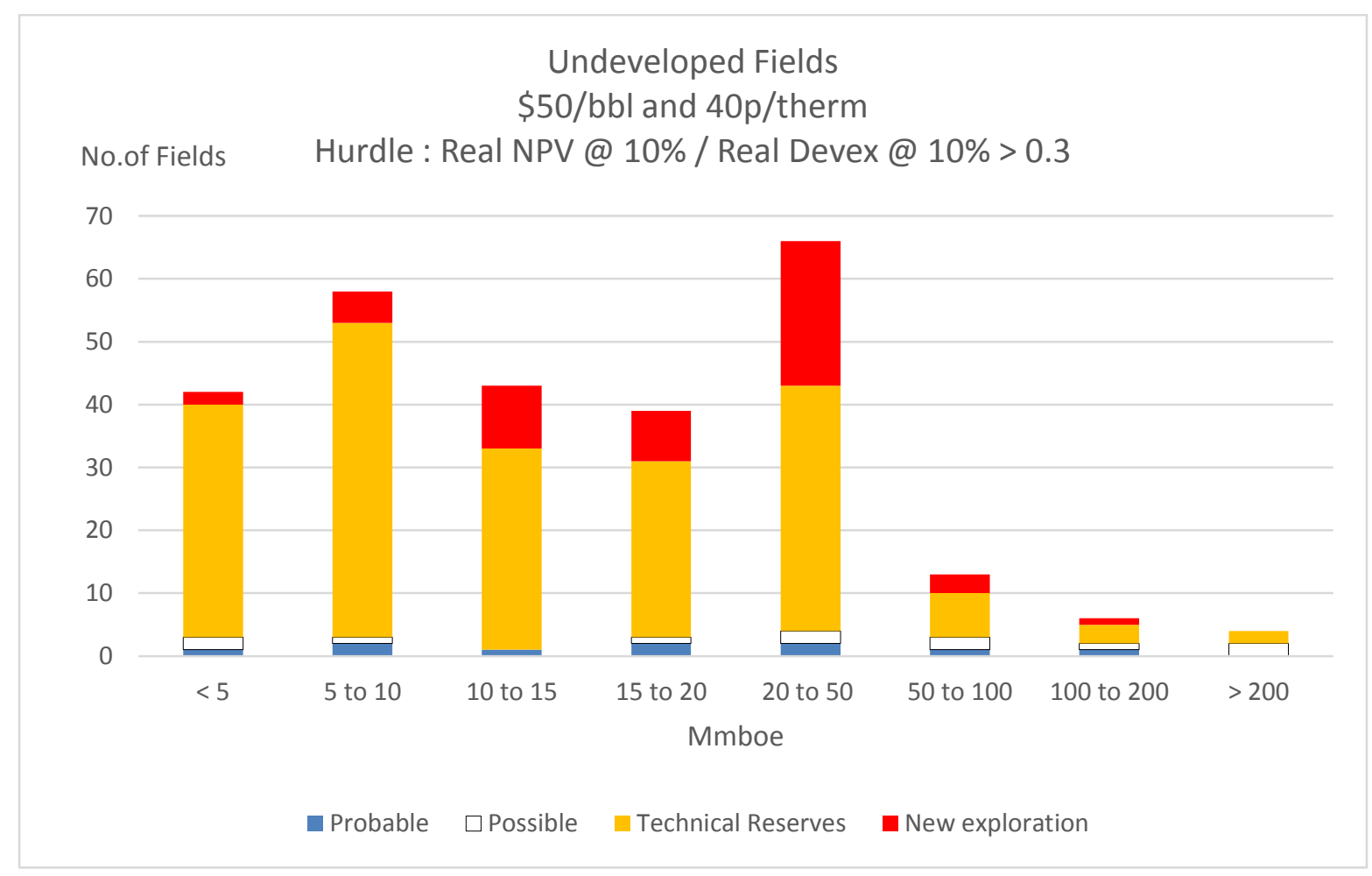

Total of 271 fields unexploited 


\section{Chart A2}

\section{Undeveloped Fields \\ $\$ 50 / \mathrm{bbl}$ and $40 \mathrm{p} /$ therm}

No.of Fields@Hurdle : Real NPV @ 10\% / Real Devex @ 10\% > 0.5

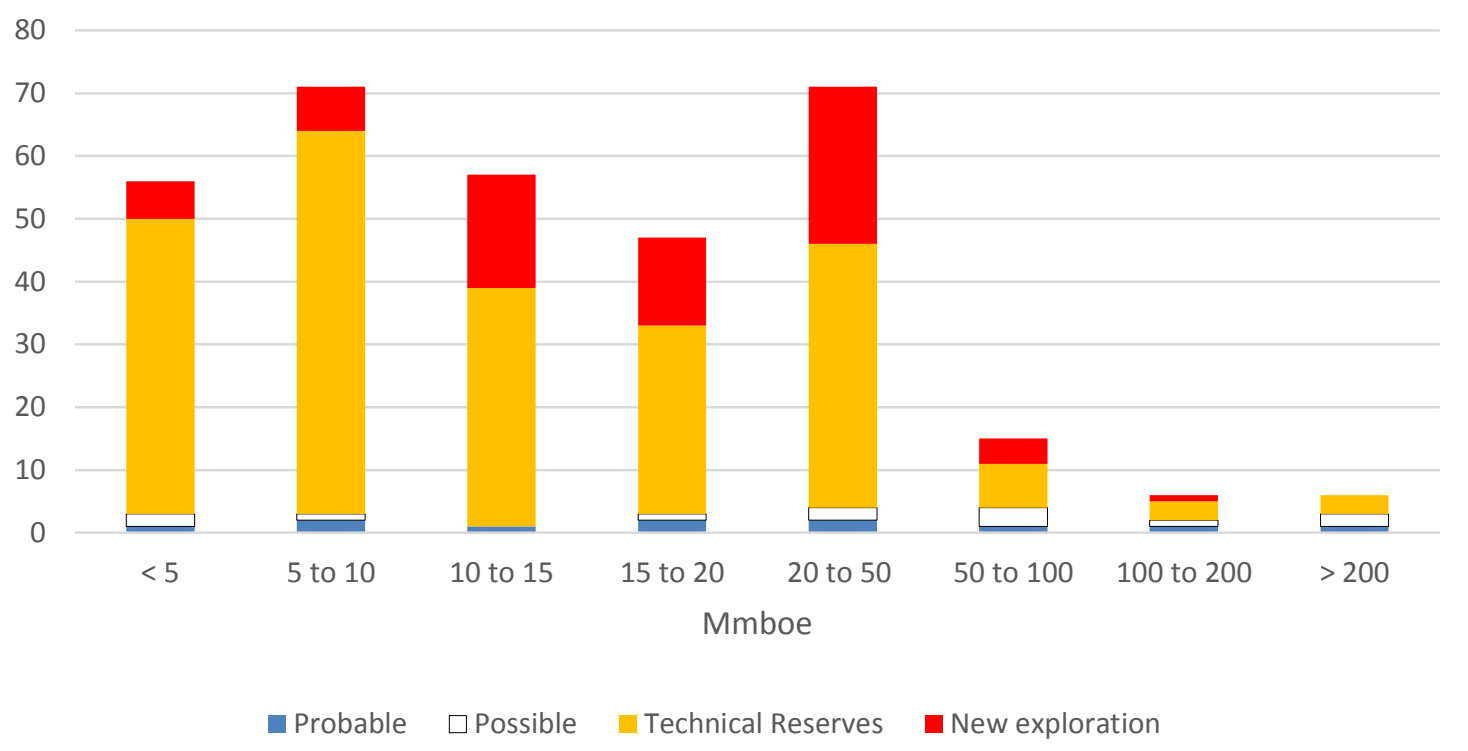

Total of 329 fields unexploited

Chart A3

Undeveloped Fields

$\$ 60 / \mathrm{bbl}$ and $50 \mathrm{p} /$ therm

No.of Fields@Hurdle : Real NPV @ 10\% / Real Devex @ 10\% >0.3

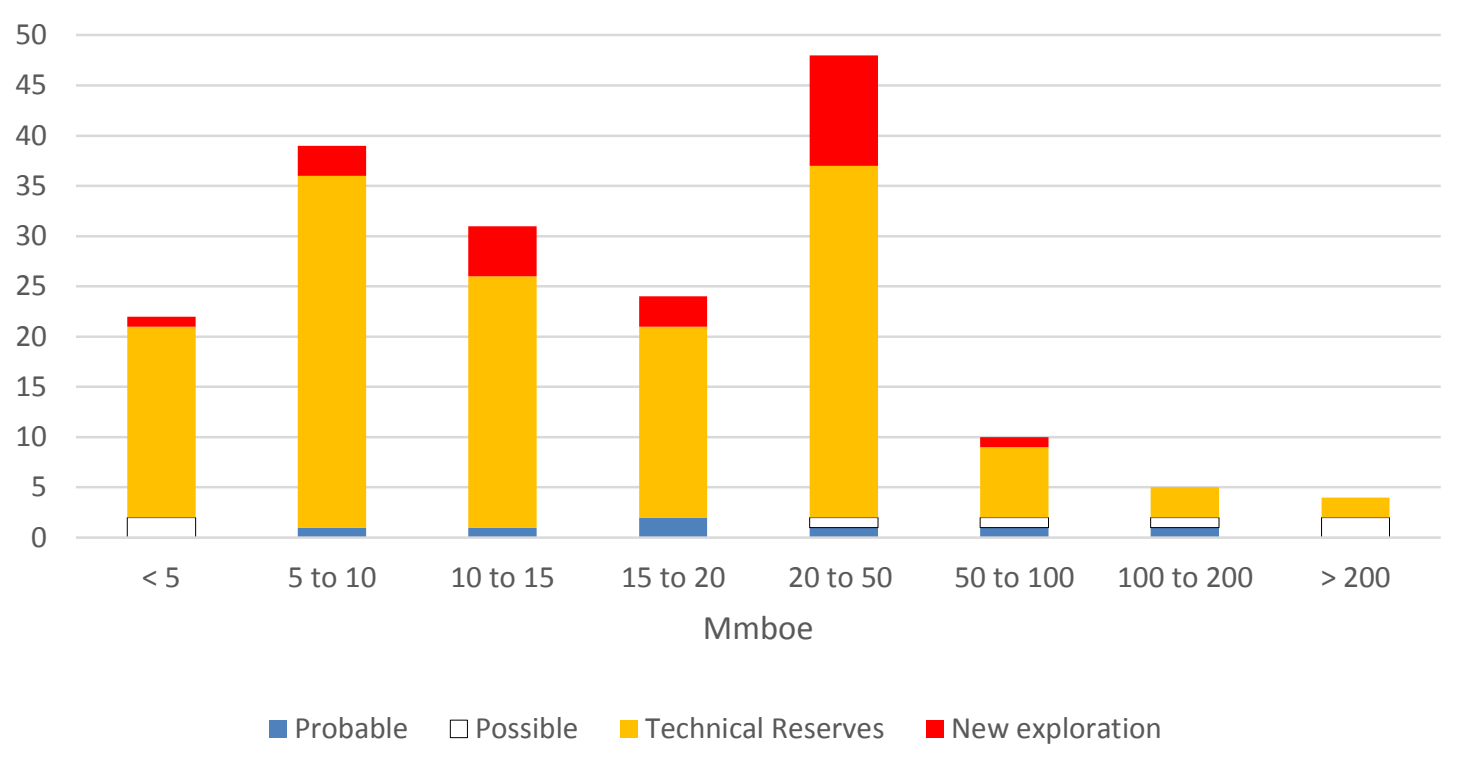

Total of 183 fields unexploited 


\section{Chart A4}

\section{Undeveloped Fields \\ $\$ 60 /$ bbl and 50p/therm}

No.of Fields@Hurdle : Real NPV @ 10\% / Real Devex @ 10\% > 0.5

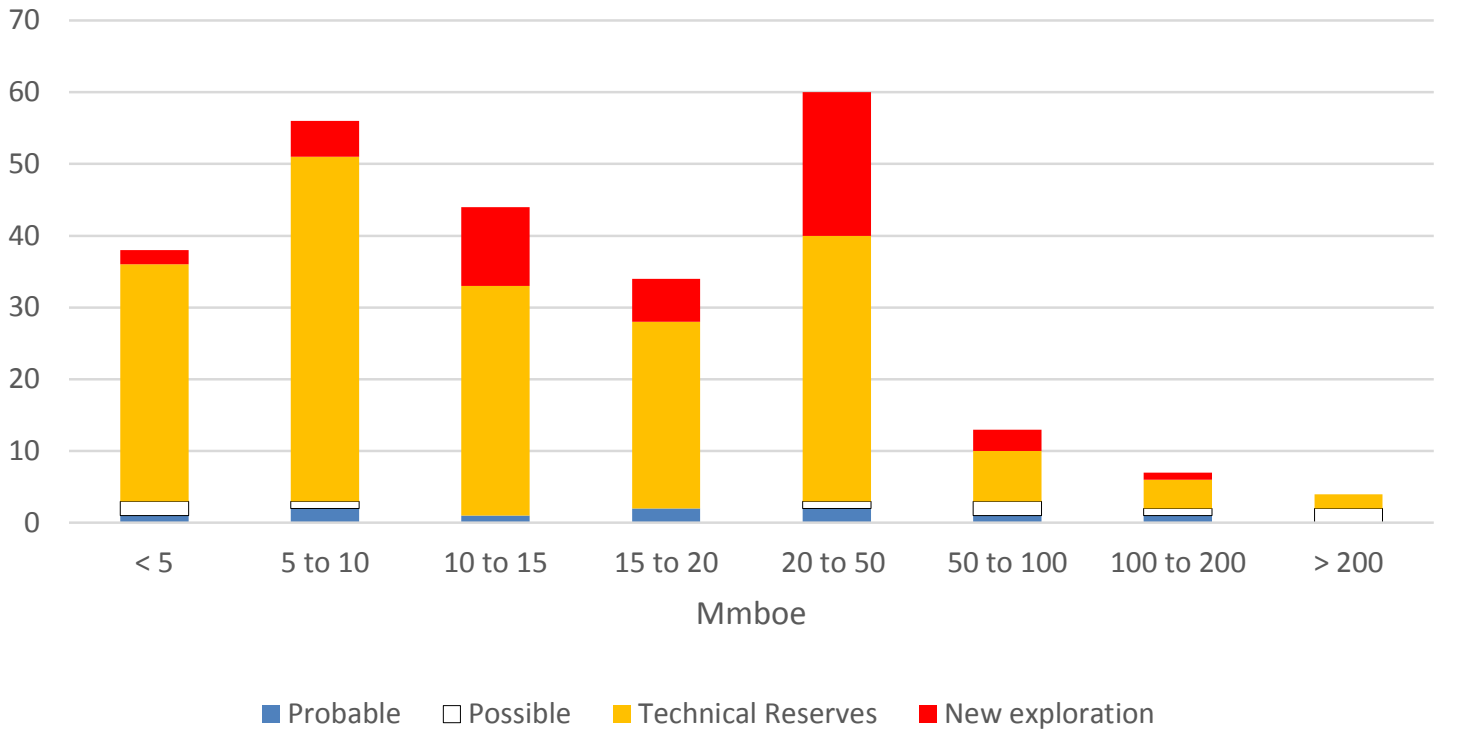

Total of 256 fields unexploited

Chart A5

Undeveloped Fields

$\$ 50 / \mathrm{bbl}$ and $40 \mathrm{p} /$ therm

No.of Fields_Hurdle : Real NPV @ 10\% / Real Devex @ 10\% > 0.3

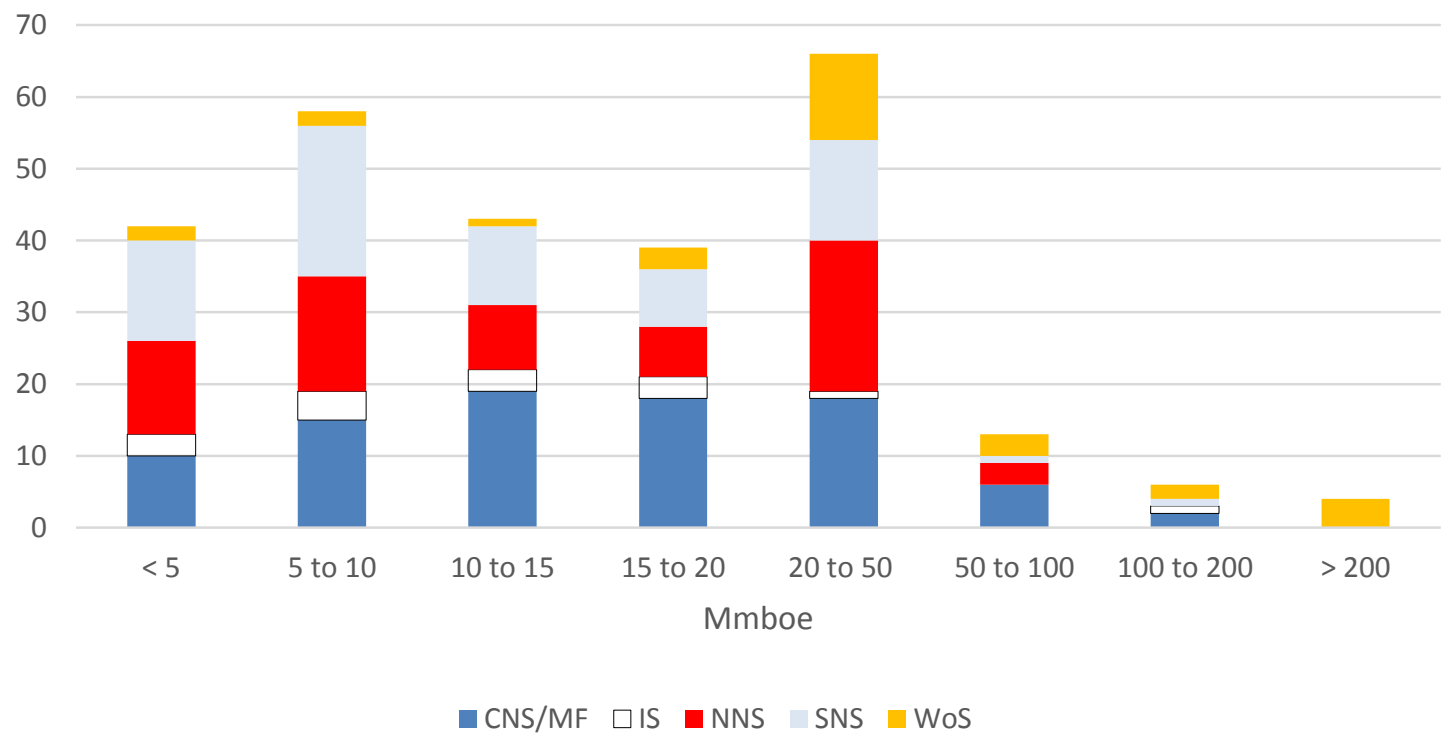




\section{Chart A6}

\section{Undeveloped Fields \\ $\$ 50 / \mathrm{bbl}$ and $40 \mathrm{p} /$ therm}

No.of Fields@Hurdle : Real NPV @ 10\% / Real Devex @ 10\% > 0.5

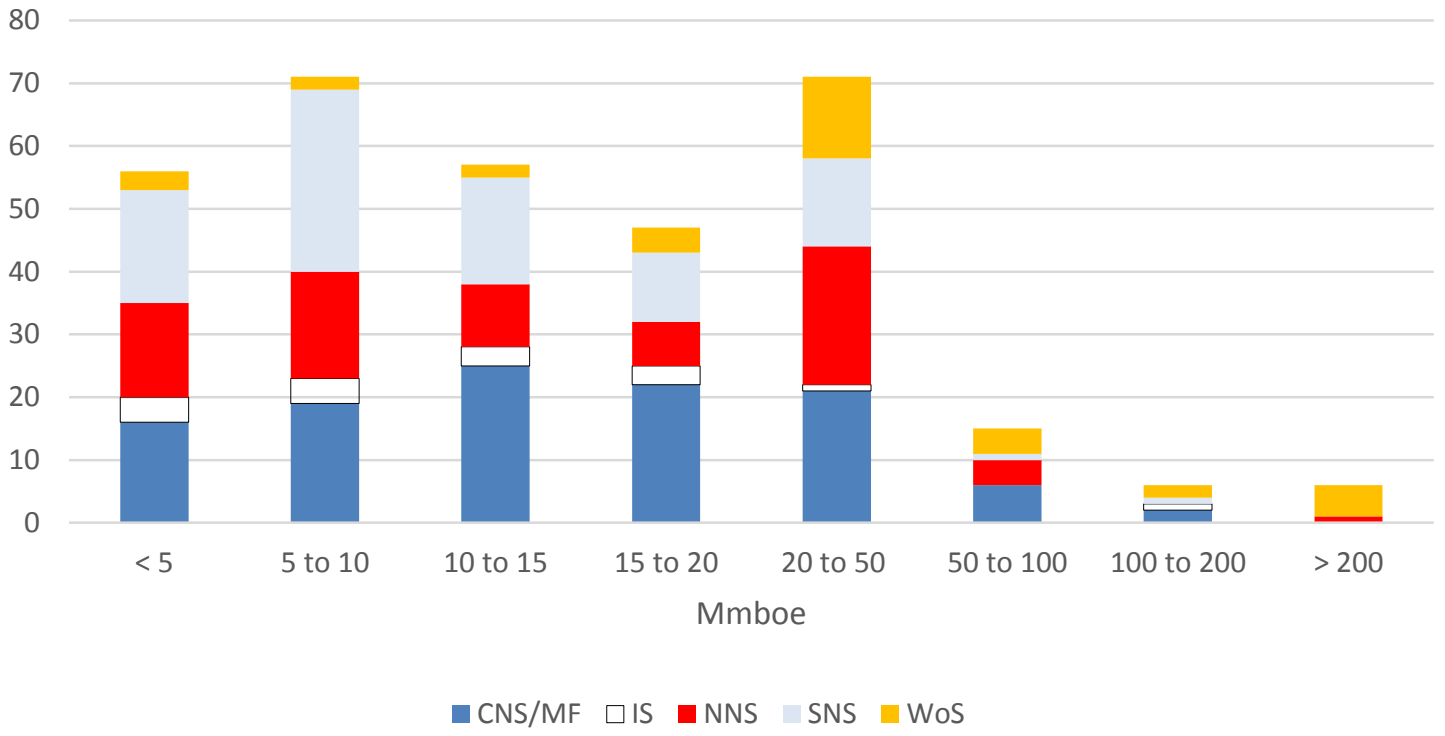

\section{Chart A7}

Undeveloped Fields

$\$ 60 / \mathrm{bbl}$ and $50 \mathrm{p} /$ therm

No.of Fields@ Hurdle : Real NPV @ 10\% / Real Devex @ 10\% >0.3

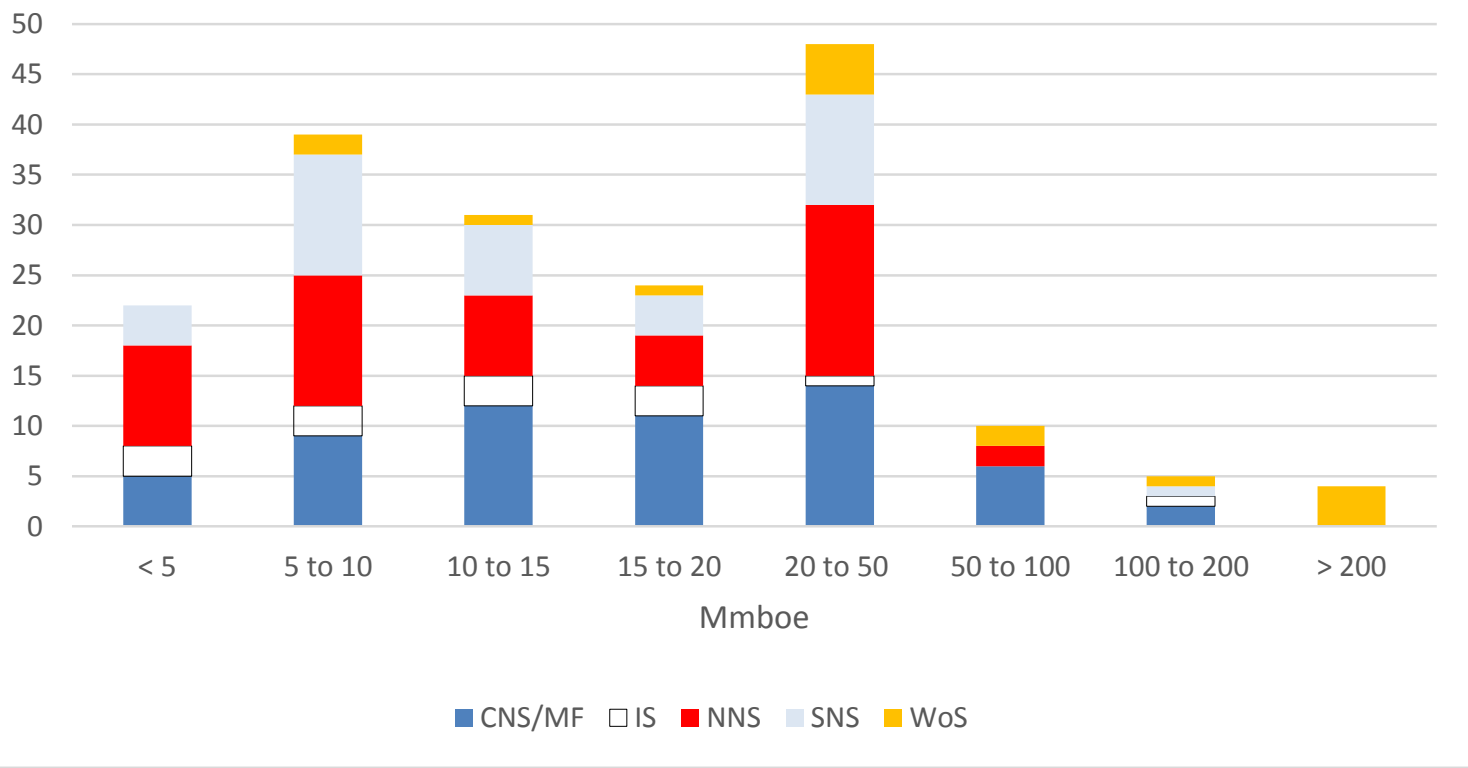




\section{Chart A8}

\section{Undeveloped Fields}

$\$ 60 /$ bbl and 50p/therm

No.of Fields@Hurdle : Real NPV @ 10\% / Real Devex @ 10\% > 0.5

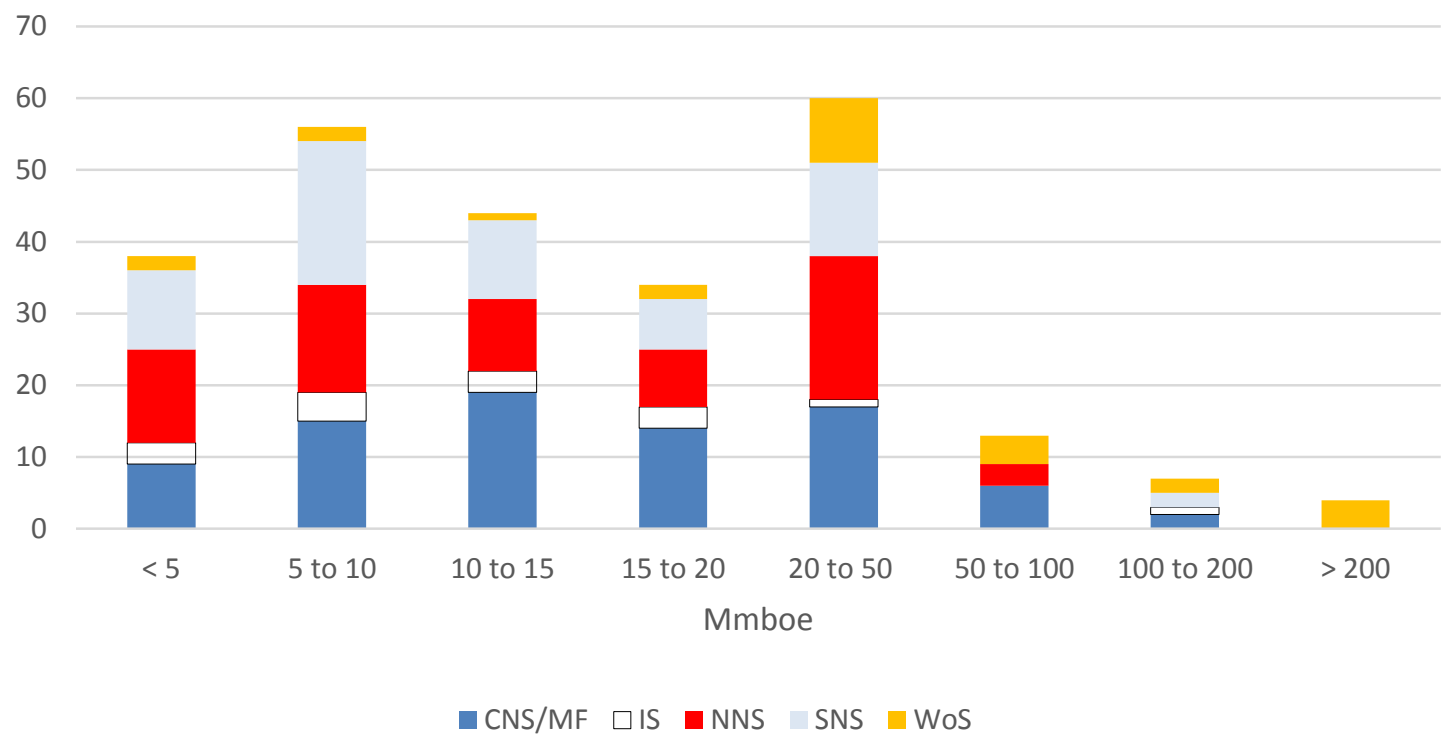

